\title{
The C-terminal SH3 domain contributes to the intramolecular inhibition of Vav family proteins
}

\author{
María Barreira, ${ }^{1,2}$ Salvatore Fabbiano,,${ }^{1,2 *}$ José R. Couceiro,,${ }^{1,2 *}$ Eva Torreira, ${ }^{3}$ Jorge L. Martínez- \\ Torrecuadrada, ${ }^{4}$ Guillermo Montoya, ${ }^{5}$ Oscar Llorca, ${ }^{3}$ Xosé R. Bustelo ${ }^{1,2 \dagger}$ \\ ${ }^{1}$ Centro de Investigación del Cáncer. Campus Unamuno, E37007 Salamanca, Spain. ${ }^{2}$ Instituto de \\ Biología Molecular y Celular del Cáncer, Consejo Superior de Investigaciones Científicas \\ (CSIC)-University of Salamanca, Campus Unamuno, E37007 Salamanca, Spain. ${ }^{3}$ Centro de \\ Investigaciones Biológicas, CSIC, 9 Ramiro de Maeztu St., E28040 Madrid, Spain. \\ ${ }^{4}$ Biotechnology Program, Centro Nacional de Investigaciones Oncológicas, $3 \mathrm{M}$. Fernández- \\ Almagro St., E28029 Madrid, Spain. ${ }^{5}$ Structural Biology and Biocomputing Program, Centro \\ Nacional de Investigaciones Oncológicas, 3 M. Fernández-Almagro St., E28029 Madrid, Spain. \\ *These authors contributed equally to this study. \\ †Corresponding author. E-mail: xbustelo@usal.es
}

\begin{abstract}
Vav proteins are phosphorylation-dependent guanine nucleotide exchange factors that catalyze the activation of members of the Rho family of guanosine triphosphatases (GTPases). The current regulatory model holds that the non-phosphorylated, catalytically inactive state of Vav proteins is maintained by intramolecular interactions among the $\mathrm{N}$-terminal domains and the central catalytic core, which block the binding of Vav proteins to GTPases. Here, we showed that this autoinhibition is mechanistically more complex, because it also involves the bivalent association of the C-terminal Src homology 3 (SH3) region of Vav with its catalytic and pleckstrin homology (PH) domains. Such interactions occurred through noncanonical, prolinerich region-independent mechanisms. Full release from this double-locked state required synergistic weakening effects from multiple phosphorylated tyrosine residues, thus providing an optimized system to generate gradients of Vav activity depending on upstream signaling inputs. This mechanism is shared by mammalian and Drosophila melanogaster Vav proteins, suggesting that it may be a common regulatory feature for this protein family.
\end{abstract}




\section{INTRODUCTION}

The Vav family is a group of tyrosine phosphorylation-dependent guanine nucleotide exchange factors (GEFs) that activate members of the Rac and Rho families of guanosine triphosphatases (GTPases) downstream of protein tyrosine kinases (1-8). This family consists of single proteins in invertebrates and three members in most vertebrate species (Vav1, Vav2, and Vav3) $(4,5)$. Genetic analyses have demonstrated that these proteins play critical functions in many biological responses, including lymphopoiesis $(3,9)$, osteogenesis $(10)$, cardiovascular homeostasis (1114), neuronal-related processes $(13,15-17)$, and tissue rhythmic behaviors in nematodes (18). Vav family proteins are also involved in human pathologies, such as cancer (19-24), metabolicrelated diseases (25), multiple sclerosis (26), immune-related deficiencies (26), and the life cycle of pathogens inside eukaryotic host cells (4).

Vav proteins are characterized by the presence of a complex array of structural domains (Fig. 1A). These include a calponin-homology $(\mathrm{CH})$ domain and an acidic (Ac) region with three regulatory phosphorylation sites $\left(\mathrm{Tyr}^{142}, \mathrm{Tyr}^{160}\right.$, and $\mathrm{Tyr}^{174}$ in the case of Vav1) (27); central Dbl homology $(\mathrm{DH})$, pleckstrin homology $(\mathrm{PH})$, and $\mathrm{C} 1$ type zinc finger $(\mathrm{ZF})$ domains that fold together to form the active catalytic core $(7,28-30)$; as well as a C-terminal arrangement of either Src homology 2 (SH2)-SH3 domains (in invertebrates) or SH3-SH2-SH3 domains (in organisms from pro-chordates to mammals) (5). The noncatalytic domains exert pleiotropic roles during signal transduction, which contribute to the intramolecular regulation of Vav proteins, the phosphorylation step, and engagement of GTPase-independent routes (4). These roles are not mutually exclusive because, for example, the $\mathrm{CH}$ region inhibits the catalytic activity of Vav in 
cis $(6,7,31)$ and, at the same time, plays effector roles that favor the engagement of $\mathrm{Ca}^{2+}-$ dependent routes that stimulate nuclear factor of activated T cells (NFAT) (32), a transcriptional factor involved in lymphocyte proliferation (33). Similarly, the most C-terminal SH3 domain (referred to hereafter as the CSH3 domain) interacts with proline-rich region (PRR)-containing proteins that favor downstream signaling and, in the case of $\mathrm{T}$ lymphocytes, the optimal phosphorylation of Vav proteins in response to activation of the $\mathrm{T}$ cell receptor (TCR) $(4,5,34)$.

According to the current regulatory model, non-phosphorylated Vav proteins are catalytically inactive because of the physical occlusion of the GTPase-binding site in the DH domain by the $\mathrm{CH}-\mathrm{Ac}$ region (31) (fig. S1A). This closed, autoinhibited structure is stabilized by interactions between the $\mathrm{Tyr}^{174}$ hydroxyl group and the GTPase-binding region of the DH domain, as well as by interdomain contacts between the $\mathrm{CH}$ domain with the DH-PH region (31) (fig. S1B). Upon cell stimulation, the phosphorylation of the three tyrosines located in the Ac region eliminates these inhibitory interactions, which leads to exposure of the catalytic site, binding to the GTPase, and the ensuing catalytic step (fig. S1A) (31). Consistent with this model, mutations that disrupt such an autoinhibitory structure result in proteins with constitutive, phosphorylation-independent catalytic activity both in vitro and in cells (fig. S1A) $(6,7,27,28,31)$.

It is still uncertain, however, whether this model alone can fully explain the regulation of Vav activity. For example, we observed that Vav1 ${ }^{\mathrm{Y} 174 \mathrm{~F}}$, a mutant protein that lacks the main inhibitory tyrosine residue, still requires tyrosine phosphorylation to become catalytically active in vitro (27). We also reported that the compound mutation of the three tyrosine residues of the Ac region does not recapitulate the activation effect derived from the deletion of the $\mathrm{CH}$ domain in 
Vav proteins $(27,28)$, thus suggesting that the autoinhibited structure can be stabilized by additional interactions outside the Ac region. Finally, Vav proteins have additional phosphorylatable residues outside of the Ac region (27), suggesting that further phosphorylationdependent steps may contribute to fine-tune the regulation of these proteins during signal transduction. Consistent with these ideas, we report here that optimal autoinhibition of Vav proteins requires cooperative intramolecular interactions mediated by the CSH3 domain. This mechanism provides a multilayered safety control system to avoid spurious activation of these proteins by signaling noise and, at the same time, a potential way to modulate the signaling competence of Vav proteins depending on either the strength or duration of extracellular stimuli.

\section{RESULTS}

\section{The CSH3 domain participates in the inhibition of Vav family proteins}

During the course of experiments aimed at establishing the regulatory role of the C-terminus of Vav1, we generated a 10 amino acid-long deletion mutant that disrupted the folding of the Vav1

CSH3 domain (Vav1 ${ }^{{ }^{835-845}}$; Fig. 1A). Given the important role of Vav1 in lymphocyte signaling $(3-5,9)$, we first tested the biological activity of this mutant in Jurkat cells (a human CD4 ${ }^{+} \mathrm{T}$ cell leukemia cell line), and we used as read-outs the Vav1-dependent activation of c-Jun N-terminal kinase (JNK), F-actin polymerization, and NFAT. JNK and F-actin are direct downstream elements of the Vav1-Rac1 pathway and therefore were used as surrogate read-outs for Vav1 catalytic activity in cells (Fig. 1B). In contrast, NFAT requires multiple signaling inputs for its activation, including signals dependent on the Vav1 $\mathrm{CH}$ domain, phospholipase $\mathrm{C}-\gamma$ (PLC- $\gamma$ )dependent $\mathrm{Ca}^{2+}$ signaling, and synergistic cross-talk with other TCR-activated pathways (Fig. 1B) $(9,32,35)$. As controls for these experiments, we used wild-type Vav1 (referred hereafter as 
$\operatorname{Vav} 1^{\mathrm{WT}}$ ) and the $\operatorname{Vav} 1^{\Lambda^{1-186}}$ and $\operatorname{Vav}^{\mathrm{Y} 174 \mathrm{~F}}$ mutant proteins (Fig. 1A). Vav1 ${ }^{\Lambda^{1-186}}$ displays phosphorylation-independent GEF activity because of the elimination of the inhibitory Nterminal domains (Fig. 1A) $(6,7,28)$; however, it cannot stimulate NFAT because of the lack of the N-terminal $\mathrm{CH}$ domain (Fig. 1B) $(28,32)$. As mentioned earlier, the Vav1 ${ }^{\mathrm{Y} 174 \mathrm{~F}}$ mutant exhibits increased activity in some assays; however, unlike Vav1 $1^{1-186}$, it still requires phosphorylation steps to become fully activated in vitro and in cells (27).

Because previous data demonstrated that the interaction of the Vav1 CSH3 domain with PRRbinding proteins was required for the biological activity of Vav1 in most cell types $(28,34,36$, 37), we expected that the CSH3-deficient Vav1 $1^{835-845}$ mutant would exhibit less activity than that of its wild-type counterpart; however, we unexpectedly found that Vav1 $1^{835-845}$ was as hyperactive as was Vav1 ${ }^{1-186}$ in experiments measuring the activation of JNK (Fig. 1, C to F) and F-actin polymerization (Fig. 1G). This increased activity was quite similar in non-stimulated and TCRstimulated Jurkat cells (Fig. 1, C to F), indicating that this mutant protein had become phosphorylation-independent. Consistent with this, we observed that Vav1 $1^{835-845}$ and $\operatorname{Vav} 1^{1-186}$, but not Vav1 ${ }^{\text {WT }}$, were similarly active in wild-type and TCR-deficient Jurkat cells (Fig. 1, C and D). Vav1 $1^{835-845}$, unlike the N-terminally truncated Vav1 proteins $(28,32)$, also showed enhanced activity when tested in NFAT activity assays (Fig. 1, H and I); however, this biological response still required the engagement of the TCR to achieve maximal stimulation (Fig. 1, H and I). We observed similar results in experiments in which chicken DT40 B cells were transiently transfected with plasmid encoding $\operatorname{Vav} 1^{835-845}$ (Fig. 1, H and I), which indicated that the increased activity of this C-terminally truncated Vav1 protein was conserved in both $\mathrm{T}$ cell and B cell lines. 
$\operatorname{Vav} 1^{{ }^{835-845}}$ also showed higher biological activity than that of Vav1 ${ }^{\mathrm{WT}}$ in assays of JNK activity and F-actin polymerization in non-hematopoietic COS1 cells; however, unlike in lymphocytes, the activity of $\operatorname{Vav} 1^{{ }^{835-845}}$ was substantially reduced compared to that of Vav1 $1^{1-186}$ (Fig. 2, A and B; fig. S2A) and $\mathrm{Vav1}^{\mathrm{Y} 3 \times \mathrm{F}}$ (fig. S2A), a mutant Vav1 in which the three inhibitory tyrosine residues of the Ac region are mutated to phenylalanines (Fig. 1A) (27). Furthermore, unlike the conventional $\operatorname{Vav}_{1^{1-186}}$ and $\operatorname{Vav} 1^{\mathrm{Y} 3 \times \mathrm{F}}$ mutant proteins $(6,27,28)$, Vav1 $1^{835-845}$ did not exhibit oncogenic activity when tested in focus-formation assays (Fig. 2C). The reduced activity of $\operatorname{Vav1}^{{ }^{835-845}}$ in COS1 and NIH3T3 cells was probably a result of the loss of CSH3-dependent effector functions, because the $\operatorname{Vav} 1^{\mathrm{Y} 3 \mathrm{x}}$ protein also lost its transforming activity $(27,28)$ when it lacked the C-terminal amino acid residues 835 to 845 (Fig. 2C). This deletion also induced the constitutive activation of Vav2, Vav3 (Fig. 2, D and E), and Drosophila Vav (Fig. 2, A and B), indicating that the inhibitory role exerted by this domain may be common to all Vav family members. Despite this, the C-terminal truncation did not change the specific signaling output induced by each Vav family member in cells. For example, we observed that Vav2 $2^{{ }^{860-868}}$ stimulated NFAT in B cells, but not in T cells, a cell type specificity also shared by Vav2 ${ }^{\mathrm{WT}}$ (fig. S2, B and C) (38). Together, these results suggest that the CSH3 domains of Vav family members exert a hitherto unknown inhibitory role that may have arisen very early on in the evolutionary history of this GEF subgroup. Moreover, these results suggest that the relative contribution of the negative and positive roles of the CSH3 domain to the biological activity of these proteins is highly dependent on the cell type and biological response involved.

\section{The CSH3 domain inhibits the catalytic activity of Vav proteins}


To investigate whether the enhanced biological activity of CSH3-deficient Vav proteins was a consequence of increased catalytic activity, we isolated hexahistidine (6xHis)-tagged variants of $\operatorname{Vav} 1^{\mathrm{WT}}, \operatorname{Vav}^{1^{835-845}}, \operatorname{Vav}^{\mathrm{WT}}$, and Vav3 $3^{841-847}$ from baculovirus-infected $S f 9$ insect cells (Fig. 3A) and subsequently tested them in vitro in GDP-GTP exchange assays. As a negative control, we used a 6xHis-Vav3 protein fragment that contains only the DH-PH region (Vav3 ${ }^{\text {DH-PH }}$, Fig. 3A). We showed previously that this protein is catalytically inactive because of the absence of the ZF region (7). As a positive control, we used the 6xHis-DH-PH region of a RhoA- and Cdc42specific GEF (human Dbs), which was provided by the commercial kit used to assay GDP-GTP exchange. With this approach, we observed that $6 \mathrm{xHis-Vav1}{ }^{\mathrm{wT}}$ was catalytically inactive on all of the GTPases tested (Fig. 3, B to D); however, as expected $(8,27,28), 6 x$ His-Vav $1^{\text {WT }}$ became catalytically active upon in vitro phosphorylation by the protein tyrosine kinase Lck (Fig. 3, E and F). In contrast, 6xHis-Vav1 $1^{835-845}$ exhibited phosphorylation-independent GDP-GTP exchange activity on both Rac1 (Fig. 3B) and RhoA (Fig. 3C). This activity was proportional to the amount of input protein used in the assays (Fig. 3, B and C). Vav1 $1^{835-845}$ did not elicit any detectable nucleotide exchange activity on Cdc42 (Fig. 3D), as was previously described for other Vav1 variants (8). Dbs showed the opposite catalytic specificity, being primarily active on RhoA (Fig. 3C) and Cdc42 (Fig. 3D), whereas it displayed much lower activity on Rac1 (Fig. $3 \mathrm{~A})$.

Parallel experiments indicated that $6 \mathrm{xHis-}-\mathrm{Vav}^{8}{ }^{841-847}$ had constitutive, phosphorylationindependent exchange activity towards Rac1 (Fig. 3G) and, to a lesser extent, RhoA (Fig. 3H). Similar to its Vav1 mutant counterpart, 6xHis-Vav3 ${ }^{841-847}$ did not show activity on Cde42 (Fig. 3I). The catalytic activity of this mutant protein was comparable to that shown by the previously 
described constitutively active Vav3 $3^{1-144}$ protein (Fig. 3G) (7). Confirming the specificity of these reactions, we did not observe any exchange activity when the purified 6xHis-Vav3 DH-PH region was tested (Fig. 3G) (7). These results indicate that Vav1 and Vav3 acquire constitutive GDP-GTP exchange activity upon the elimination of the most distal amino acids of their respective CSH3 domains. Corroborating these in vitro results, we found that Vav1 $1^{1-186}$ and $\operatorname{Vav} 1^{835-845}$, but not $\operatorname{Vav} 1^{\mathrm{WT}}$, ectopically expressed in $\operatorname{COS} 1$ cell lysates interacted with bacterially expressed glutathione-S-transferase (GST)-fused Rac $1^{\mathrm{G} 15 \mathrm{~A}}\left(\mathrm{GST}-\mathrm{Rac} 1^{\mathrm{G} 15 \mathrm{~A}}\right.$ ) and GST$\mathrm{RhoA}^{\mathrm{G} 17 \mathrm{~A}}$ proteins in standard pull-down assays (Fig. 3J). These results provided further evidence for the exposure of the Vav1 catalytic site upon the removal of the CSH3 domain, because these GTPase mutants interact with active forms of upstream GEFs because of their nucleotide-free state (39). Finally, with GTPase-linked immunosorbent assays, we demonstrated that the CSH3-depleted mutants of both Vav1 and DmVav promoted the activation of endogenous Rac1 when ectopically expressed in COS1 cells (Fig. 3, K and L). Such activity was very similar to that shown by the constitutively active Vav $1^{1^{1-186}}$ mutant protein (Fig. 3, K and L). As expected, the full-length Vav1 and DmVav proteins were inactive in these assays (Fig. 3, K and $\mathrm{L}$ ). These results indicate that the $\mathrm{CSH} 3$ domain contributes to the regulation of both the catalytic and biological activities of Vav family proteins, possibly through an inhibitory intramolecular mechanism similar to that exerted by the $\mathrm{N}$-terminal $\mathrm{CH}$ domain and Ac region.

\section{The CSH3 domain inhibits Vav1 activity in cis}

To elucidate the inhibitory role of the CSH3 domain, we first investigated whether it could be mediated by a canonical interaction with PRRs. Arguing against this possibility, we observed that the inactivation of the PRR-binding site of the Vav1 CSH3 domain (through the introduction 
of the P833L mutation) did not induce the activation of full-length Vav1 (Fig. 4, A and B). This result was consistent with previous experimental data $(4,5,34)$. These observations led us to investigate whether the CSH3 domain inhibited Vav1 through a PRR-independent mechanism in cis To this end, we performed GST-based pull-down experiments to detect possible interactions of the wild-type (GST-CSH3 ${ }^{\mathrm{WT}}$ ) and the P833L mutant (GST-CSH3 ${ }^{\mathrm{P} 833 \mathrm{~L}}$ ) versions of the Vav1 CSH3 domain with Vav1 proteins ectopically expressed in COS1 cells. Because we surmised that access to the putative CSH3-binding site of $\operatorname{Vav} 1^{\mathrm{WT}}$ could be blocked by the interaction of its own CSH3 (Fig. 4C), we decided to include in these experiments the mutants Vav1 ${ }^{835-845}$ and Vav1 ${ }^{\wedge^{1-186}}$. Based on earlier results (Figs. 1 to 3), we expected that the CSH3-binding site of $\operatorname{Vav1} 1^{835-845}$ would be fully exposed and, therefore, that this mutant would serve as a good positive control for these experiments (Fig. 4C). On the other hand, the use of the Vav1 $1^{{ }^{1-186}}$ mutant enabled us to check whether the strength of the intramolecular CSH3-Vav1 interaction could be influenced by the previously described $\mathrm{CH}$ domain and Ac region-dependent conformational changes associated with the catalytic activation of Vav proteins (29-31).

We found that GST-CSH3 ${ }^{\text {WT }}$ physically interacted with Vav1 ${ }^{835-845}$, but not with Vav1 ${ }^{\text {WT }}$ or $\operatorname{Vav} 1^{\wedge^{1-186}}$ (Fig. 4D), indicating that the truncation of the CSH3 domain was required to fully expose its intramolecular binding site. The GST-CSH3 ${ }^{\mathrm{P} 83 \mathrm{~L}}$ protein consistently showed better interactions with Vav1 ${ }^{835-845}$ than did the GST-CSH3 ${ }^{\mathrm{WT}}$ bait (Fig. 4D), thus corroborating the idea that this intramolecular inhibitory mechanism is mediated by a non-canonical, PRRindependent mechanism. Furthermore, the GST-CSH3 ${ }^{\mathrm{P} 833 \mathrm{~L}}$ bait also showed weaker, but reproducible, binding to $\operatorname{Vav1}^{\mathrm{WT}}$ and, to a larger extent, to Vav1 ${ }^{1-186}$ (Fig. 4D). All of these interactions were specific, because the non-chimeric GST protein did not interact with any of the 
Vav1 proteins used in these experiments (Fig. 4D). These interactions were also highly selective, as demonstrated by the lack of efficient binding of the GST-CSH3 ${ }^{\mathrm{P} 33 \mathrm{~L} \mathrm{~L}}$ bait to other C-terminally truncated Vav family proteins (Fig. 4E). Together, these results suggest that the stability of the intramolecular CSH3-Vav1 interaction is stronger when Vav1 is in the non-active state, is partially destabilized upon the release of the inhibitory $\mathrm{N}$-terminal regions (Vav1 $\left.1^{1-186}\right)$, and is totally disrupted when the CSH3 is truncated $\left(\operatorname{Vav1} 1^{835-845}\right)$. Furthermore, these results suggest that the binding of PRR-containing proteins to the canonical PRR-binding site of CSH3 might indirectly disrupt the interaction between CSH3 and Vav1.

\section{The CSH3 domain binds to the DH-PH region of Vav1}

The interaction of the GST-CSH3 $3^{\mathrm{PB33L}}$ bait with both Vav1 $1^{1-186}$ and Vav $1^{835-845}$ that we observed in the earlier experiments indicated that the internal CSH3-binding site must lie outside the $\mathrm{CH}$ Ac and CSH3 regions. The use of additional mutant proteins also excluded the possibility that the binding site could be located in the PRR-NSH3 region of Vav1 (fig. S3), thus suggesting that the interaction was likely to take place within the catalytic DH-PH-ZF cassette. To test this possibility, we investigated the interaction of the GST-CSH3 ${ }^{\text {P833 }}$ bait with different combinations of the domains present in that cassette in pull-down experiments (Fig. 4F). To facilitate these experiments, we expressed these regions in COS1 cells as fusions with enhanced green fluorescent fusion protein (EGFP). We observed that GST-CSH3 ${ }^{\text {P833L }}$ interacted with EGFPs containing the DH (EGFP-DH-PH-ZF, EGFP-DH-NPH, and EGFP-DH) and PH (EGFPDH-PH-ZF and EGFP-PH) domains of Vav1 (Fig. 4, G and H; fig. S4A); however, it did not associate with the isolated ZF domain (Fig. 4G) or the $\alpha 6$ helix of the DH domain (fig. S4A). Furthermore, the ZF domain seemed to constrain the interaction of the Vav1 CSH3 domain with 
its targets, because the EGFP-DH-NPH and EGFP-PH constructs showed better binding to the GST-CSH3 ${ }^{\text {P833L }}$ bait in these experiments than did the EGFP-DH-PH-ZF construct (Fig. 4G and fig S4A). Furthermore, the DH region showed a better association to the bait when the DH region was attached to the NPH fragment (Fig. 4H). These results suggest that the CSH3 domain probably has two independent docking sites within the $\mathrm{DH}-\alpha 6-\mathrm{PH}$ region and, in addition, that the stability of such interactions may be influenced by conformational fluctuations imposed by the intervening $\alpha 6$ helix and the adjacent $\mathrm{ZF}$ region.

Additional pull-down experiments indicated that the ectopically expressed EGFP-Vav1 DH-PHZF cassette interacted more efficiently with GST-CSH3 ${ }^{\mathrm{P} 33 \mathrm{~L}}$ than with other known interacting partners, such as the downstream GTPases and the inhibitory N-terminal $\mathrm{CH}$ region (fig. S4B). Confirming that the interaction between the CSH3 domain and the DH-PH-ZF region of Vav1 did not require the participation of other proteins present in the COS 1 cell lysates used in the pull-down experiments, we found with purified proteins (Fig. 4I) and surface plasmon resonance techniques that a bacterially expressed Vav1 DH-PH-ZF region fused to the maltose binding protein (MBP) associated with the filter-immobilized GST-CSH3 ${ }^{\mathrm{WT}}$ bait (Fig. 4J). As a negative control, MBP fused to $\beta$-galactosidase (Fig. 4I) showed no detectable interaction with the GST$\mathrm{CSH}^{\mathrm{WT}}$ bait (Fig. 4J).

To further support these observations, we performed electron microscopy (EM) experiments to obtain a low-resolution image of the unphosphorylated $6 \mathrm{xHis}-\mathrm{Vav} 1^{\Lambda^{1-144}}$ mutant. This protein lacks the inhibitory $\mathrm{CH}$ domain and, similar to Vav1 $1^{1-186}$, shows constitutive, phosphorylationindependent activity $(7,28)$. Although EM analysis does not yield data at atomic resolution, it 
can provide useful information about the shape and volume of proteins under analysis, as well as the stereo-spatial distribution of structural domains within these volumes. The analysis of purified fractions of $6 x$ His-Vav1 $1^{1^{1-144}}$ (fig. S5A) revealed that 6xHis-Vav1 $1^{1-144}$ displayed a homogenous structure characterized by the presence of a bulky area (referred to as the "head") and an elongated extension (designated as the "tail") (fig. S5B). Images derived from different rotated views of the molecule along its axis were collected (fig. S5C) and processed to generate an average three-dimensional $(3 \mathrm{D})$ reconstruction with an overall resolution of $\approx 32.5 \AA$ (fig. S5D).

We next used in silico docking methods to define the stereo-spatial distribution of the DH-PH$\mathrm{ZF}$ and $\mathrm{SH} 3-\mathrm{SH} 2-\mathrm{SH} 3$ regions within the EM-generated volume. Because the structure of the Vav1 C-terminus is unknown, we used the available crystal structure of Grb2 (40), an adaptor protein with a Vav1-like arrangement of $\mathrm{SH} 2$ and $\mathrm{SH} 3$ domains, to model docking. These methods assigned the catalytic DH-PH-ZF core to the head region of 6xHis-Vav1 $1^{{ }^{1-144}}$ (fig. S5D). Although the limited resolution of the EM structure prevented us from performing an unbiased modeling, the flat shape of this area and its connectivity to the C-terminal tail favored certain orientations of the DH-PH-ZF cassette (fig. S5D). The SH2 domain and one of the two SH3 domains of Grb2 could be fitted within the tail of $6 x$ His-Vav1 $1^{1-144}$ without any deviation from their localization within the crystal structure of Grb2 (fig. S5D). In contrast, the second SH3 region of Grb2 required a substantial clockwise rotation towards the head region to be fully accommodated within the density of $6 x$ His-Vav1 $1^{1-144}$ (fig. S5D). Such movement is structurally possible, because previous results have shown that Grb2 adopts multiple conformational states because of the flexibility of its interdomain linker regions (41). Consistent with our biochemical 
data, this rotation placed the $\mathrm{SH} 3$ domain in close proximity to the $\mathrm{PH}$ domain and the $\mathrm{C}$ terminal side of the DH domain, including the $\alpha 6$ helix, of Vav1 (fig. S5D). This location is also in the vicinity of the docking site of the $\mathrm{CH}$ domain and part of the Ac region when Vav1 is in the non-phosphorylated, inactive conformation (31). However, unlike the case of the $\mathrm{CH}$ region, the presence of the $\mathrm{CSH} 3$ domain in that location should not interfere with the GEF activity of Vav1, because we previously showed that the 6xHis-tagged Vav $1^{\wedge^{1-144}}$ and Vav3 $3^{1-144}$ oncoproteins have phosphorylation-independent GEF activity in vitro $(7,28)$.

\section{The DH domain $\alpha 6$ helix stabilizes the inhibitory CSH3-Vav1 interaction}

To gain further information about this previously uncharacterized regulatory mechanism, we first focused our attention on the $\mathrm{DH}$ domain $\alpha 6$ helix (Fig. 5A). This region was of interest because its integrity was clearly important for the interaction between the CSH3 domain and the DH-PH region that we detected in pull-down experiments (Fig. 4, G and H; fig. S4A). Furthermore, the $\mathrm{DH} \alpha 6$ helix undergoes large topological changes during the activation step of Vav proteins (fig. S6) (29-31). We hypothesized that if residues of the $\alpha 6$ helix were important for the stability of the intramolecular CSH3-Vav1 interaction, then their mutation in Vav1 $1^{835-845}$ would result in the loss of interaction with the GST-CSH3 fusion protein in pull-down experiments.

We chose the residues to be mutated based on evolutionary conservation criteria, their localization in areas undergoing topological changes between the inactive and active catalytic states of Vav1 (fig. S6), and by their being present in all of the EGFP-Vav1 fragments that we

found could bind to the $\mathrm{CSH} 3$ region (Fig. 5A). As a control, we mutated two less-conserved residues $\left(\mathrm{Thr}^{384}\right.$ and $\mathrm{Leu}^{388}$ ), which are located further downstream in the DH domain $\alpha 6$ helix 
(Fig. 5A). We mutated the chosen residues to alanines to avoid major conformational changes (42). Our analysis of a first collection of DH $\alpha 6$ Vav1 ${ }^{835-845}$ mutants indicated that the amino acid pairs of $\mathrm{Val}^{373}$ and $\mathrm{Lys}^{374}$ and $\mathrm{Arg}^{375}$ and $\mathrm{Asp}^{376}$ were indeed important for the binding of both the GST-Vav1 CSH3 ${ }^{\mathrm{WT}}$ and GST-Vav1 CSH3 ${ }^{\mathrm{P} 33 \mathrm{~L}}$ proteins to Vav1 $1^{835-845}$ (Fig. 5B). By contrast, the residues $\mathrm{Asn}^{371}, \mathrm{Glu}^{372}, \mathrm{Thr}^{384}$, and $\mathrm{Leu}^{388}$ were dispensable for such an interaction (Fig. 5B, left panels). The two residues $\mathrm{Val}^{373}$ and $\mathrm{Lys}^{374}$ favored in a concerted manner the interaction of the Vav1 CSH3, because their single mutation was not sufficient to eliminate the interaction between Vav1 ${ }^{835-845}$ and GST-Vav1 CSH3 (Fig. 5B, right panels). In contrast, the $\mathrm{Asp}^{376}$ residue of the $\mathrm{Arg}^{375} \mathrm{Asp}^{376}$ pair was the key one that contributed to the interaction (Fig. $5 \mathrm{~B}$, right panels). Some of the residues identified in these experiments seem to have pleiotropic roles, because $\mathrm{Lys}^{374}$ and $\mathrm{Asp}^{376}$ participate in interactions with the switch II regions of Rac1 and with the PH-ZF region of Vav1, respectively (fig. S6B) (29, 30). However, this is not a general feature of this interaction, because mutation of other residues involved in the Vav1-Rac1 association, such as $\mathrm{Asn}^{371}$ and $\mathrm{Arg}^{375}$ (fig. S6B), did not impair the binding of Vav1 $1^{835-845}$ to the GST-CSH3 ${ }^{\text {P833L }}$ fusion protein (Fig. 5B).

We next analyzed the biological activity of the Vav1 ${ }^{\mathrm{D} 376 \mathrm{~A}}$ mutant to confirm its involvement in the CSH3-dependent inhibitory mechanism. We assumed that if this residue contributed to Vav1 autoinhibition, its mutation would release the CSH3 domain from its binding site and, therefore, would result in the enhanced activation of the full-length protein in cells. If so, such data could also contribute to ruling out the possibility that the disruption of the interaction between GST$\mathrm{CSH}^{\mathrm{P} 83 \mathrm{LL}}$ and Vav1 ${ }^{835-845}$ that we observed earlier (Fig. 5B) might be because of spurious effects of the D376A mutation in the overall Vav1 structure. Confirming our pull-down data, we 
observed that $\operatorname{Vav} 1^{\mathrm{D} 376 \mathrm{~A}}$, but not $\operatorname{Vav} 1^{\mathrm{K} 374 \mathrm{~A}}$, displayed increased biological activity compared to that of Vav1 ${ }^{\mathrm{WT}}$ in both JNK and NFAT assays (Fig. 5, C and D). Similarly, we observed that the D376A mutation led to an increase in the binding of the full-length Vav1 protein to the target GTPase Rac1 (Fig. 5E). These results indicate that specific residues within the C-terminal $\alpha 6$ helix of the DH domain of Vav1, a region that undergoes a large rotation and displacement during Vav1 activation (fig. S6), contribute to the stabilization of the interaction between the CSH3 domain and the central domains of Vav1. However, this is not mediated by direct interactions, because the $\alpha 6$ helix of Vav1 alone did not bind to the CSH3 domain (fig. S4A).

\section{Residues at the RT loop and the C-terminal end of the CSH3 domain are involved in the inhibition of Vav1}

To identify the $\mathrm{CSH} 3$ residues involved in the intramolecular CSH3-Vav1 interaction, we assumed that their single or compound mutation into alanine residues would release this interaction and, therefore, make the intramolecular binding site of the CSH3 domain accessible to the GST-CSH3 bait proteins used in our pull-down experiments. A first round of pull-down experiments ruled out the individual involvement of 23 surface-exposed CSH3 residues (fig. S7, $\mathrm{A}$ and $\mathrm{B})$, although the point mutation of two of these $\left(\operatorname{Vav1}^{\mathrm{D} 792 \mathrm{~A}}\right.$ and $\left.\operatorname{Vav} 1^{\mathrm{V} 837 \mathrm{~A}}\right)$ very slightly increased the extent of the interaction between full-length Vav1 and the GST-Vav1 CSH3 ${ }^{\text {P833L }}$ bait (fig. S7B). The subsequent generation of compound mutations of $\mathrm{Asp}^{792}$, $\mathrm{Phe}^{793}$, and $\mathrm{Cys}^{794}$; $\mathrm{Asp}^{792}, \mathrm{Phe}^{793}$, $\mathrm{Cys}^{794}-\mathrm{x}$, and $\mathrm{Arg}^{796}$; as well as $\mathrm{Tyr}^{836}, \mathrm{Val}^{837}, \mathrm{Glu}^{838}, \mathrm{Glu}^{839}$, and $\mathrm{Asp}^{840}$ around those sites, which are referred to as DFCmut, DFC-Rmut, and YVEEDmut, respectively (Fig. 6A), revealed that mutations affecting the DFC-R and YVEED patches did promote increased binding of the respective mutant proteins to the GST-CSH3 ${ }^{\text {P833L }}$ bait (Fig. 6B, left panels). When 
taking into consideration the abundance of each mutant protein in the COS1 cell lysates used in these pull-down experiments (Fig. 6B, bottom panel on the left), we observed that the DFCmut had a slightly stronger effect in favoring the opening of the full-length Vav1 protein than the YVEEDmut (Fig. 6B, top panel, compare lanes 3 and 5). The combined mutation of the DFC-R patch and the YVEED region did not further increase the extent of binding of the mutant proteins to the bait (Fig. 6B, top panel on the left; compare lanes 4 and 6). These results indicate that these two sites of the CSH3 domain contribute to the formation of the autoinhibited state of fulllength Vav1 protein.

Confirming the involvement of the DH domain $\alpha 6$ helix in these interactions, we observed that the compound Vav1 $1^{\mathrm{D} 376 \mathrm{~A}+\mathrm{DFC}-\mathrm{Rmut}}$ mutant protein interacted very poorly with the GST-CSH3 ${ }^{\mathrm{P} 33 \mathrm{~L}}$ fusion protein (Fig. 6B, right panels). Experiments with transfected Jurkat cells indicated that the Vav1 $1^{\text {DFC-R+YVEEDmut }}$ protein induced the TCR-independent stimulation of JNK activity (Fig. 6, C and D) and F-actin polymerization (Fig. 6E), similarly to $\operatorname{Vav} 1^{833-845}$ and $\operatorname{Vav} 1^{\mathrm{D} 376 \mathrm{~A}}$. The Vav1 ${ }^{\mathrm{DFC}-}$ ${ }^{R+Y V E E D m u t}$ protein also enhanced basal NFAT activity, a response that was further increased upon TCR stimulation (fig. S8, A and B). The combined DFC-R+YVEED and D376A mutations did not increase the biological activity already displayed by the Vav1 ${ }^{\text {DFC-R+YVEEDmut }}$ and Vav1 $1^{\text {D376A }}$ proteins (Fig. 6, C and D; fig. S8, A and B), indicating that all of those residues functioned redundantly in the regulation of Vav1 activity.

We obtained similar results when we tested these proteins in COS1 cells with JNK activity assays (fig. S8, C and D) and GST-Rac1 ${ }^{\mathrm{G} 15 \mathrm{~A}}$-binding experiments (fig. S8E). The cooperative action of the CSH3 DFC-R and YVEED residues was required to fully inhibit Vav1 in cells, as 
evidenced by the lower biological activity shown by Vav1 ${ }^{\text {DFC-Rmut }}$ and Vav1 $1^{\text {YVEEDmut }}$ proteins in cells when compared to that shown by Vav1 ${ }^{\text {DFC-R+YVEEDmut }}$ (Fig. 6, F and G). However, we found that Vav1 ${ }^{\text {DFC-Rmut }}$ showed increased basal activity compared to that of Vav1 ${ }^{\text {WT }}$ (Fig. 6, F and G), indicating that the DFC-R motif contributes more substantially to the stabilization of the autoinhibited state of Vav1 than does the YVEED motif when tested in cells. Ruling out the possibility that the activation of the Vav1 $1^{\mathrm{D} 376 \mathrm{~A}+\mathrm{DFC}-\mathrm{Rmut}}$ mutant might be a result of the deleterious effects of the mutations in the overall folding of the CSH3 domain, we demonstrated that a Vav1 CSH3 domain that had mutations in the DFC-R, YVEED, and DFC-R+YVEED regions could still efficiently bind to the heterogeneous ribonucleoprotein K (hnRNPK), a protein that interacts with the Vav1 CSH3 domain through a canonical, PRR-based interaction (fig. S8F) $(43,44)$. As a control, we found that the interaction between hnRNPK and the CSH3 domain was abolished when the PRR-binding site of CSH3 was inactivated by the incorporation of the P833L mutation (fig. S8F) $(43,44)$.

The large spatial distribution of the Vav1 CSH3 domain residues involved in the inhibition of the full-length protein led us to investigate the possibility that the DFC and YVEED motifs might be involved in the recognition of independent regions of the catalytic DH-PH-ZF core, an idea that is also consistent with our earlier observations that indicate that the Vav1 CSH3 domain binds to both the isolated $\mathrm{DH}$ and $\mathrm{PH}$ regions of Vav1 (Fig. 4, G and H; fig. S4A). To evaluate this possibility, we investigated the binding of the GST-CSH3 ${ }^{\text {DFC-Rmut+P833L }}$, GST-CSH3 ${ }^{\text {P833L+YVEEDmut }}$, and GST-CSH3 $3^{\text {DFC-Rmut+P833L+YVEEDmut }}$ fusion proteins to all of the domains present in the Vav1 catalytic core (Fig. 4F). We observed that mutation of the DFC-R region eliminated the interaction between the GST fusion protein and the Vav1 DH-NPH region, but not the Vav1 PH 
region (Fig. 6H). Conversely, mutation of the YVEED region abolished the interaction between the bait and the Vav1 PH region, but not the Vav1 DH-NPH region (Fig. 6H). As was expected from our previous results, compound mutations of the DFC-R and YVEED regions eliminated the interaction between GST-CSH3 $3^{\mathrm{P} 33 \mathrm{~L}}$ and all of the ectopic proteins, including EGFP fused to the entire DH-PH-ZF cassette (Fig. 6H). These results indicate that the Vav1 CSH3 domain uses residues present in the RT-loop (DFC-R motif) and its C-terminal end (YVEED motif) to interact with the DH and PH regions, respectively (Fig. 6A).

\section{Multiple phosphorylation sites are involved in the activation of Vav1 in cells}

Given the close connection between Vav1 and tyrosine kinase-regulated signaling pathways (5, 45), we decided to investigate whether the loss of the CSH3-dependent inhibitory interaction could be mediated by tyrosine phosphorylation-dependent events. In addition to the previously known phosphorylation sites at $\mathrm{Tyr}^{142}$, $\operatorname{Tyr}^{160}$, and $\mathrm{Tyr}^{174}$ (27), we found through mass spectrometry techniques that Vav1 was consistently phosphorylated at three additional tyrosine residues $\left(\mathrm{Tyr}^{541}\right.$, $\mathrm{Tyr}^{544}$, and $\left.\mathrm{Tyr}^{836}\right)$ in TCR-stimulated Jurkat cells and EGF-stimulated COS1 cells (table S1). $\mathrm{Tyr}^{541}$ and $\mathrm{Tyr}^{54}$ are located in the ZF domain of Vav1, and they establish bonds with residues present in the PH-ZF region (fig. S6B) $(29,30)$, whereas $\mathrm{Tyr}^{836}$ is located in the YVEED motif of the CSH3 domain (Fig. 6A).

To confirm the proteomics data with independent techniques, we generated rabbit polyclonal phospho-specific antibodies against each of these residues and, in addition, to two of the previously known phosphorylation sites: $\operatorname{Tyr}^{142}$ and $\operatorname{Tyr}^{160}$. A phospho-specific antibody against the key regulatory residue $\mathrm{Tyr}^{174}$ was reported previously (27). We demonstrated the specificities 
of these antibodies through the detection of the phosphorylation of each of residues of interest in $\operatorname{Vav} 1^{\mathrm{WT}}$, but not in the appropriate phospho-site mutant proteins, in EGF-stimulated COS1 cells (fig. S9). With these antibodies, we demonstrated that endogenous Vav1 proteins became effectively and rapidly phosphorylated on $\mathrm{Tyr}^{541}$, $\mathrm{Tyr}^{54}$, and $\mathrm{Tyr}^{836}$ upon the TCR-dependent stimulation of Jurkat cells (Fig. 7A). Such phosphorylation was comparable in amplitude and kinetics to that shown by the three previously described $\mathrm{N}$-terminal phosphorylation sites of Vav1: $\operatorname{Tyr}^{142}, \operatorname{Tyr}^{160}$, and $\operatorname{Tyr}^{174}$ (Fig. 7A).

We mutated these previously uncharacterized phospho-sites into either phenylalanine or glutamate residues in full-length Vav1 to assess their contributions to the activation of Vav1 in cells. In addition, we modified these residues in the context of the Vav1 ${ }^{\mathrm{Y} 174 \mathrm{~F}}$ mutant protein to detect potential synergisms with the phospho-sites involved in the release of the inhibitory Nterminal domains. When we tested these mutants in JNK assays, we found that the effects of the mutations were highly contingent upon both the stimulation state and type of Vav1 protein used. In unstimulated Jurkat cells, the Y541F, Y544F, Y836F, and Y836E Vav1 point mutants displayed biological activities slightly greater than that of $\mathrm{Vav} 1^{\mathrm{WT}}$, whereas the $\mathrm{Y} 836 \mathrm{~F}$ and Y836E mutants had activities that were greater than those shown by both Vav1 $1^{\mathrm{WT}}$ and Vav1 $1^{\mathrm{Y} 174 \mathrm{~F}}$ (Fig. 7, B and C). The Vav1 ${ }^{\mathrm{Y} 541 \mathrm{E}}$ and $\operatorname{Vav} 1^{\mathrm{Y} 544 \mathrm{E}}$ mutant proteins exhibited activities similar to that of Vav1 ${ }^{\mathrm{WT}}$ (Fig. 7, B and C), indicating that the single mutation of each of those two residues did not substantially affect the basal activities of these proteins. However, in Jurkat cells stimulated with anti-CD3 antibody, the phospho-site mutants were unexpectedly less active than were the $\operatorname{Vav} 1^{\mathrm{WT}}$ and $\operatorname{Vav} 1^{\mathrm{Y} 174 \mathrm{~F}}$ proteins (Fig. 7, B and C), indicating that the phosphosite mutants had become insensitive to upstream stimulation. A similar defect was seen in the case of Vav1 ${ }^{\text {P833L }}$ 
(Fig. 4A), which was probably a result of the known requirement of the canonical PRR-binding site of the Vav1 CSH3 domain for the optimal phosphorylation of Vav1 in lymphoid cells (34). A similar explanation can be used in the case of the Y833F and Y836E mutations, because these residues are located in the vicinity of the PRR-binding site. Consistent with this interpretation, the Vav1 $1^{\text {YVEEDmut }}$ protein (which contains the Y836A mutation and can bind to PRR-containing proteins) showed activities very similar to that of Vav1 ${ }^{\mathrm{wT}}$ in TCR-stimulated cells (Fig. 6, C and F).

In this functional context, it is possible that the lack of responsiveness of the Vav1 ZF phosphosite mutants to TCR stimulation could be caused by conformational changes that, by restricting the accessibility of the PRR-binding site of the CSH3 domain to other signaling proteins, could inhibit phosphorylation of the protein. Consistent with this idea, we found that the concurrent mutation of $\mathrm{Tyr}^{174}$ restored the TCR-responsiveness of the Y544E mutant protein (Fig. 7, B and C). Furthermore, this mutation synergized with the rest of phospho-site mutations, which led to the generation of constitutively activate proteins in all cases (Fig. 7, B and C). The most marked effect was observed in the case of the compound Y174F,Y836E mutant protein, which displayed biological activities that were similar to those of the Vav1 $1^{1-186}$ and Vav1 $1^{835-845}$ mutants (compare Fig. 7B and Fig. 1C), but were increased compared to those of the Vav1 $1^{\mathrm{Y} 174 \mathrm{~F}}$ or Vav1 $1^{\mathrm{Y} 3 \mathrm{~F}}$ mutants (Fig. 7, B and C). Although the Vav1 ${ }^{\mathrm{Y} 174 \mathrm{~F}+\mathrm{Y} 544 \mathrm{E}}$ protein was not constitutively active, it enhanced the activation of JNK compared to that of $\mathrm{Vav} 1^{\mathrm{WT}}$ under both unstimulated and stimulated conditions (Fig. 7, B and C). These results indicate that the full activation of Vav1 under physiological conditions requires the synergistic effect of multiple phosphorylation sites located in the Ac, ZF, and, to a much larger extent, the $\mathrm{CSH} 3$ regions. In addition, these results suggest 
that Vav1 can adopt different conformational or functional states depending on the specific tyrosine residues and domains that are phosphorylated at any given time.

To establish a connection between the constitutive activation of the phospho-site mutant proteins and the release of the intramolecular CSH3-Vav1 interaction, we evaluated their interactions with the GST-CSH3 ${ }^{\mathrm{P} 83 \mathrm{~L}}$ bait in pull-down experiments. Consistent with a partial release of such an inhibitory interaction, we observed that the Y174F mutation promoted the increased binding of full-length Vav1 to the GST-CSH3 ${ }^{\mathrm{P} 33 \mathrm{~L}}$ bait (Fig. 7D, left panel). This effect was similar to that caused by truncation of the inhibitory N-terminal domains (Fig. 4D). The positive effect caused by the Y174F mutation was eliminated when combined with the ZF and CSH3 phosphosite mutations (Fig. 7D, left panel), suggesting that each of these residues regulate, dependent on their phosphorylation states, the formation of conformational states that affect the stability of the intramolecular CSH3-Vav1 interaction.

Ruling out the possibility that the lack of association between either of the two ZF phospho-site mutant proteins and the GST-CSH3 ${ }^{\mathrm{P} 833 \mathrm{~L}}$ fusion protein was because of the re-establishment of the intramolecular interaction between the DH-PH-ZF region and CSH3 domain, we found that these mutations also abolished interactions with the GST-CSH3 ${ }^{\mathrm{P} 83 \mathrm{~L}}$ bait when introduced into the CSH3-truncated Vav1 ${ }^{835-845}$ protein (Fig. 7D, right panel). The binding defects caused by these two phospho-site mutations were not because of spurious effects on the overall structure of Vav1, because the $\mathrm{Vav1}^{\mathrm{Y}^{541 \mathrm{~F}+}+_{\Delta} 835-845}$ and $\mathrm{Vav1}^{\mathrm{Y}^{4} 44 \mathrm{~F}+{ }_{\Delta} 835-845}$ mutant proteins still retained their ability to interact with GST-Rac1 ${ }^{\mathrm{G} 15 \mathrm{~A}}$ (Fig. 7E). Together, these results indicate that the phosphorylation 
state of $\mathrm{Tyr}^{836}$ and, to a lesser extent, those of $\mathrm{Tyr}^{541}$ and $\mathrm{Tyr}^{544}$, contributes to the regulation of Vav1 activity through synergistic cross-talk with phosphosites localized with the Ac region.

\section{Discussion}

We showed that optimal autoinhibition of Vav proteins requires the coordinated interaction of the $\mathrm{CH}-\mathrm{Ac}$ and $\mathrm{CSH} 3$ regions with the central catalytic core (Fig. 7F and fig. S10, point $\mathrm{i}$ ). This autoinhibited structure restricts both the catalytic-dependent and -independent outputs of these proteins, as evidenced by the concurrent stimulation of downstream JNK and NFAT signaling upon disruption of the CSH3-mediated inhibition by mutagenesis techniques. Within this autoinhibited structure, the $\mathrm{CH}$ domain and Ac region seem to be primarily involved in the occlusion of the catalytic site, and, to a much lesser extent, in the stabilization of the intramolecular CSH3-Vav1 interaction (Fig. 7F and fig. S10, points ii and iii). Conversely, the CSH3-mediated interaction does not block the catalytic activity per se; rather, it seems to work as an extra safety latch for the stability of the interaction between the $\mathrm{CH}$ and Ac regions and the catalytic core.

Consistent with these ideas, we showed that N-terminally deleted proteins were constitutively active despite maintaining the intramolecular CSH3-Vav1 interaction (fig. S10, point ii). Furthermore, we showed, through in vitro GDP-GTP exchange assays and assays conducted in TCR-deficient Jurkat cells, that elimination of CSH3-mediated inhibition led to the constitutive activation of Vav proteins even under conditions that did not favor the phosphorylationdependent release of the $\mathrm{CH}$ and Ac regions from the catalytic core (fig. S10, points iv and v). These two inhibitory inputs were eliminated by the synergistic effects of several phosphorylated 
tyrosine residues (Fig. 7F and fig. S10, point vi), thus providing a simple mechanistic framework to couple the kinase association step with the acquisition of full signaling competence by these proteins during signal transduction. Our mutagenesis experiments revealed that the activation of Vav proteins can be achieved by mutating the regulatory tyrosine residues to either phenylalanine or glutamic acid residues. This suggests that, similarly to the key $\mathrm{Tyr}^{174}$ residue $(27,31,46)$, the hydroxyl groups of the sites that we identified probably contribute to stabilize the intramolecular inhibitory mechanism reported here. Crystallographic studies will be required to fully elucidate the multiple interdomain contacts that contribute to the inhibition of the catalytic activities of these proteins.

SH3-mediated autoinhibition events have been described for other Rho GEFs, including intersectin (47, 48), kalirin (49), Rho GEF4 (also known as ArhGEF4 and adenomatous polyposis coli protein-stimulated GEF [Asef]) $(50,51)$, and Rho GEF5 (also known as ArhGEF5 and transforming immortalized mammary oncogene product [TIM]) family members (52). The mechanism described here bears some similarity, but not identity, to the SH3-mediated autoinhibition of ArhGEF4 and ArhGEF5 family proteins. Thus, the autoinhibition of ArhGEF4 is mediated by noncanonical interactions of its $\mathrm{N}$-terminal $\mathrm{SH} 3$ domain with residues located in the DH-PH region, including the $\mathrm{DH} \alpha 6$ helix $(50,51)$. However, in this case, the SH3 domain is directly involved in blocking the GTPase-binding site rather than in stabilizing a second inhibitory motif $(50,51)$. The activation step is also different, because it relies exclusively on the release of the SH3 domain through the interaction of other proteins with an adjacent motif (50). ArhGEF5 family proteins do have a double inhibitory system consisting of a tyrosine-based inhibitory motif and a CSH3 region (52); however, CSH3-mediated inhibition is based on the 
recognition of a PRR located outside of the DH-PH cassette (52). The mechanism by which this interaction is broken during signal transduction is not yet known. These results indicate that the SH3-regulated Rho GEF subfamilies use rather idiosyncratic mechanisms to transit in and out of the autoinhibited state.

The autoinhibitory and phosphorylation-dependent activation mechanisms described here may provide additional regulatory layers for the spatiotemporal control of Vav proteins during cell signaling. For example, the requirement of multiple phosphorylation sites for the activation step offers an obvious buffering mechanism against spurious activation events derived from the stochastic phosphorylation of Vav proteins at single sites. Such background phosphorylation "noise" does exist in cells, as evidenced by the basal amount of Vav phosphorylation that we detected under unstimulated conditions. The intensity, diversity, or both of signaling downstream of $\mathrm{Vav}$ may also vary depending on the total number and location of the phosphotyrosines engaged at a given time (fig. S10, points vi and vii), thus offering a fine-tuning mechanism to adapt such signaling responses to the strength, duration, or type of incoming extracellular stimuli. In the same regulatory context, our observations indicating that mutation of the canonical PRR-binding site of the CSH3 domain enhances the interaction between CSH3 and Vav1 suggest that the association of PRR-containing proteins with phosphorylated Vav proteins may constrain the return to the autoinhibited state and, as a consequence, prolong Vav signaling under specific stimulation conditions or in specific subcelullar localizations (fig. S10, point vi). This may explain the reason for the high functional and structural diversity found so far for the canonical binding partners of Vav family CSH3 domains $(4,5)$. 
The dependency of an SH3-mediated interaction to maintain an autoinhibited state also has its disadvantages, because it could lead to spurious activation events through SH3-displacement mechanisms (fig. S10, point viii). In this context, it is worth noting that the CSH3 domain of Vav is a common signaling target for Nef and M2, two PRR-containing proteins encoded by HIV and $\gamma$-herpesviruses, respectively $(53,54)$. Such a mechanism may be at work in the case of Nef, because previous results have shown that it stimulates Vav proteins in a phosphorylationindependent manner (53). It is also worth noting that our data do not exclude the possibility that, in addition to its direct effect on catalytic activity, the intramolecular localization of the CSH3 domain might regulate the biological activity of Vav family proteins through additional mechanisms. For example, it is feasible that the release of the CSH3 domain during the activation step could favor the surface exposure of other regions of the molecule involved in interactions with other protein partners or cellular structures, such as the plasma membrane. Further work will be needed to fully understand all of the implications of this previously uncharacterized regulatory mechanism in the dynamic control of Vav proteins during both physiological and pathological signaling conditions.

\section{MATERIALS AND METHODS}

\section{Antibodies}

Primary antibodies used in this study include a rabbit polyclonal antibody against Vav1 (\#301-5) that was generated in house with a maltose-binding protein fused to the Vav1 DH domain purified from Escherichia coli as an immunogen (28); a rabbit polyclonal antibody against GST (Sigma); and monoclonal antibodies against human CD3 (UCHT1 clone, Merck Millipore), EGFP (Covance), tubulin $\alpha$ (Santa Cruz Biotechnology), chicken IgM (Southern Biotech), and 
hnRNPK (Merck Millipore). The rabbit polyclonal antibody that is specific for the phosphorylated $\mathrm{Tyr}^{174}$ residue of Vav1 has been described previously (27). The other phosphospecific antibodies against Vav1 residues that were used here were generated with tyrosinephosphorylated peptides as immunogens (Invitrogen custom service). After their generation, the antibodies were positively and negatively selected by chromatographic steps with the appropriate phosphorylated and non-phosphorylated synthetic peptides. Specific recognition of the target phosphorylated sequence was demonstrated by ELISA with the appropriate phosphorylated and non-phosphorylated peptides and, in addition, by comparing the signals generated in Western blots with immunoprecipitated wild-type (WT) and phospho-site mutant versions of Vav1 from non-stimulated and EGF-stimulated COS1 cells (fig. S9).

\section{Cell lines}

Jurkat, DT40, COS1, and NIH3T3 cells were obtained, cultured, and stimulated as described previously $(28,55,56)$.

\section{Expression vectors and in vitro mutagenesis}

All constructs used in this work used the mouse versions of mammalian Vav family members. Mammalian expression vectors encoding $\operatorname{Vav1}^{\mathrm{WT}}$ (pJC11), EGFP-Vav1 $1^{\perp^{1-186}}$ (pNM108),

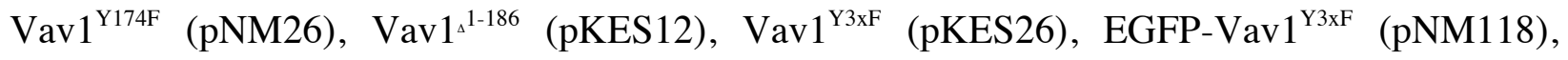
Vav1 $^{\text {P833L }}$ (pKES42), EGFP-Vav1 DH-PH-ZF (pNM103), EGFP-Vav1 DH-NPH (pNM109), EGFP-Vav1 PH (pNM111), and EGFP-Vav1 ZF (pNM113) proteins were described previously $(27,28,57)$. The Vav1 $1^{835-845}$-encoding mammalian expression vector pKES29 was generated by polymerase chain reaction (PCR) amplification with the Vav1 ${ }^{\mathrm{WT}}$-encoding vector $\mathrm{pJC} 11$ (57) as a 
template and the primers 5'-GCTCTGTCATGGACACCC-3' (forward, which amplifies just before the Bsu 36I restriction site present in Vavl cDNA) and 5'AGCTAGTCTAGAATATTCAGTTAGAAGGGAACCAGCC-3' (reverse, with the Xba I cloning site underlined). The amplified cDNA fragment was digested with Bsu 36I and Xba I and then ligated into Bsu 36I- and XbaI-linearized pcDNA3 plasmid pKES18, which encodes $\operatorname{Vav} 1^{\mathrm{WT}}$. Plasmids encoding the EGFP-tagged Vav1 ${ }^{835-845}$ (pMB6) and Vav1 $1^{\mathrm{Y}^{3 \times F_{4}}{ }^{835-845}}$ (pMB46) proteins were generated by PCR amplification with the EGFP-tagged Vav $1{ }^{\text {WT }}$-encoding vector pSRM3 as a template (58) and the primers: 5'-CCAGGACAAGAAAAGGAATG-3' (forward, which amplifies from just before the Bam $\mathrm{HI}$ site present in Vav1 cDNA) and 5'AGCTAGGATCCAATATTCAGTTAGAAGGGAACCAGCC-3' (reverse, with the Bam HI site underlined). The amplified cDNA fragment was digested with Bam HI and ligated into Bam HIlinearized vectors encoding either EGFP-Vav1 ${ }^{\mathrm{WT}}$ (pSRM3) or Vav1 ${ }^{\mathrm{Y} 3 \mathrm{KF}}$ (pKES14) (27). A mammalian expression vector encoding EGFP-tagged Vav2 ${ }^{860-868}$ (pMB127) was generated by introducing a stop codon in the Vav2 cDNA present in the EGFP-Vav2 ${ }^{\mathrm{WT}}$-encoding vector pAA7 with the primers 5'-CGGTTGGTTTCCTTCGACGTAGGTGGAAGAGGAAGGCGTCCAG-3' and 5'-CTGGACGCCTTCCTCTTCCACCTACGTCGAAGGAAACCAACCG-3' (with the stop codon underlined). To generate the vector encoding EGFP-Vav3 ${ }^{841-847}$ (pMB121), a cDNA fragment was amplified by PCR with the pC-HA-Vav3 plasmid (Addgene) as template and the primers 5'-ATACTCGAGGCCACCATGGAGCCGTGGAAGCAGTGCGCTC-3' (forward, with the Xho I site underlined) and 5'CCGGGCGAATTCTTATGTGGATGGAAACCAGCCCACCC-3' (reverse, with the Eco RI site underlined). Upon digestion with Xho I and Eco RI, the $\operatorname{Vav}^{841-847}$ cDNA was ligated into the Bam HI- and Eco RI-linearized plasmid pEGFP-C2 (Clontech). To obtain vectors encoding 
$D m \operatorname{Vav}^{\mathrm{WT}}$ (pMB122) and $D m \mathrm{Vav}^{\mathrm{v}^{781-793}}$ (pMB128), the appropriate cDNA fragment was PCR amplified from the DmVav-encoding vector pID18 (37) with the primers 5'ATACTCGAGGCCACCATGGCCAGCAGCAGTAGCAGCAAC-3' (forward, with the Eco RI site underlined) in both cases, and either the primer 5'CCGGGCGAATTCTCAAAGCTCTTCGCTGGCCAATTTCTG-3' (reverse, with the Eco RI site underlined) or the primer $\quad$ ' CCGGGCGAATTCTCACTTGGGAAAGTAGCCCACCGTATC-3' (reverse, with the Eco RI site underlined) respectively, and cloned into pEGFP-C2, as described earlier. The expression vector encoding EGFP-Vav1 DH (pMB49) was generated by introducing a stop codon into the Vav1 cDNA present in pNM109, the vector encoding EGFP-Vav1 DH-NPH, with the primers 5'-CTAGTGAAACACACACAGTAGGCTACAGAGAAGGAGAAC-3' GTTCTCCTTCTCTGTAGCCTACTGTGTGTGTTTCACTAG-3' (with the stop codon underlined). The expression vector pMB48, which encodes EGFP-Vav1 DH $\alpha 6$ helix, was generated by PCR amplification with pSRM3 as the template and the primers 5'GGCGAATTCCAGGAGCTAGTGAAACACACACAGGATGC-3' (forward, with the Eco RI site underlined) and 5'-AGCTAGGATCCAATATTCAGTTCAGAGACTGGTCCAGGTTC-3' (reverse, with the Bam HI site underlined). Upon digestion with Eco RI and Bam HI, the Vav1 cDNA fragment was ligated into Eco RI- and Bam HI-linearized vector pEGFP-C2. Vectors encoding additional Vav1 mutant proteins (table S2) were generated by in situ mutagenesis techniques with the QuikChange mutagenesis kit (Agilent Technologies). Oligonucleotides used for the mutagenesis steps are shown in table S3. Baculovirus expression plasmids encoding 6xHis-Vav1 ${ }^{\text {wT }}, 6 x H i s-V a v 3^{\text {WT }}, 6 x H i s-V a v 1^{{ }^{1-144}}, 6 x H i s-V a v 3^{{ }^{1-144}}$, and 6xHis-Vav3 DH-PH were described previously $(7,28,59)$. To express $6 x$ His-Vav1 $1^{{ }^{835-845}}$ and $6 x H i s-V a v 3^{{ }^{841-847}}$ in $S f 9$ cells, 
we mutated the pFastBac plasmids (Life Technologies) containing the full-length Vav1 and Vav3 cDNAs to create a stop codon at the indicated truncation points to generate the pPTK3 and pMB149 vectors, respectively. The bacterial expression vector encoding GST-Vav1 CH (pJZL81) has been described previously (28). Vectors encoding GST-Rac1 ${ }^{\mathrm{G} 15 \mathrm{~A}}$ [pGEXRac1(15A)] and GST-RhoAG17A [pGEX-RhoA(17A)] were obtained from A. D. Cox (Chapel Hill School of Medicine, University of North Carolina, Chapel Hill, NC). The bacterial expression vector encoding the Vav1 CSH3 (pGEX-SH3) was obtained from P. Simas (Instituto de Medicina Molecular, Facultade de Medicina, Lisboa University, Lisbon, Portugal). This plasmid was used to generate the indicated mutations with the QuikChange mutagenesis kit (see tables S2 and S3). To express MBP-Vav1 DH-PH-ZF in bacteria, the Vav1 cDNA encoding these regions as well as 10 flanking amino acid residues was subcloned into the pMAL-c plasmid (New England Biolabs) according to standard procedures to generate the final pXRB7 plasmid. All newly generated plasmids were subjected to DNA sequence analysis to rule out the possibility of unwanted mutations.

\section{Biological assays}

For JNK activation assays in lymphoid cells, exponentially growing Jurkat cells $\left(2 \times 10^{7}\right.$ cells $)$ and DT40 cells $\left(1 \times 10^{7}\right.$ cells) were co-electroporated (at $250 \mathrm{~V}$ and $\left.950 \mu \mathrm{F}\right)$ with pFR-Luc (10 $\mu \mathrm{g}$; Agilent Technologies), pFA2-cJun (5 $\mu \mathrm{g}$, Agilent Technologies), and $20 \mu \mathrm{g}$ of the appropriate Vav1-encoding expression vector. When required, electroporations were supplemented with empty plasmids to maintain a constant total amount of transfected DNA among samples. After 36 hours, cells were either left unstimulated or were stimulated with antibodies against human CD3 (in the case of Jurkat cells) or chicken IgM (in the case of DT40 
cells) for 7 hours, lysed, and then luciferase activities were determined with the Dual Luciferase Assay System (Promega). In the case of COS1 cells, exponentially growing cells were transfected with liposomes (Lipofectamine 2000, Invitrogen) with 1, 0.5, and $2 \mu \mathrm{g}$ of the pFRLuc, pFA2-cJun, and appropriate expression vectors, respectively. Luciferase activity was determined 36 hours after transfection, as described earlier. For NFAT activation assays, cells were co-electroporated with the pNFAT/luc reporter vector $(10 \mu \mathrm{g}$; provided by G. R. Crabtree, Stanford University, CA), pRL-SV40 (Promega), which encodes the Renilla luciferase (5 ng), and $20 \mu \mathrm{g}$ of the appropriate experimental or empty expression vectors. After 36 hours, luciferase activities in unstimulated and stimulated cells were determined as described earlier. The values of firefly luciferase activity obtained in the different samples were always normalized to take into account the activity of the Renilla luciferase obtained in each sample. Results presented in figures represent the fold-change in the NFAT or JNK1 activities of the indicated experimental samples relative to those of unstimulated cells transfected with the control vector (which was given an arbitrary value of 1). Values are presented as means and standard deviations (SDs) from the indicated number of independent transfections, each of which were performed in triplicate. To confirm that comparable amounts of proteins were used in all samples, aliquots of lysates from the each of the experiments described earlier were subjected to SDS-polyacrylamide gel electrophoresis (SDS-PAGE) and Western blotting analysis with appropriate antibodies. A representative example of these Western blotting analyses is included in each figure. To analyze the F-actin cytoskeleton, $1 \times 10^{6}$ Jurkat cells were transfected with $30 \mu \mathrm{g}$ of the indicated expression plasmids with the Neon Tranfector System (Program \#5; Invitrogen). After 36 hours, cells were transferred onto 12-mm diameter, poly-D-lysine-coated coverslips (BioCoat) and allowed to settle for $20 \mathrm{~min}$. In the case of COS1 cells, cells in each 6-well culture plate were 
transfected with $1 \mu \mathrm{g}$ of the plasmid of interest with Lipofectamine 2000. After 24 hours, cells were trypsinized, plated onto 12-mm diameter coverslips (Menzel-Glaser) pre-treated for $10 \mathrm{~min}$ with poly-L-Lysine ( $1 \mu \mathrm{g} / \mathrm{ml}$, Invitrogen), and then cultured for 12 to 24 hours. After these specific procedures, all cells were fixed in $4 \%$ formaldehyde in phosphate-buffered saline (PBS) for $15 \mathrm{~min}$, washed twice with PBS, permeabilized in $25 \mathrm{mM}$ Tris- $\mathrm{HCl}(\mathrm{pH} 8.0)$ containing $0.5 \%$ Triton X-100 (Sigma) for $10 \mathrm{~min}$, washed three times with TBS-T [25 mM Tris-HCl (pH 8.0), $150 \mathrm{mM} \mathrm{NaCl}, 0.1 \%$ Tween-20], and blocked for 15 min with $2 \%$ bovine serum albumin (BSA, Sigma) in TBS-T. After a 20-min incubation with rhodamine-labeled phalloidin (Invitrogen; diluted 1:200 in TBS-T, 2\% BSA) to visualize the F-actin cytoskeleton, cell preparations were washed thrice with TBS-T, and mounted onto microscope slides with Mowiol (Calbiochem). In the case of Jurkat cells, 4',6-diamidino-2-phenylindole (Invitrogen, $1 \mu \mathrm{g} /$ well) was included for 5 min in the last washing step to label the cell nuclei. Samples were analyzed with a Leica TCS SP5 confocal microscope. Images were captured with LAS AF software (version 2.6.0.72266, Leica). Focus formation assays were performed with NIH3T3 cells as previously described (28, 60). GTPase-linked immunosorbent assays were performed with a commercial kit (Cytoskeleton), as described previously $(19,23)$.

\section{Protein detection by Western blotting analysis}

Immunoprecipitations and Western blotting analysis were performed according to standard protocols, as described previously (55).

\section{GDP-GTP exchange assays}


Proteins were expressed and purified from baculovirus-infected $S f 9$ cells as described previously $(7,59)$, and then were gel-quantified with BSA (Sigma) as a concentration standard. The final concentration of 6xHis-tagged proteins $(0.25,0.5,0.8$ or $1 \mu \mathrm{M})$ used in the GDP-GTP exchange reactions is indicated in the appropriate figures. Where indicated, 6xHis-Vav1 ${ }^{\mathrm{wT}}$ was phosphorylated in vitro with a GST-Lck fusion protein purified from $S f 9$ cells, as described previously $(7,59)$. As controls, we performed kinase reactions containing either Vav $1^{\mathrm{WT}}$ or the kinase alone. After the kinase reactions were incubated at room temperature for $30 \mathrm{~min}$, aliquots were taken and used in GDP-GTP exchange reactions. The final concentrations of Vav1 and Lck in these assays were 1 and $0.1 \mu \mathrm{M}$, respectively. Exchange assays were performed with a commercial kit (RhoGEF exchange assay BK100, Cytoskeleton). In some experiments, we used the human Dbs DH-PH region, which was provided by the exchange assay kit, as a comparative control at the recommended final concentration of $0.8 \mu \mathrm{M}$. The 6xHis-tagged GTPases provided by the kit were used in these reactions at a final concentration of $2 \mu \mathrm{M}$ in all assays. Fluorescence activities were measured every $30 \mathrm{~s}$ for $30 \mathrm{~min}$ with a Synergy 4 plate reader (Biotek) with Gen5 software (Biotek). For graphical representation, raw data were imported into Excel 12.3.6 (Microsoft), selecting values obtained in 150-s intervals for final representation.

\section{Purification of proteins from E. coli}

Isopropyl $\beta$-D-1-thiogalactopyranoside-induced GST and MBP proteins in E. coli were purified with glutathione-Sepharose (GE Healthcare Life Biosciences) and amylose-coated beads (New England Biolabs), respectively. In the case of MBPs, cultures were induced for 1 hour at $25^{\circ} \mathrm{C}$ to minimize the generation of truncated versions that ran with a mobility of $\sim 37$ to $42 \mathrm{kD}$ by SDS-

PAGE (containing mostly MBP alone). After washes, GST and MBP proteins were eluted with 
$10 \mathrm{mM}$ glutathione (Sigma) and $10 \mathrm{mM}$ maltose (Sigma), respectively. Eluted proteins were dialyzed in PBS and used as indicated in the figure legends. In the case of pull-down experiments, GST proteins were kept immobilized on glutathione-Sepharose beads. For plasmon resonance determinations, the purified MBP-DH-PH-ZF protein was subjected to a size exclusion chromatography step with an fast protein liquid chromatography apparatus (GE Healthcare Life Biosciences) to eliminate the aforementioned small MBP fragments that copurified with the full-length MBP-DH-PH-ZF chimeric protein. In all cases, protein quantitation was performed with electrophoresed aliquots of samples and gradients of BSA as standards.

\section{GST pull-down experiments}

COS1 cells were transfected with $8 \mu \mathrm{g}$ of each plasmid by the diethylaminoethyldextran/chloroquine method (61) and were cultured for a further 48 hours. Cells were then washed with PBS and disrupted in lysis buffer [20 mM Tris- $\mathrm{HCl}$ (pH 7.5), $150 \mathrm{mM} \mathrm{NaCl}, 5 \mathrm{mM}$ $\mathrm{MgCl}_{2}, 0.5 \%$ Triton X-100, $5 \mathrm{mM} \beta$-glycerophosphate (Sigma), $1 \mathrm{mM}$ dithiothreitol (DTT, USB), and a mixture of protease inhibitors (Cømplete, Roche)]. After eliminating cellular debris by centrifugation at $18,600 \mathrm{xg}$ for $10 \mathrm{~min}$ at $4^{\circ} \mathrm{C}$, lysates were incubated for 5 hours at $4^{\circ} \mathrm{C}$ with $\sim 25 \mu \mathrm{g}$ (in the case of $\operatorname{Rac}^{\mathrm{G} 15 \mathrm{~A}}$ and $\mathrm{RhoA}{ }^{\mathrm{G} 17 \mathrm{~A}}$ ) or $15 \mu \mathrm{g}$ (for the rest of the assays) of the indicated GST proteins purified from E. coli. Protein complexes were trapped with glutathionesepharose beads (GE Healthcare Life Biosciences), washed thrice in lysis buffer, resuspended in SDS-PAGE sample buffer, fractionated electrophoretically, and subjected to Western blotting analysis with antibodies against Vav1, EGFP, or hnRNPK. To detect the GST proteins brought down by the beads, blots were stained with a Ponceau solution (Sigma) before the Western blotting step. Alternatively, the samples were analyzed by Western blotting with antibodies 
against GST after the detection of the pulled down proteins. Aliquots of the same cell lysates that were used for the pull-down experiments were fractionated electrophoretically and subjected to Western blotting analysis to determine the amount of protein in each case. The minimal number of repetitions of an experiment is given in the appropriate figure legend.

\section{Surface plasmon resonance determinations}

These experiments were performed with a Biacore $\mathrm{X}$-100 equipment (Biacore $\mathrm{AB}$ ) at the Centro de Investigaciones Biológicas facility. GST-CSH3 ${ }^{\mathrm{WT}}$ protein was immobilized onto a sensor chip CM5 (GE Healthcare) through the amine-coupling procedure according to the supplier's instructions. Experiments were performed in HBS-EP running buffer [0.01 M HEPES (pH 7.4), $150 \mathrm{mM} \mathrm{NaCl}, 3 \mathrm{mM}$ EDTA, $0.005 \%$ (vol/vol) surfactant P20]. MBPs (100 $\mu \mathrm{M})$ were dialyzed overnight in running buffer without surfactant and then were injected at a flow rate of $30 \mu \mathrm{l} / \mathrm{min}$ through both GST-CSH3 ${ }^{\mathrm{WT}}$-containing and non-protein-containing (control) cells. Dissociation was performed in HBS-EP running buffer. For graphical representation, raw data were imported into Prism-5 (GraphPad) and plotted. When required, regeneration of the cell chip was performed with an injection of $50 \mathrm{mM} \mathrm{NaOH}$ for 30 seconds.

\section{EM analysis and 3D reconstruction}

A 6xHis-tagged version of the Vav1 $1^{1-144}$ mutant protein was expressed in insect $S f 9$ cells and purified by metal affinity chromatography, as described previously $(6,7)$. Eluates were subjected to size-exclusion chromatography with a Superdex 200 PC3.2/30 column (GE Healthcare) equilibrated in $50 \mathrm{mM}$ Tris- $\mathrm{HCl}(\mathrm{pH} 7.5), 100 \mathrm{mM} \mathrm{NaCl}, 1 \mathrm{mM} \mathrm{MgCl}_{2}, 1 \mathrm{mM}$ DTT, and 10\% glycerol. Aliquots of fractions obtained were analyzed by SDS-PAGE and silver stained or, 
alternatively, were adsorbed on carbon-coated grids, stained with $2 \%(\mathrm{w} / \mathrm{v})$ uranyl formate (Sigma), and analyzed in a JEOL 1230 transmission electron operated at $100 \mathrm{kV}$. EM images were collected with a low-dose protocol and a 4k x 4k TVIPS CMOS detector under the control of EM-TOOLS software (TVIPS). Final magnification of the CMOS micrographs was $68,222 \times$, which were then down-sampled to a final $4.56 \AA$ per pixel. The contrast transfer function for each micrograph was estimated with CTFFIND3 (contrast transfer function and FIND 3 ) (62) and corrected with Bsoft (Bernard's software) (63). 4,970 images of individual molecules were selected from micrographs and processed with EMAN (64). Reference-free averages were obtained from XMIPP ( $\underline{X}$-Window-based microscopy image processing package). The structure was obtained by angular refinement methods as implemented in EMAN (electron microscopy analysis) (64) and with several templates for refinement, including different random noisy Gaussian blobs, which converged to the same solution. The resolution of the structures was estimated as $32.5 \AA$ A by Fourier shell correlation and a 0.5 correlation coefficient.

\section{Structural modeling}

Visualization of protein structures was performed with MacPyMol software (version 1.5, DeLano Scientific LLC). Protein data bank (PDB) files for Vav1 CH-Ac-DH-PH-ZF (3KY9), Vav1 DH-PH-ZF (2VRW), and Vav CSH3 (2DM1 and 2KBT) were retrieved from the RCSB PDB. The structure of the Vav1 CSH3 domain was modeled bioinformatically from the PDB 2DM1 file with Phyre2 software (www.sbg.bio.ic.ac.uk/phyre2) (65).

\section{Phospho-site determinations}


Vav1 immunoprecipitates obtained from unstimulated and EGF-stimulated COS1 cells and from unstimulated and anti-CD3-stimulated Jurkat cells were separated electrophoretically and stained with imidazole and zinc. Bands corresponding to Vav1 were cut from the gel, trypsinized, and analyzed with a MALDI-TOFF apparatus (Ultraflex, Bruker). Phospho-sites detected in three independent determinations were used for further characterization. In addition to the sites described in this work, we also detected that $\mathrm{Tyr}^{725}$ of $\mathrm{Vav} 1$ was phosphorylated only in the case of EGF-stimulated COS1 cells. We have also identified a number of serine and threonine residues that were not characterized in this study. To confirm the phosphorylation of those sites using independent techniques, we analyzed their phosphorylation status in Vav1 immunoprecipitates obtained from Jurkat cells that were subjected to Western blotting analyses with phospho-specific antibodies. After this step, blots were stripped and then incubated with antibodies specific for Vav1.

\section{Image-processing}

All images and figures were assembled and processed for final presentation with Canvas 12 software (Deneba Systems).

\section{Statistical analyses}

Where indicated, the Mann-Whitney $U$ test was applied to the data using, as a minimum, three independent experiments, each of which were performed with triplicate samples. $* P \leq 0.05$, $* * P$ $\leq 0.01$, and $* * * P \leq 0.001$. In all figures, data values and error bars are given as means \pm SEM.

\section{SUPPLEMENTARY MATERIALS}

Fig. S1. The known activation step of Vav family proteins. 
Fig. S2. Truncation of the CSH3 domain promotes the activation of Vav1 in cells.

Fig. S3. The Vav1 CSH3 domain does not interact with the Vav1 PRR-NSH3 region.

Fig. S4. The CSH3 inhibits Vav1 in cis.

Fig. S5. EM structure of unphosphorylated $6 \times$ His-Vav1 $1^{1-144}$.

Fig. S6. Characterization of residues of the $\mathrm{DH}$ domain $\alpha 6$ helix that contribute to the stability of the inhibitory CSH3-Vav1 interaction.

Fig. S7. The CSH3 domain of Vav1 uses two different topological regions to interact with the $\mathrm{DH}$ and $\mathrm{PH}$ domains.

Fig. S8. Effect of the mutation of CSH3 DFC-R and YVEED sites in Vav1 biological activity.

Fig. S9. Characterization of phospho-specific antibodies specific for Vav1.

Fig. S10. Proposed model for the regulation of Vav family proteins.

Table S1. Detection of indicated phosphosites in Vav1 using mass spectrometry.

Table S2. List of additional plasmids.

Table S3. List of primers.

\section{REFERENCES AND NOTES}

1. X. R. Bustelo, M. Barbacid, Tyrosine phosphorylation of the vav proto-oncogene product in activated b cells. Science (New York, N.Y 256, 1196-1199 (1992).

2. X. R. Bustelo, J. A. Ledbetter, M. Barbacid, Product of vav proto-oncogene defines a new class of tyrosine protein kinase substrates. Nature 356, 68-71 (1992).

3. M. Turner, D. D. Billadeau, Vav proteins as signal integrators for multi-subunit immunerecognition receptors. Nat Rev Immunol 2, 476-486 (2002).

4. X. R. Bustelo, in Encyclopedia of signaling molecules, S. Choy, Ed. (Springer, New York, 2012), chap. 23, pp. 1963-1976.

5. X. R. Bustelo, Regulatory and signaling properties of the vav family. Molecular and cellular biology 20, 1461-1477 (2000).

6. K. E. Schuebel, N. Movilla, J. L. Rosa, X. R. Bustelo, Phosphorylation-dependent and constitutive activation of rho proteins by wild-type and oncogenic vav-2. The EMBO journal 17, 6608-6621 (1998). 
7. N. Movilla, X. R. Bustelo, Biological and regulatory properties of vav-3, a new member of the vav family of oncoproteins. Molecular and cellular biology 19, 7870-7885 (1999).

8. P. Crespo, K. E. Schuebel, A. A. Ostrom, J. S. Gutkind, X. R. Bustelo, Phosphotyrosinedependent activation of rac-1 gdp/gtp exchange by the vav proto-oncogene product. Nature 385, 169-172 (1997).

9. V. L. Tybulewicz, Vav-family proteins in t-cell signalling. Curr Opin Immunol 17, 267-274 (2005).

10. R. Faccio, S. L. Teitelbaum, K. Fujikawa, J. Chappel, A. Zallone, V. L. Tybulewicz, F. P. Ross, W. Swat, Vav3 regulates osteoclast function and bone mass. Nat Med 11, 284-290 (2005).

11. V. Sauzeau, M. A. Sevilla, J. V. Rivas-Elena, E. de Alava, M. J. Montero, J. M. LopezNovoa, X. R. Bustelo, Vav3 proto-oncogene deficiency leads to sympathetic hyperactivity and cardiovascular dysfunction. Nat Med 12, 841-845 (2006).

12. V. Sauzeau, M. Jerkic, J. M. Lopez-Novoa, X. R. Bustelo, Loss of vav2 proto-oncogene causes tachycardia and cardiovascular disease in mice. Molecular biology of the cell 18, 943952 (2007).

13. V. Sauzeau, J. A. C. Horta-Junior, A. S. Riolobos, G. Fernandez, M. A. Sevilla, D. E. Lopez, M. J. Montero, B. Rico, X. R. Bustelo, Vav3 is involved in gabaergic axon guidance events important for the proper function of brainstem neurons controlling cardiovascular, respiratory, and renal parameters. Molecular biology of the cell 21, 4251-4263 (2010).

14. V. Sauzeau, M. A. Sevilla, M. J. Montero, X. R. Bustelo, The rho/rac exchange factor vav2 controls nitric oxide-dependent responses in mouse vascular smooth muscle cells. J Clin Invest 120, 315-330 (2010). 
15. C. Quevedo, V. Sauzeau, M. Menacho-Marquez, A. Castro-Castro, X. R. Bustelo, Vav3deficient mice exhibit a transient delay in cerebellar development. Molecular biology of the cell 21, 1125-1139 (2011).

16. C. W. Cowan, Y. R. Shao, M. Sahin, S. M. Shamah, M. Z. Lin, P. L. Greer, S. Gao, E. C. Griffith, J. S. Brugge, M. E. Greenberg, Vav family gefs link activated ephs to endocytosis and axon guidance. Neuron 46, 205-217 (2005).

17. C. F. Hale, K. C. Dietz, J. A. Varela, C. B. Wood, B. C. Zirlin, L. S. Leverich, R. W. Greene, C. W. Cowan, Essential role for vav guanine nucleotide exchange factors in brain-derived neurotrophic factor-induced dendritic spine growth and synapse plasticity. J Neurosci 31, 12426-12436 (2011).

18. K. R. Norman, R. T. Fazzio, J. E. Mellem, M. V. Espelt, K. Strange, M. C. Beckerle, A. V. Maricq, The rho/rac-family guanine nucleotide exchange factor vav-1 regulates rhythmic behaviors in c. Elegans. Cell 123, 119-132 (2005).

19. C. Citterio, M. Menacho-Marquez, R. Garcia-Escudero, R. M. Larive, O. Barreiro, F. Sanchez-Madrid, J. M. Paramio, X. R. Bustelo, The rho exchange factors vav2 and vav3 control a lung metastasis-specific transcriptional program in breast cancer cells. Science signaling 5, ra71 (2012).

20. K. H. Chang, A. Sanchez-Aguilera, S. Shen, A. Sengupta, M. N. Madhu, A. M. Ficker, S. K. Dunn, A. M. Kuenzi, J. L. Arnett, R. A. Santho, X. Agirre, J. P. Perentesis, M. W. Deininger, Y. Zheng, X. R. Bustelo, D. A. Williams, J. A. Cancelas, Vav3 collaborates with p190-bcrabl in lymphoid progenitor leukemogenesis, proliferation and survival. Blood 120, 800-811 (2012). 
21. S. Katzav, D. Martin-Zanca, M. Barbacid, Vav, a novel human oncogene derived from a locus ubiquitously expressed in hematopoietic cells. The EMBO journal 8, 2283-2290 (1989).

22. M. E. Fernandez-Zapico, N. C. Gonzalez-Paz, E. Weiss, D. N. Savoy, J. R. Molina, R. Fonseca, T. C. Smyrk, S. T. Chari, R. Urrutia, D. D. Billadeau, Ectopic expression of vav1 reveals an unexpected role in pancreatic cancer tumorigenesis. Cancer Cell 7, 39-49 (2005).

23. M. Menacho-Marquez, R. Garcia-Escudero, V. Ojeda, A. Abad, P. Delgado, C. Costa, S. Ruiz, B. Alarcon, J. M. Paramio, X. R. Bustelo, The rho exchange factors vav2 and vav3 favor skin tumor initiation and promotion by engaging extracellular signaling loops. PLoS Biol 11, e1001615 (2013).

24. H. Martin, R. S. Mali, P. Ma, A. Chatterjee, B. Ramdas, E. Sims, V. Munugalavadla, J. Ghosh, R. R. Mattingly, V. Visconte, R. V. Tiu, C. P. Vlaar, S. Dharmawardhane, R. Kapur, Pak and rac gtpases promote oncogenic kit-induced neoplasms. J Clin Invest 123, 4449-4463 (2013).

25. M. Menacho-Marquez, R. Nogueiras, S. Fabbiano, V. Sauzeau, O. Al-Massadi, C. Dieguez, X. R. Bustelo, Chronic sympathoexcitation through loss of vav3, a rac1 activator, results in divergent effects on metabolic syndrome and obesity depending on diet. Cell Metab 18, 199211 (2013).

26. M. Jagodic, C. Colacios, R. Nohra, A. S. Dejean, A. D. Beyeen, M. Khademi, A. Casemayou, L. Lamouroux, C. Duthoit, O. Papapietro, L. Sjoholm, I. Bernard, D. Lagrange, I. Dahlman, F. Lundmark, A. B. Oturai, H. B. Soendergaard, A. Kemppinen, J. Saarela, P. J. Tienari, H. F. Harbo, A. Spurkland, S. V. Ramagopalan, D. A. Sadovnick, G. C. Ebers, M. Seddighzadeh, L. Klareskog, L. Alfredsson, L. Padyukov, J. Hillert, M. Clanet, G. Edan, B. 
Fontaine, G. J. Fournie, I. Kockum, A. Saoudi, T. Olsson, A role for vav1 in experimental autoimmune encephalomyelitis and multiple sclerosis. Sci Transl Med 1, 10ra21 (2009).

27. M. Lopez-Lago, H. Lee, C. Cruz, N. Movilla, X. R. Bustelo, Tyrosine phosphorylation mediates both activation and downmodulation of the biological activity of vav. Molecular and cellular biology 20, 1678-1691 (2000).

28. J. L. Zugaza, M. A. Lopez-Lago, M. J. Caloca, M. Dosil, N. Movilla, X. R. Bustelo, Structural determinants for the biological activity of vav proteins. The Journal of biological chemistry $277,45377-45392$ (2002).

29. J. Rapley, V. L. Tybulewicz, K. Rittinger, Crucial structural role for the ph and c1 domains of the vav1 exchange factor. EMBO Rep 9, 655-661 (2008).

30. J. E. Chrencik, A. Brooun, H. Zhang, Mathews, II, G. L. Hura, S. A. Foster, J. J. Perry, M. Streiff, P. Ramage, H. Widmer, G. M. Bokoch, J. A. Tainer, G. Weckbecker, P. Kuhn, Structural basis of guanine nucleotide exchange mediated by the t-cell essential vav1. Journal of molecular biology 380, 828-843 (2008).

31. B. Yu, I. R. Martins, P. Li, G. K. Amarasinghe, J. Umetani, M. E. Fernandez-Zapico, D. D. Billadeau, M. Machius, D. R. Tomchick, M. K. Rosen, Structural and energetic mechanisms of cooperative autoinhibition and activation of vav1. Cell 140, 246-256 (2010).

32. J. Wu, S. Katzav, A. Weiss, A functional t-cell receptor signaling pathway is required for p95vav activity. Molecular and cellular biology 15, 4337-4346 (1995).

33. F. Macian, Nfat proteins: Key regulators of t-cell development and function. Nat Rev Immunol 5, 472-484 (2005). 
34. O. Ksionda, A. Saveliev, R. Kochl, J. Rapley, M. Faroudi, J. E. Smith-Garvin, C. Wulfing, K. Rittinger, T. Carter, V. L. Tybulewicz, Mechanism and function of vav1 localisation in tcr signalling. Journal of cell science 125, 5302-5314 (2012).

35. Z. Zhou, J. Yin, Z. Dou, J. Tang, C. Zhang, Y. Cao, The calponin homology domain of vav1 associates with calmodulin and is prerequisite to $t$ cell antigen receptor-induced calcium release in jurkat $t$ lymphocytes. The Journal of biological chemistry 282, 23737-23744 (2007).

36. M. Groysman, M. Nagano, B. Shaanan, S. Katzav, Mutagenic analysis of vav reveals that an intact sh3 domain is required for transformation. Oncogene 17, 1597-1606 (1998).

37. J. R. Couceiro, M. D. Martin-Bermudo, X. R. Bustelo, Phylogenetic conservation of the regulatory and functional properties of the vav oncoprotein family. Experimental cell research 308, 364-380 (2005).

38. G. M. Doody, D. D. Billadeau, E. Clayton, A. Hutchings, R. Berland, S. McAdam, P. J. Leibson, M. Turner, Vav-2 controls nfat-dependent transcription in b- but not t-lymphocytes. The EMBO journal 19, 6173-6184 (2000).

39. R. Garcia-Mata, K. Wennerberg, W. T. Arthur, N. K. Noren, S. M. Ellerbroek, K. Burridge, Analysis of activated gaps and gefs in cell lysates. Methods Enzymol 406, 425-437 (2006).

40. S. Maignan, J. P. Guilloteau, N. Fromage, B. Arnoux, J. Becquart, A. Ducruix, Crystal structure of the mammalian grb2 adaptor. Science (New York, N.Y 268, 291-293 (1995).

41. S. Yuzawa, M. Yokochi, H. Hatanaka, K. Ogura, M. Kataoka, K. Miura, V. Mandiyan, J. Schlessinger, F. Inagaki, Solution structure of grb2 reveals extensive flexibility necessary for target recognition. Journal of molecular biology 306, 527-537 (2001). 
42. J. A. Wells, Systematic mutational analyses of protein-protein interfaces. Methods Enzymol 202, 390-411 (1991).

43. X. R. Bustelo, K. L. Suen, W. M. Michael, G. Dreyfuss, M. Barbacid, Association of the vav proto-oncogene product with poly(rc)-specific rna-binding proteins. Molecular and cellular biology 15, 1324-1332 (1995).

44. O. Hobert, B. Jallal, J. Schlessinger, A. Ullrich, Novel signaling pathway suggested by sh3 domain-mediated p95vav/heterogeneous ribonucleoprotein $\mathrm{k}$ interaction. The Journal of biological chemistry 269, 20225-20228 (1994).

45. X. R. Bustelo, Regulation of vav proteins by intramolecular events. Front Biosci 7, d24-30 (2002).

46. B. Aghazadeh, W. E. Lowry, X. Y. Huang, M. K. Rosen, Structural basis for relief of autoinhibition of the dbl homology domain of proto-oncogene vav by tyrosine phosphorylation. Cell 102, 625-633 (2000).

47. C. Kintscher, S. Wuertenberger, R. Eylenstein, T. Uhlendorf, Y. Groemping, Autoinhibition of gef activity in intersectin 1 is mediated by the short sh3-dh domain linker. Protein Sci 19, 2164-2174 (2010).

48. K. F. Ahmad, W. A. Lim, The minimal autoinhibited unit of the guanine nucleotide exchange factor intersectin. PloS one 5, e11291 (2010).

49. M. R. Schiller, K. Chakrabarti, G. F. King, N. I. Schiller, B. A. Eipper, M. W. Maciejewski, Regulation of rhogef activity by intramolecular and intermolecular sh3 domain interactions. The Journal of biological chemistry 281, 18774-18786 (2006). 
50. N. Mitin, L. Betts, M. E. Yohe, C. J. Der, J. Sondek, K. L. Rossman, Release of autoinhibition of asef by apc leads to cdc42 activation and tumor suppression. Nat Struct Mol Biol 14, 814-823 (2007).

51. K. Murayama, M. Shirouzu, Y. Kawasaki, M. Kato-Murayama, K. Hanawa-Suetsugu, A. Sakamoto, Y. Katsura, A. Suenaga, M. Toyama, T. Terada, M. Taiji, T. Akiyama, S. Yokoyama, Crystal structure of the rac activator, asef, reveals its autoinhibitory mechanism. The Journal of biological chemistry 282, 4238-4242 (2007).

52. M. E. Yohe, K. Rossman, J. Sondek, Role of the c-terminal sh3 domain and n-terminal tyrosine phosphorylation in regulation of tim and related dbl-family proteins. Biochemistry 47, 6827-6839 (2008).

53. O. T. Fackler, W. Luo, M. Geyer, A. S. Alberts, B. M. Peterlin, Activation of vav by nef induces cytoskeletal rearrangements and downstream effector functions. Molecular cell 3, 729-739 (1999).

54. L. Rodrigues, M. Pires de Miranda, M. J. Caloca, X. R. Bustelo, J. P. Simas, Activation of vav by the gammaherpesvirus $\mathrm{m} 2$ protein contributes to the establishment of viral latency in b lymphocytes. J Virol 80, 6123-6135 (2006).

55. A. Castro-Castro, V. Ojeda, M. Barreira, V. Sauzeau, I. Navarro-Lerida, O. Muriel, J. R. Couceiro, F. X. Pimentel-Muinos, M. A. Del Pozo, X. R. Bustelo, Coronin 1a promotes a cytoskeletal-based feedback loop that facilitates rac1 translocation and activation. The EMBO journal 30, 3913-3927 (2011).

56. M. J. Caloca, J. L. Zugaza, X. R. Bustelo, Mechanistic analysis of the amplification and diversification events induced by vav proteins in b-lymphocytes. The Journal of biological chemistry 283, 36454-36464 (2008). 
57. J. Coppola, S. Bryant, T. Koda, D. Conway, M. Barbacid, Mechanism of activation of the vav protooncogene. Cell Growth Differ 2, 95-105 (1991).

58. S. Ruiz, E. Santos, X. R. Bustelo, Rasgrf2, a guanosine nucleotide exchange factor for ras gtpases, participates in t-cell signaling responses. Molecular and cellular biology 27, 81278142 (2007).

59. N. Movilla, M. Dosil, Y. Zheng, X. R. Bustelo, How vav proteins discriminate the gtpases rac1 and rhoa from cdc42. Oncogene 20, 8057-8065 (2001).

60. A. J. van der Eb, F. L. Graham, Assay of transforming activity of tumor virus DNA. Methods Enzymol 65, 826-839 (1980).

61. H. Luthman, G. Magnusson, High efficiency polyoma DNA transfection of chloroquine treated cells. Nucleic Acids Res 11, 1295-1308 (1983).

62. J. A. Mindell, N. Grigorieff, Accurate determination of local defocus and specimen tilt in electron microscopy. J Struct Biol 142, 334-347 (2003).

63. J. B. Heymann, D. M. Belnap, Bsoft: Image processing and molecular modeling for electron microscopy. J Struct Biol 157, 3-18 (2007).

64. S. J. Ludtke, P. R. Baldwin, W. Chiu, Eman: Semiautomated software for high-resolution single-particle reconstructions. J Struct Biol 128, 82-97 (1999).

65. L. A. Kelley, M. J. Sternberg, Protein structure prediction on the web: A case study using the phyre server. Nat Protoc 4, 363-371 (2009).

Acknowledgments: We thank M. Dosil for comments on the manuscript, M. Blázquez and personnel of the CIC Microscopy and Genomics and Proteomics units for technical assistance, Hugo Yébenes for technical assistance with Biacore, and J.M. de Pereda for advice on protein purification by size exclusion chromatography. Funding: Work in the laboratory of X.R.B. has been funded by grants from the Spanish Ministry of Economy and Competitiveness (SAF200907172, SAF2012-3171, RD06/0020/0001, and RD12/0036/0002), the Castilla-León Autonomous Government (CSI039A12-1), and the Asociación Española Contra el Cáncer (AECC). O.L. has 
been supported by grants from the Spanish Ministry of Economy and Competitiveness (SAF2011-22988 and RD06/0020/1001). The salary of M.B. has been partially supported by a JAE-Predoc contract (CSIC), the AECC, and grant RD06/0020/0001. S.F. is supported by a graduate student FPI contract from the Spanish Ministry of Economy and Competitiveness (BES-2010-031386). Spanish funding is co-sponsored by the European Regional Development Fund. Author contributions: M.B. participated in all experiments, analyzed data, and contributed to writing the manuscript; S.F. purified $6 \times$ His-tagged proteins from Sf9 cells, optimized conditions for their purification and performed exchange assays. He also purified MBPs for Biacore analyses and, together with E.T., participated in Biacore experiments; J.R.C. identified Vav1 phosphosites and characterized the phospho-specific antibodies to Vav1; E.T. and O.L. performed the EM structural work and analyzed data obtained in those experiments. J.L.M.-T. and G.M. produced the baculoviruses and performed the large-scale expression of proteins in $S f 9$ cells. M.B., S.F., E.T., O.L., and X.R.B. prepared figures; and X.R.B. directed the work, analyzed the data, and wrote the manuscript. Competing interests: The authors declare that they have no competing interests.

Fig. 1. Characterization of the inhibitory action of the CSH3 domain of Vav1. (A) Outlines of the wild-type (WT) and mutant Vav1 proteins used in this work. (B) The Vav1 signaling pathway in T cells. The direct Rac1-dependent pathway stimulated by Vav1 is shown in red. Responses requiring additional signaling elements are in black. cNFAT, cytosolic NFAT; nNFAT, nuclear NFAT. ( $\mathbf{C}$ to $\mathbf{F}$ ) Analysis of the extent of JNK activation by the indicated Vav1 proteins expressed in (C and E) WT and (C) TCR-deficient Jurkat cells that were either left unstimulated or were stimulated with anti-CD3 antibody ( $\alpha-C D 3)$. (D and F) The abundances of the ectopically expressed proteins and tubulin $\alpha$ (as a loading control) were determined by Western blotting (WB) analysis. Representative experiments are shown. (G) Confocal microscopy was used to analyze the cytoskeletal changes induced by the indicated Vav1 proteins in unstimulated Jurkat cells. Scale bar: $5 \mu \mathrm{m}$. Images are representative of four experiments. (H) Analysis of the activation of NFAT by the indicated Vav1 proteins in unstimulated (-) and stimulated (+) Jurkat cells (left) and DT40 cells (right). (I) The abundances of the ectopic proteins and of the loading control in a representative experiment from $(\mathrm{H})$ were determined by Western blotting analysis. In $(\mathrm{C}),(\mathrm{E})$, and $(\mathrm{H}), P$ values are given relative to unstimulated cells 
(red asterisks) and stimulated cells (blue asterisks) cells expressing Vav1 ${ }^{\mathrm{WT}}$ or, alternatively, for the indicated experimental pairs (brackets). $* P \leq 0.05, * * P \leq 0.01$, and $* * * P \leq 0.001$. Data are means \pm SEM from six experiments for Jurkat cells and three experiments for DT40 cells. Each experiment was performed with triplicate samples. NS, not significant.

\section{Fig. 2. CSH3-mediated inhibition is a common regulatory feature of Vav family members.}

(A and B) Analysis of the activation of JNK in COS1 cells transfected with plasmids expressing EGFP alone or EGFP fusions of the indicated Vav1 proteins. $P$ values are given relative to either $\operatorname{Vav} 1^{\mathrm{WT}}$ or the indicated experimental pairs (in brackets). Data are means \pm SEM from three independent experiments, each performed with triplicate samples. $* * * P \leq 0.001$. (B) The relative abundances of the expressed proteins and loading controls were determined by Western blotting analysis and are shown from one representative experiment. DmVav, Drosophila melanogaster Vav. (C) Example of oncogenic activity exhibited by the indicated Vav1 proteins in NIH3T3 focus formation assays. Similar results were obtained in two additional experiments, each of which was performed in triplicate. (D) Analysis of JNK activity in Jurkat cells transfected with plasmid encoding EGFP alone or the indicated EGFP-tagged Vav proteins and then left unstimulated or stimulated with anti-CD3 antibody. (E) Western blotting analysis of the cells used in (D) was performed with antibodies against the indicated proteins. One representative experiment is shown. $P$ values in (D) are given as for Fig. 1C. Data are means \pm SEM from three independent experiments, each performed in triplicate.

Fig. 3. The CSH3 domain inhibits the enzymatic activity of Vav. (A) Gel showing the aliquots of $6 \times$ His-Vav proteins used in this study. MWM, molecular weight marker. (B to D) 
Analysis of the GDP-GTP exchange activity of the indicated amounts of Vav1 and Dbs proteins on the (B) Rac1, (C) RhoA, and (D) Cdc42 GTPases over time. Data are from three independent experiments. a.u., arbitrary units. (E) Western blotting analysis of the phosphorylation of $6 \times$ His$\operatorname{Vav} 1^{\mathrm{WT}}$ in the presence or absence of GST-Lck. (F) Aliquots of in vitro kinase reactions containing 6xHis-Vav1 ${ }^{\mathrm{WT}}$ alone, GST-Lck alone or $6 \mathrm{xHis-Vav1}{ }^{\mathrm{WT}}$ plus GST-Lck were tested in Rac1 GDP/GTP exchange assays. The final concentration of each protein in the exchange reaction is indicated on the right. Data are from two independent experiments. Note that only aliquots from kinase reactions containing Vav1 and Lck proteins showed activity in this assay. (G to I) Exchange activity of the indicated concentrations of the indicated Vav3 and Dbs proteins on (G) Rac1, (H) RhoA, and (I) Cdc42. Data are from three independent experiments. (J) Top: Western blotting analysis of pull-down reactions containing the indicated Vav proteins and GST-tagged GTPases. Middle: Analysis of the amounts of GST proteins. Bottom: Western blotting analysis of the amounts of input Vav proteins. (K) Analysis of endogenous Rac1 activity in COS1 cells expressing the indicated Vav proteins. $P$ values are given relative to data obtained with Vav $1^{\mathrm{WT}}$ or the indicated experimental pairs (brackets). Data are means \pm SEM from three independent experiments, each performed in triplicate. (L) Western blotting analysis of the abundances of Vav proteins and tubulin $\alpha$ (loading control) in the samples used in (K). Blots are from a single representative experiment.

Fig. 4. The CSH3 inhibits Vav1 in cis. (A) Analysis of the activity of JNK (top) and NFAT (bottom) in Jurkat cells that were left untransfected (None) or were transfected with plasmids encoding the indicated Vav1 proteins and then were left untreated or were treated with anti-CD3 antibody. $P$ values are given as described for Fig. 1C. Data are from three independent 
experiments, each performed in triplicate. (B) Western blotting analysis of ectopic protein abundance and loading controls for the experiments shown in (A). Data are from a single representative experiment. (C) Scheme showing the rationale used in our pull-down experiments. SBS, SH3-binding site. (D to $\mathbf{H})$ Analysis of the interactions between GST-tagged proteins and Vav1 proteins. (D, E, G, and H) Top: Data show pull-down assays between the indicated GSTtagged proteins and the indicated Vav1 proteins. In (D), the EGFP tag was only used in the case

of $\operatorname{Vav} 1^{\Delta^{1-186}}$. The relative amounts of bait and ectopically expressed proteins used in the pulldown assays are shown in the middle and lower panels, respectively. Data are representative of a single experiment, and similar results were obtained in three additional experiments. $(\mathrm{F})$ The EGFP-Vav1 proteins used in the pull-down assays. The shaded area indicates domains that show positive interactions with the GST-CSH3 bait protein (see $\mathrm{G}$ and $\mathrm{H}$ ). Note that the NPH fragment cannot form a functional PH domain because it lacks critical residues for proper domain folding. (I) Analysis of purified GST and MBP proteins. $\beta$-gal, $\beta$-galactosidase. (J) Surface plasmon resonance measurements were used to determine interactions between the indicated purified MBPs and GST-CSH3 ${ }^{\mathrm{WT}}$ shown in (I). Two independent injections are shown.

Fig. 5. The DH domain $\alpha 6$ helix stabilizes the CSH3-Vav1 interaction. (A) Top: The sequence of the Vav1 DH domain $\alpha 6$ helix indicating areas contained in EGFP-DH-NPH (white box) and EGFP-PH (gray box) that showed positive interactions with GST-CSH3 ${ }^{\mathrm{P} 83 \mathrm{~L}}$ (Fig. 4). Mutated residues are colored. Bottom: The 3D structure of the Vav1 DH domain $\alpha 6$ helix showing the positions of the mutated residues. (B) Top: Analysis of the interaction between GST-CSH3 $3^{\mathrm{P} 83 \mathrm{~L}}$ and the indicated untagged Vav1 proteins expressed in COS1 cells. The relative amounts of GST-CSH3 bait protein (middle) and ectopically expressed Vav1 proteins (bottom) 
were determined by Ponceau staining and Western blotting analysis, respectively. Data are representative of three independent experiments. (C) Jurkat cells were transfected with plasmids encoding the indicated proteins and then were left untreated or were treated with anti-CD3 antibody before being analyzed for JNK (top) and NFAT (bottom) activities. $P$ values are given as for Fig. 1C. Data are from three independent experiments, each performed in triplicate. (D) Protein abundances and loading controls for the samples analyzed in (C) were determined by Western blotting analysis. Data are from a single representative experiment. (E) Top: Interactions between the indicated Vav1 proteins and GST-Rac1 ${ }^{\mathrm{G} 15 \mathrm{~A}}$. The relative amounts of GST proteins (middle) and the input amounts of Vav1 proteins (bottom) used in the pull-down assays were determined. Data are representative of four independent experiments.

Fig. 6. The CSH3 domain of Vav1 uses two binding sites to interact with the DH and PH domains. (A) Primary (top) and 3D (bottom) structures of the Vav1 CSH3 domain indicating residues mutated in these experiments (in light and dark red). The PRR-binding site is in green. (B) Top: Pull-down assays showing interactions between the GST-CSH3 ${ }^{\mathrm{P} 833 \mathrm{~L}}$ fusion protein and the indicated Vav1 proteins. The amounts of bait protein (middle) and ectopically expressed proteins (bottom) proteins is shown. Data are representative of three independent experiments. (C to $\mathbf{G})$ Jurkat cells were transfected with plasmids encoding the indicated proteins and then were left untreated or were treated with antibody against CD3. Samples were then analyzed to determine the extent of (C and F) JNK activation and (E) F-actin polymerization. (D and G) The abundances of Vav1 proteins (upper panels) and loading controls (lower panels) were determined by Western blotting. Data from representative experiments are shown. $P$ values in $(\mathrm{C})$ and (E) are given as for Fig. 1C. Data are from three independent experiments. (H) Analysis of 
interactions between the indicated GST-CSH3 proteins (indicated underneath the middle panel) and Vav1 domains (top). The amounts of bait protein (middle) and ectopic proteins (bottom) are shown. Data are representative of four independent experiments. The specific interaction sites of the $\mathrm{DH}$ and $\mathrm{PH}$ domains with the $\mathrm{CSH} 3$ identified in these experiments are also depicted in panel A (bottom, structure on the right).

Fig. 7. Vav1 is regulated by multiple phosphorylation sites. (A) Jurkat cells were left unstimulated or were stimulated with anti-CD3 antibody for the indicated times before being subjected to immunoprecipitation (IP) with anti-Vav1 antibody. The kinetics of the phosphorylation of the indicated tyrosine residues in Vav1 were determined by Western blotting analysis with phospho-specific antibodies. As controls, the indicated blots (matched by the same colored asterisks) were stripped and reanalyzed with anti-Vav1 antibodies. Data are representative of eight independent experiments. (B) Analysis of the JNK activity of Jurkat cells transfected with plasmids expressing the indicated proteins and then left untreated or treated with anti-CD3 antibody. $P$ values are given as for Fig. 1C. Data are means from three independent experiments, each performed in triplicate. (C) The abundances of the expressed Vav1 proteins (top) and loading controls (bottom) of the samples used in (B) were determined by Western blotting analysis. Data from a single representative experiment are shown. (D and E) Pull-down assays were performed to determine interactions between the indicated Vav1 proteins and (D) GST-CSH3 ${ }^{\text {P833L }}$ and (E) GST-Rac1 ${ }^{\text {G15A }}$. Data in (D) and (E) are representative of two and three independent experiments, respecitvely. The amounts of bait (middle) and ectopically expressed (bottom) proteins were determined. (F) Depiction of the intramolecular mechanism involved in the phosphorylation-dependent activation of Vav family proteins. Light blue rectangle: the $\alpha$ 
helix that harbors the Ac domain $\mathrm{Tyr}^{174}$ phospho-site; dark blue and red rectangles: noncanonical interaction motifs of the CSH3 domain; light blue dots: non-phosphorylated tyrosine residues; yellow dots phosphorylated tyrosine residues (pY); red asterisks: mutations in phosphor-sites in the Ac region. The depicted movements of the CH-Ac and NSH3-SH2-CSH3 regions are hypothetical. 
Figure 1

Barreira et al.

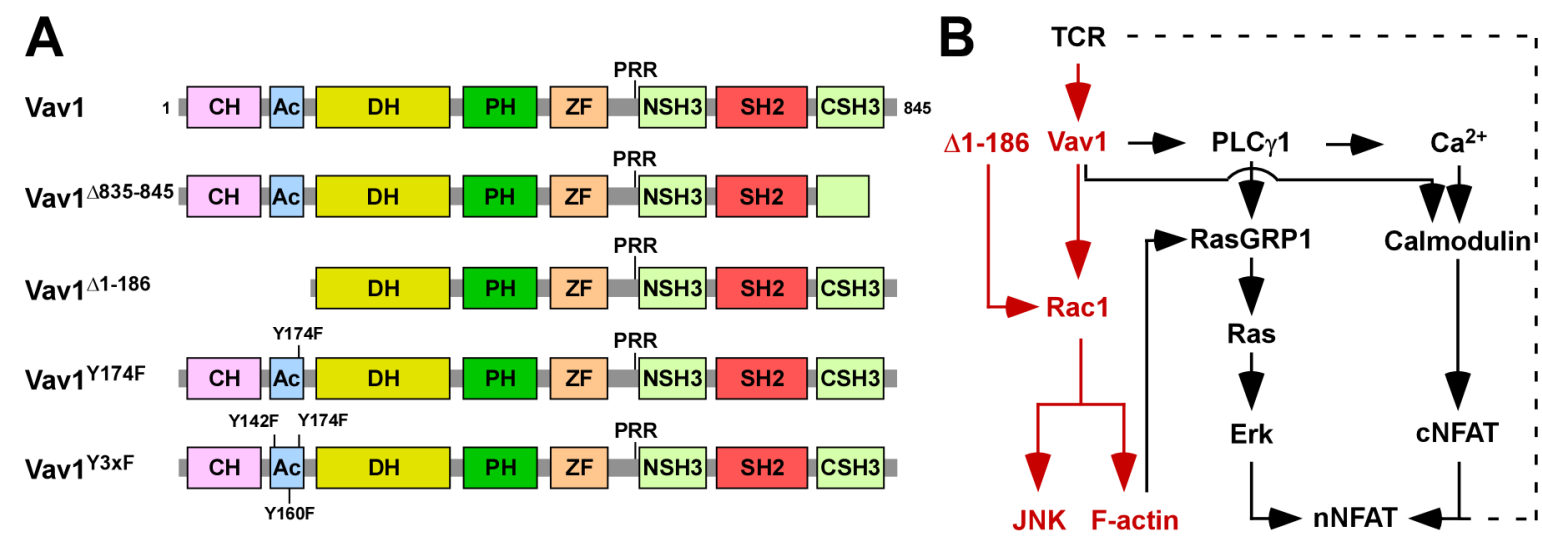

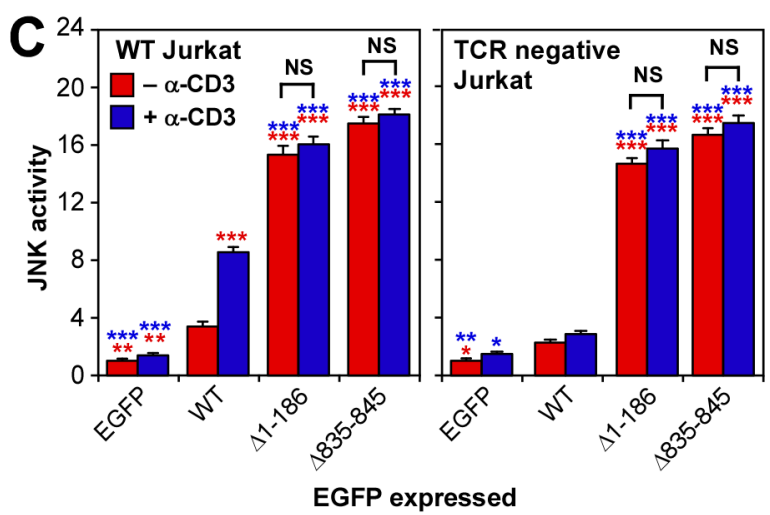

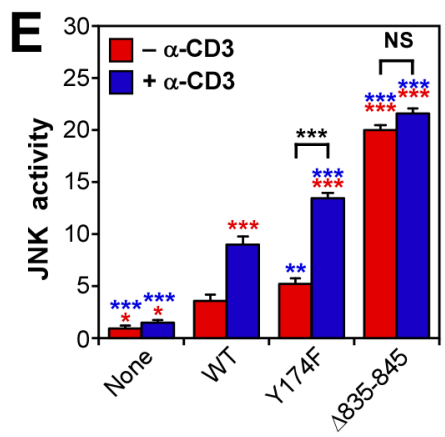

Vav1 protein expressed

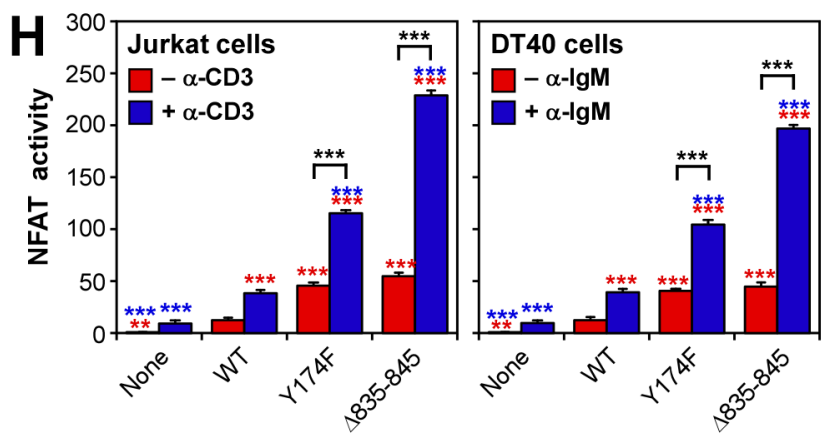

Vav1 protein expressed
D

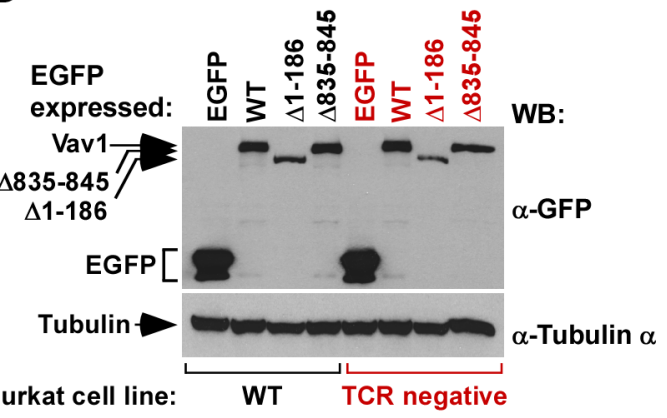

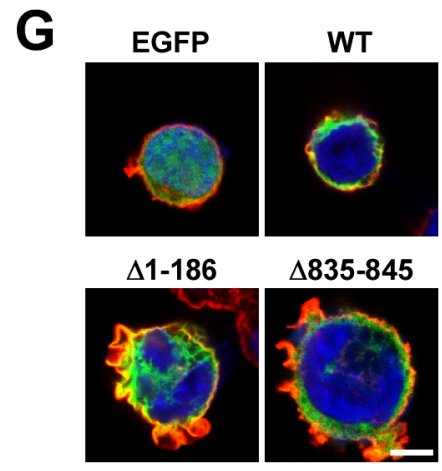

EGFP/F-actin/DAPI

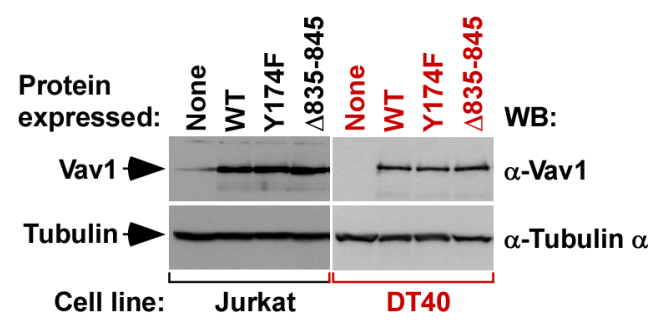


Figure 2

Barreira et al.

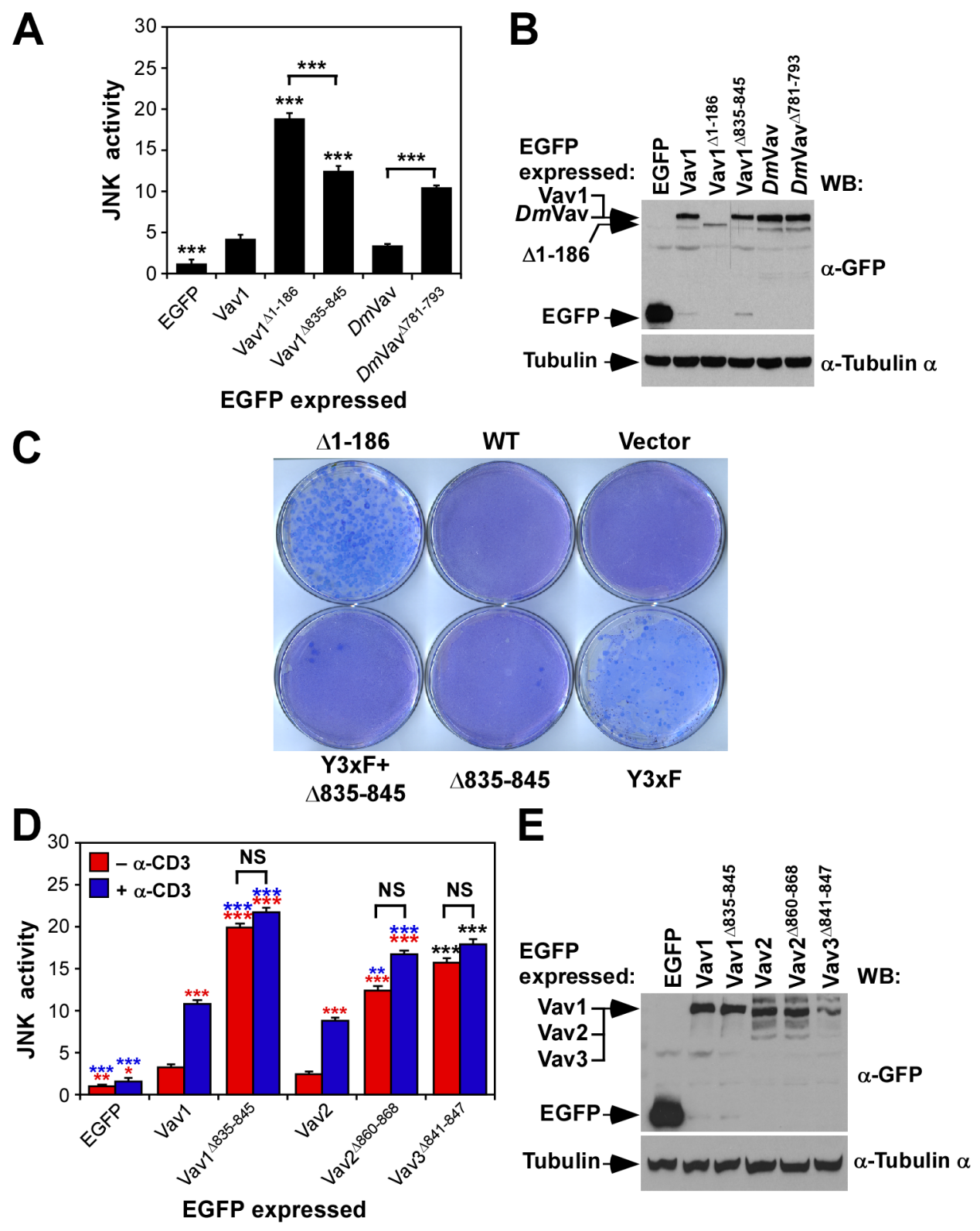


Figure 3
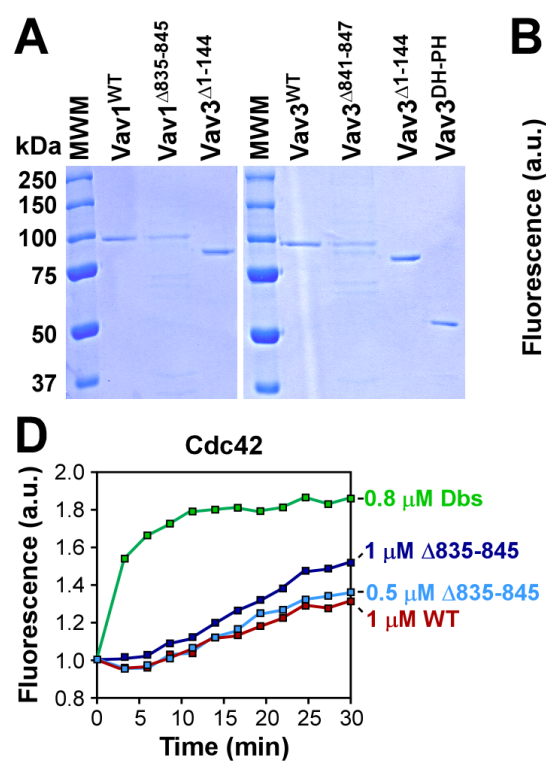

B

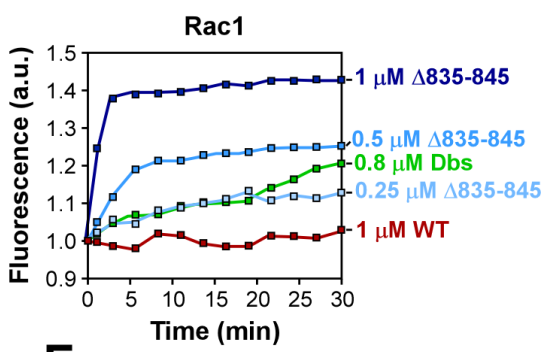

E

6xHis-Vav1WT: + + + GST-Lck: - + + WB:

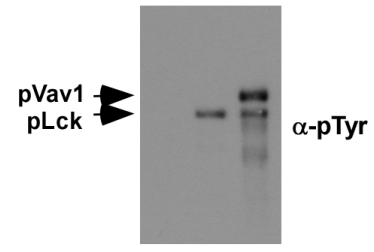

$\mathrm{H}$

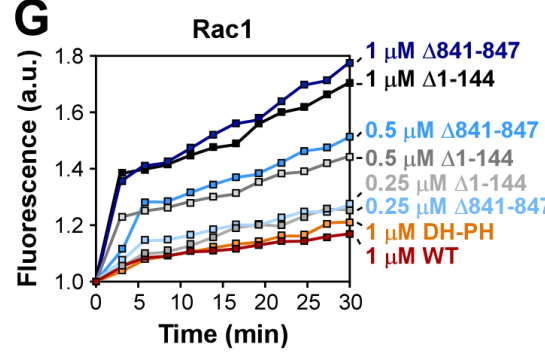

J

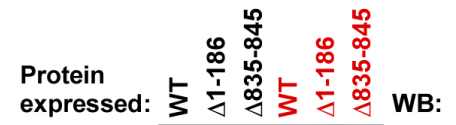
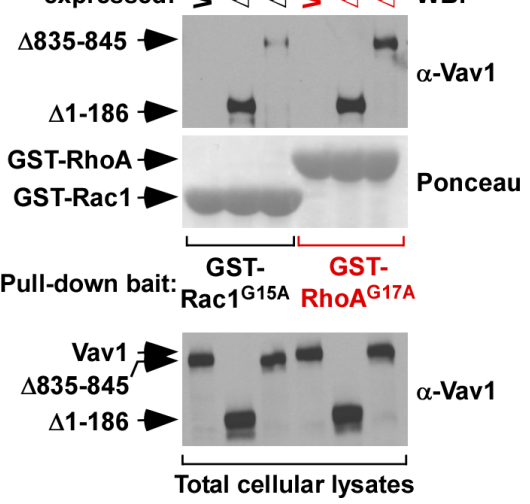

K

Vav protein expressed
C

Barreira et al.

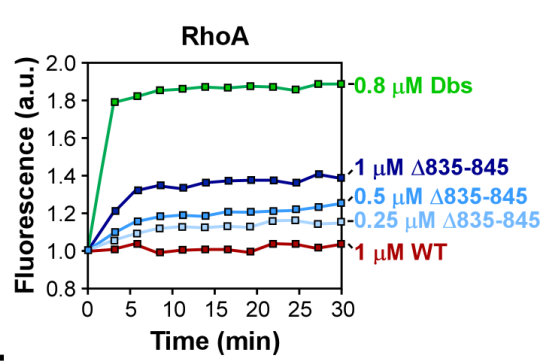

$\mathbf{F}$
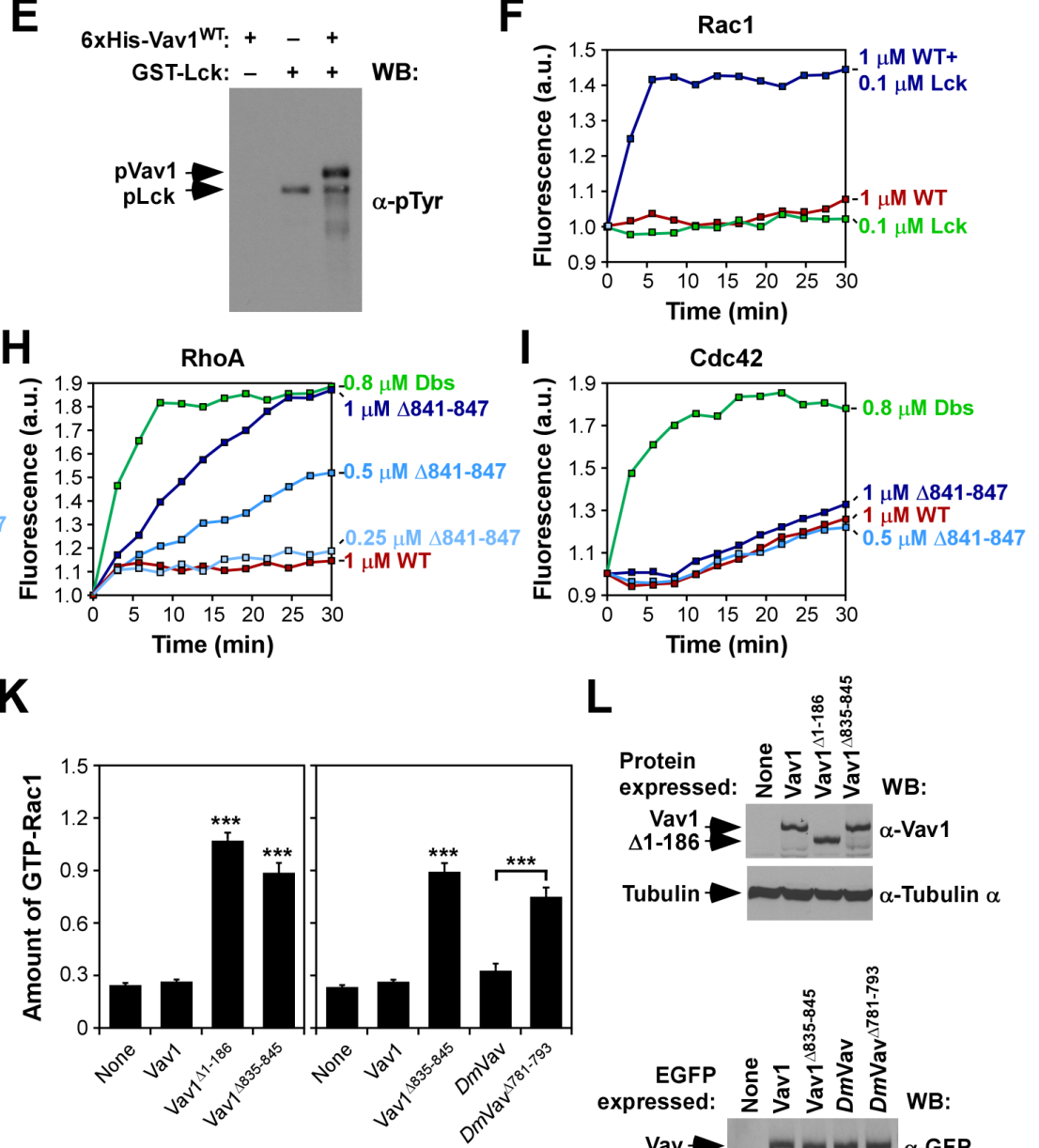

L

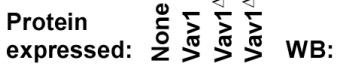

Vav1
$\Delta 1-186=-\omega_{-V a v 1}$

Tubulin $\alpha$-Tubulin $\alpha$

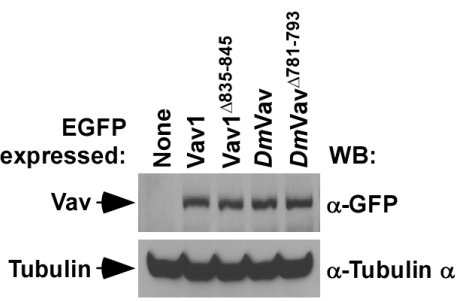


A

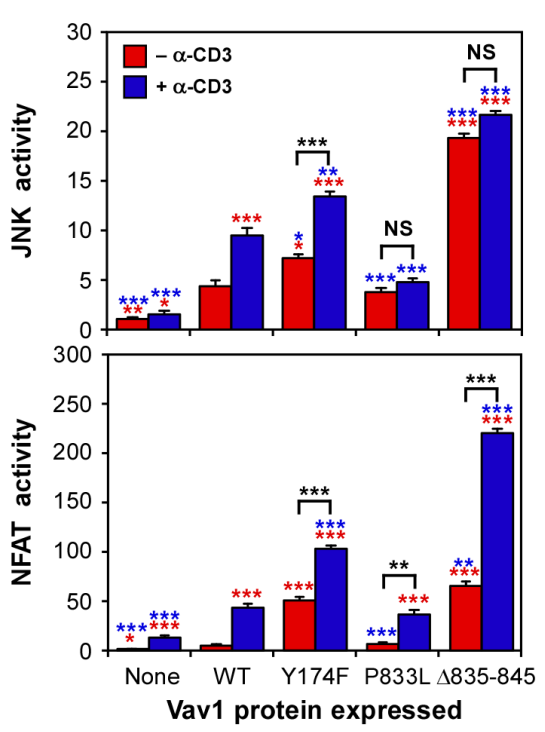

C

Barreira et al.
D

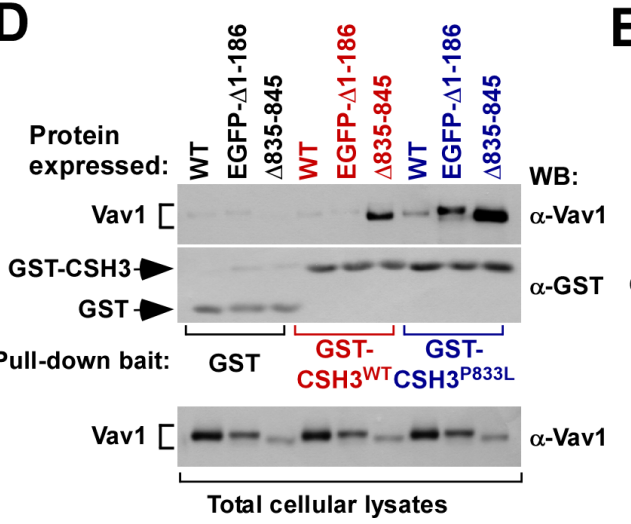

G
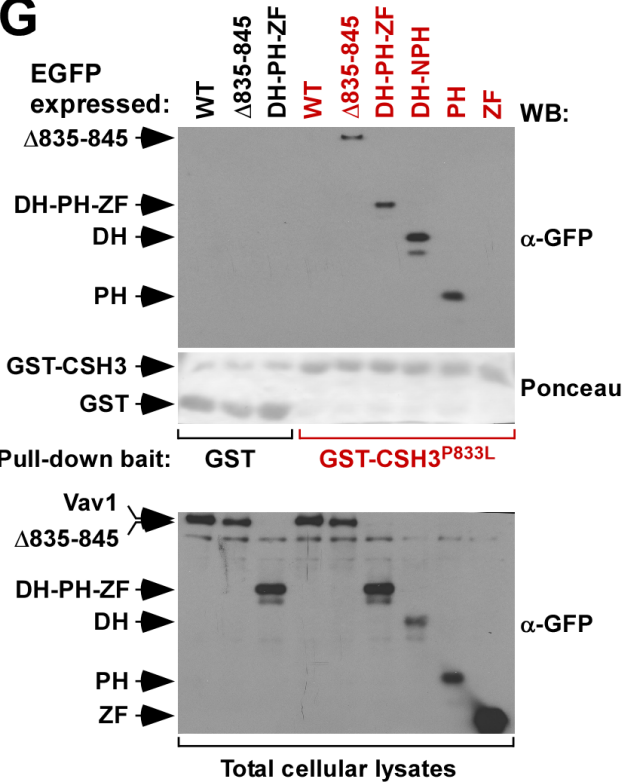

H

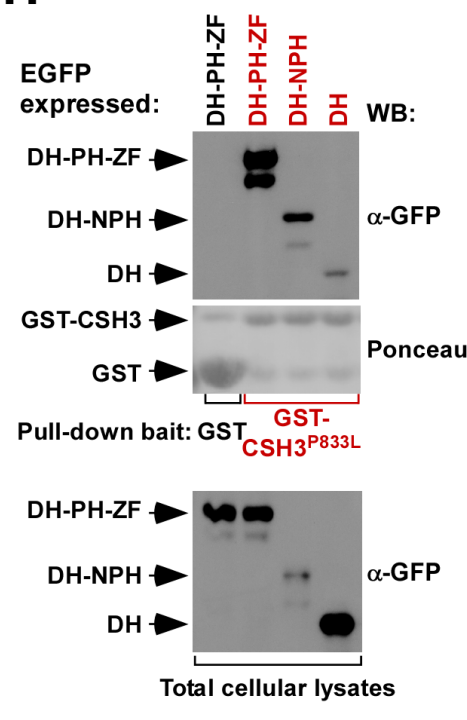

B

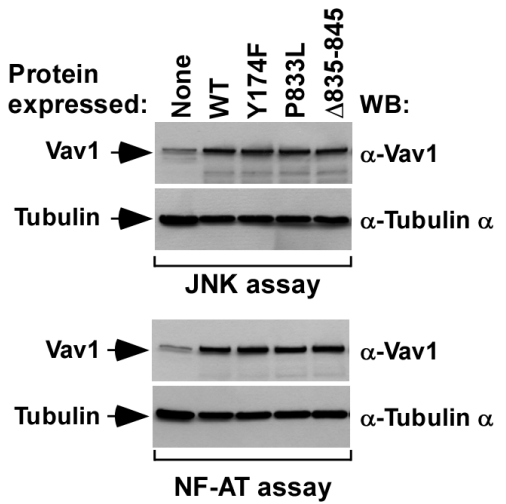

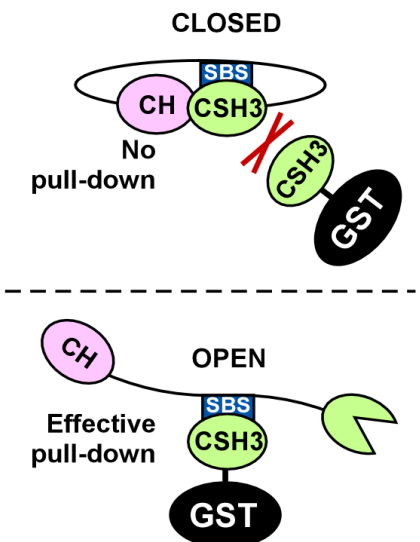

E

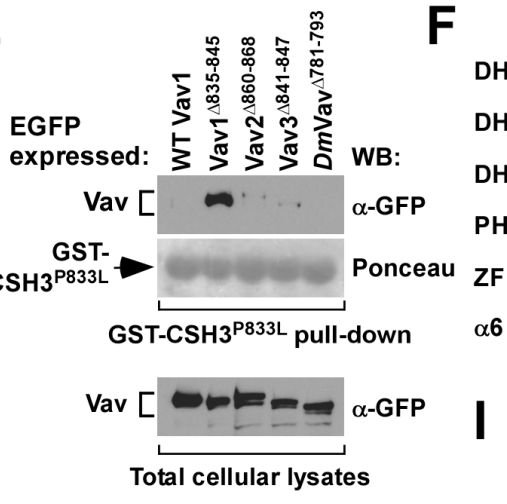

$\begin{array}{lll}508 & \text { ZF } & 571\end{array}$

${ }^{341} 1 \square^{397}$

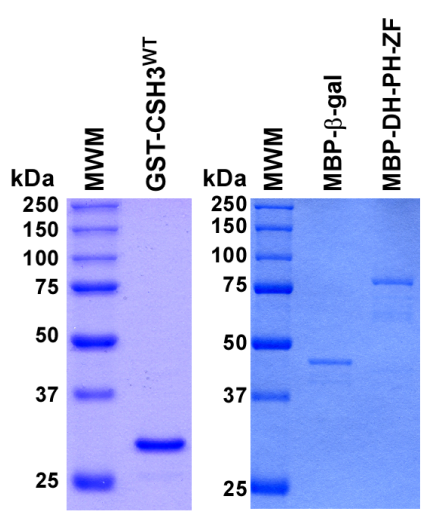

$J$

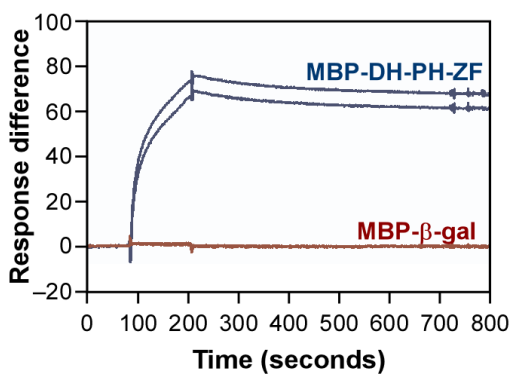


Figure 5

Barreira et al.

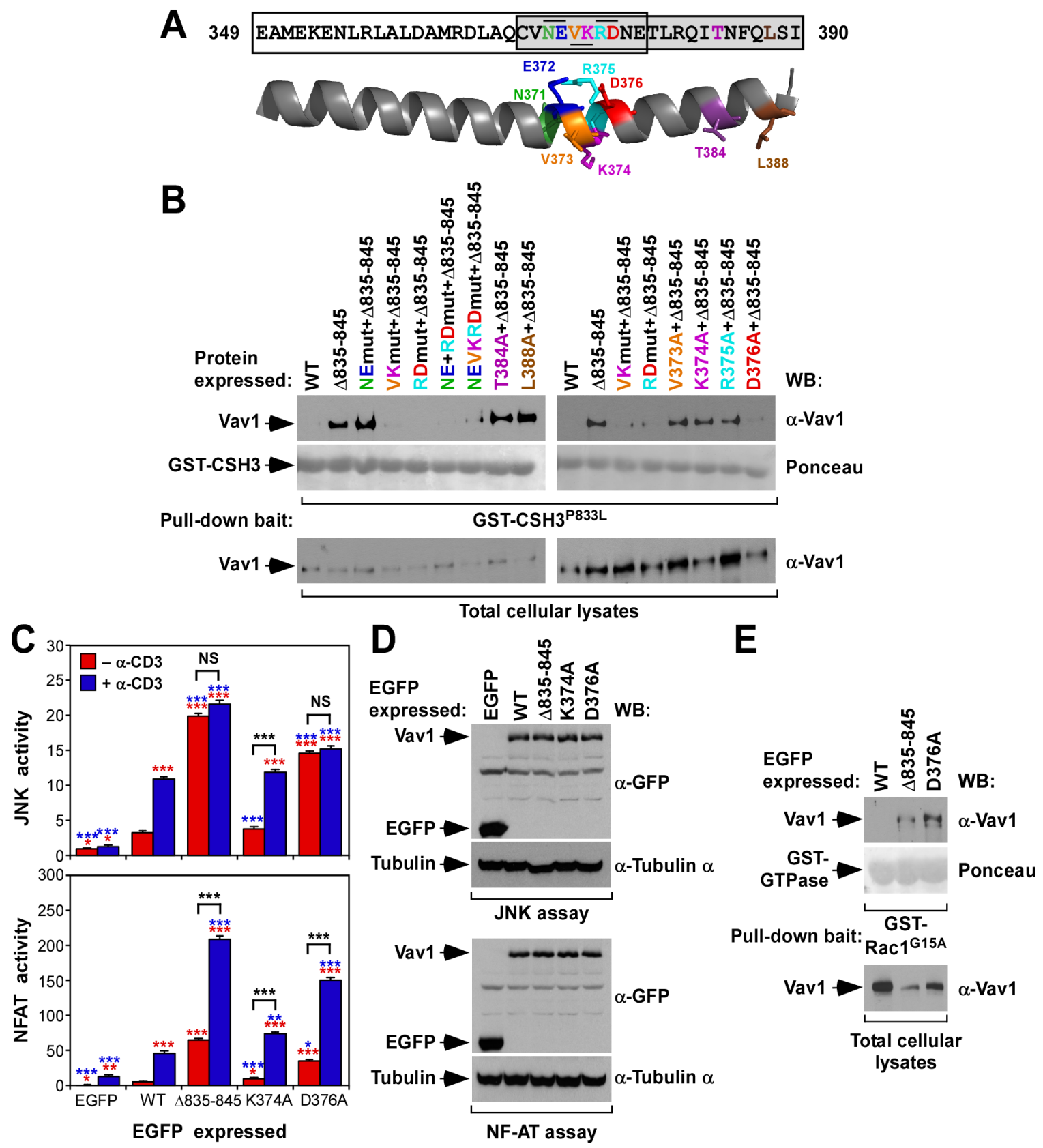


Figure 6

Barreira et al.

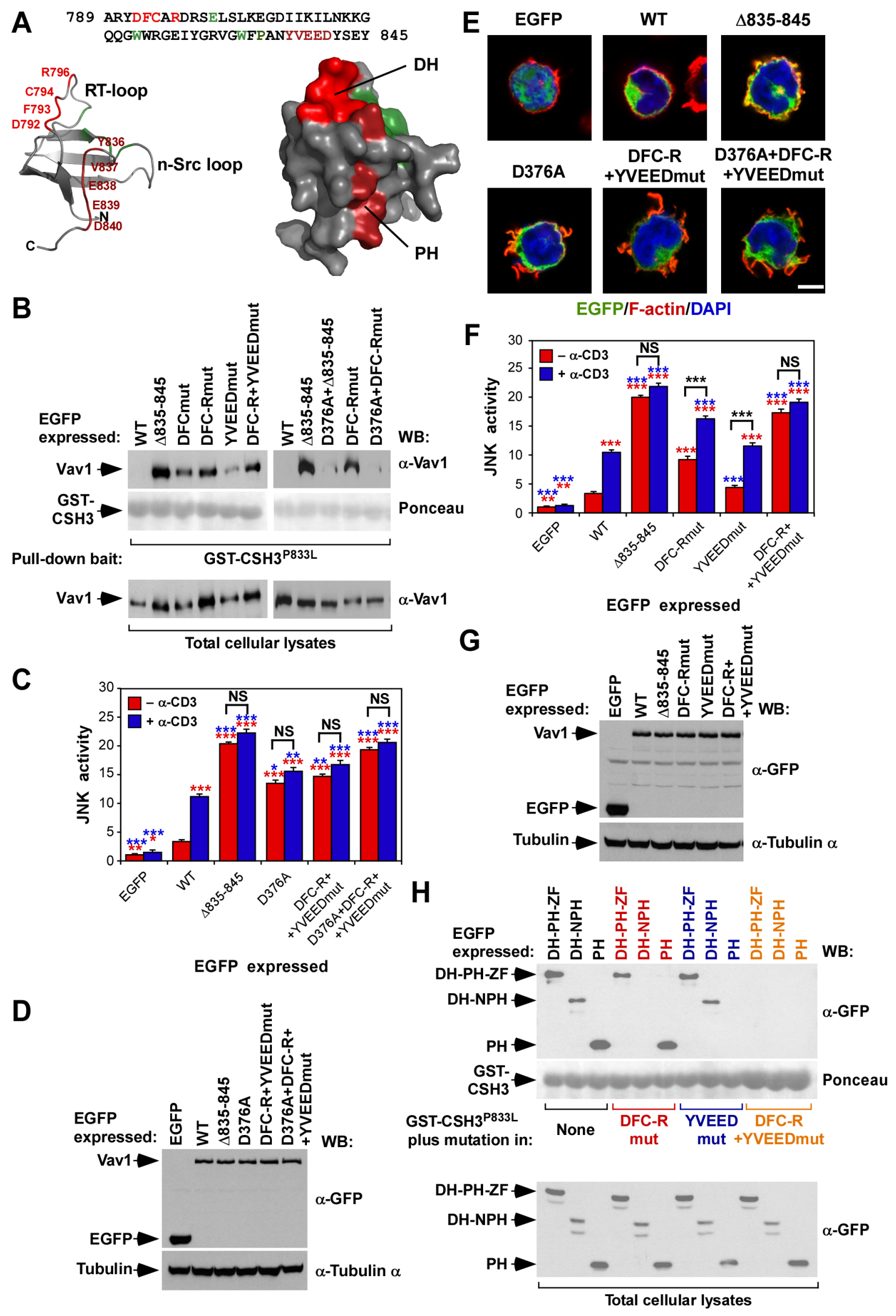


Figure 7

Barreira et al.
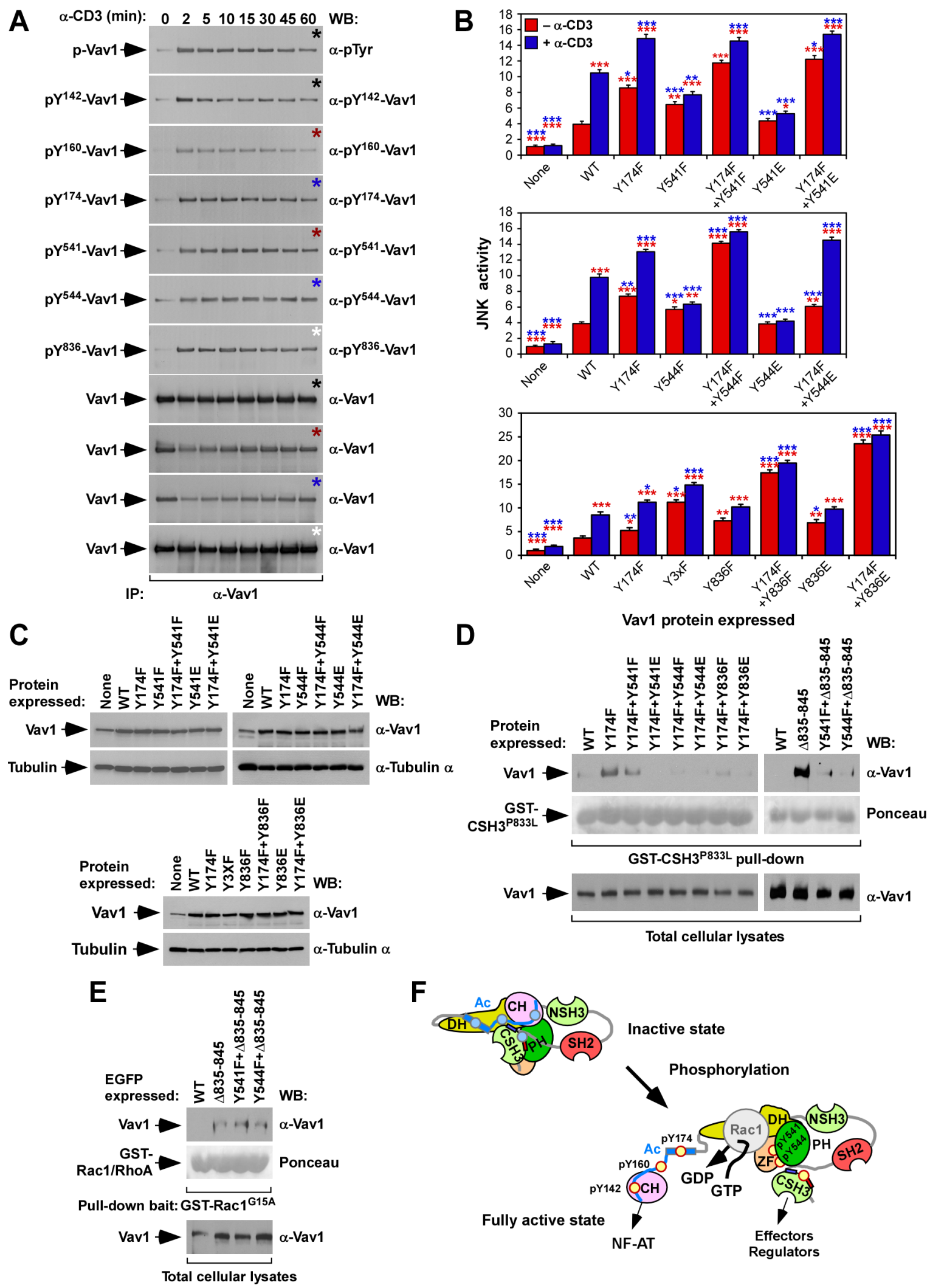


\title{
Supplementary Materials for
}

\section{The C-terminal SH3 domain contributes to the intramolecular inhibition of Vav family proteins}

\author{
María Barreira, Salvatore Fabbiano, José R. Couceiro, Eva Torreira, Jorge L. Martínez- \\ Torrecuadrada, Guillermo Montoya, Oscar Llorca, and Xosé R. Bustelo*
}

*To whom correspondence should be addressed. E-mail: xbustelo@usal.es This PDF file includes

Fig. S1. The known activation step of Vav family proteins.

Fig. S2. Truncation of the CSH3 domain promotes the activation of Vav1 in cells.

Fig. S3. The Vav1 CSH3 domain does not interact with the Vav1 PRR-NSH3 region.

Fig. S4. The CSH3 inhibits Vav1 in cis.

Fig. S5. EM structure of unphosphorylated $6 \times$ His-Vav1 $1^{1-144}$.

Fig. S6. Characterization of residues of the DH domain $\alpha 6$ helix that contribute to the stability of the inhibitory CSH3-Vav1 interaction.

Fig. S7. The CSH3 domain of Vav1 uses two different topological regions to interact with the $\mathrm{DH}$ and $\mathrm{PH}$ domains.

Fig. S8. Effect of the mutation of CSH3 DFC-R and YVEED sites in Vav1 biological activity.

Fig. S9. Characterization of phospho-specific antibodies specific for Vav1.

Fig. S10. Proposed model for the regulation of Vav family proteins.

Table S1. Detection of indicated phosphosites in Vav1 using mass spectrometry.

Table S2. List of additional plasmids.

Table S3. List of primers. 


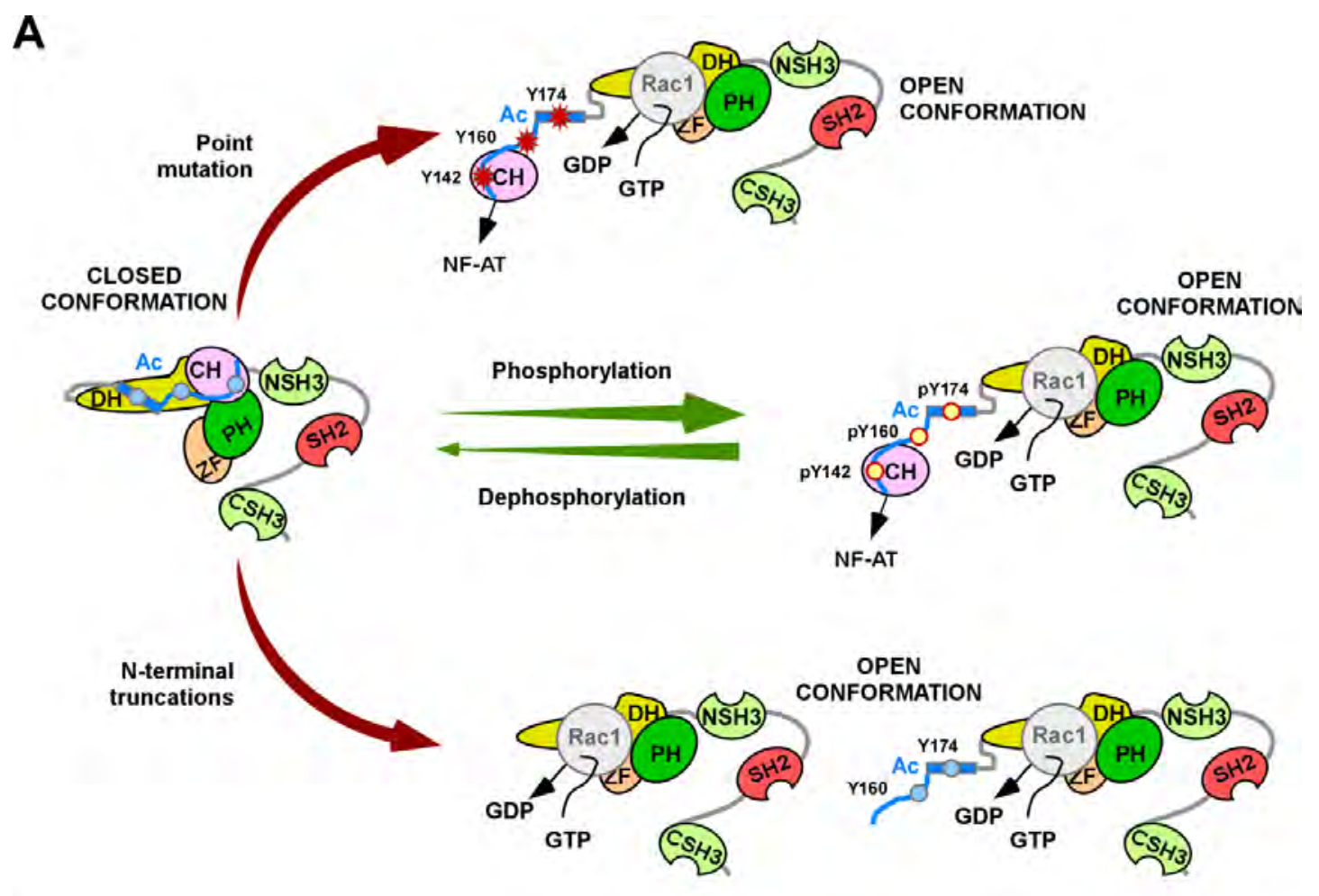

B

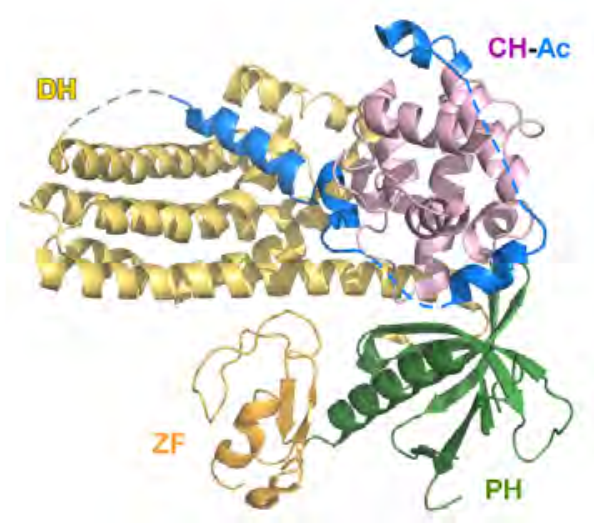

Fig. S1. The known activation steps of Vav family proteins. (A) Schematic representation of the physiological (green arrows) and oncogenic (red arrows) mechanisms of activation of Vav family proteins. The localization of the $\mathrm{CH}$-Ac region depicted in the open conformation is hypothetical, because no 3D structures are available. The specific localization of the NSH3-SH2-CSH3 cassette in both the inactive and active conformations of these proteins is also unknown for the same reason. The $\alpha$ helix that harbors the Ac domain $\mathrm{Tyr}^{174}$ phospho-site is depicted as a blue rectangle. Light blue dots represent nonphosphorylated tyrosine residues, whereas yellow dots represent phosphorylated tyrosine (pY) residues. Red asterisks indicate mutations in phospho-sites. Further details are given in the main text. (B) Crystal structure of the CH-Ac-DH-PH-ZF region of Vav1 (31). Broken lines indicate regions that could not be solved in the crystal structure. 
A

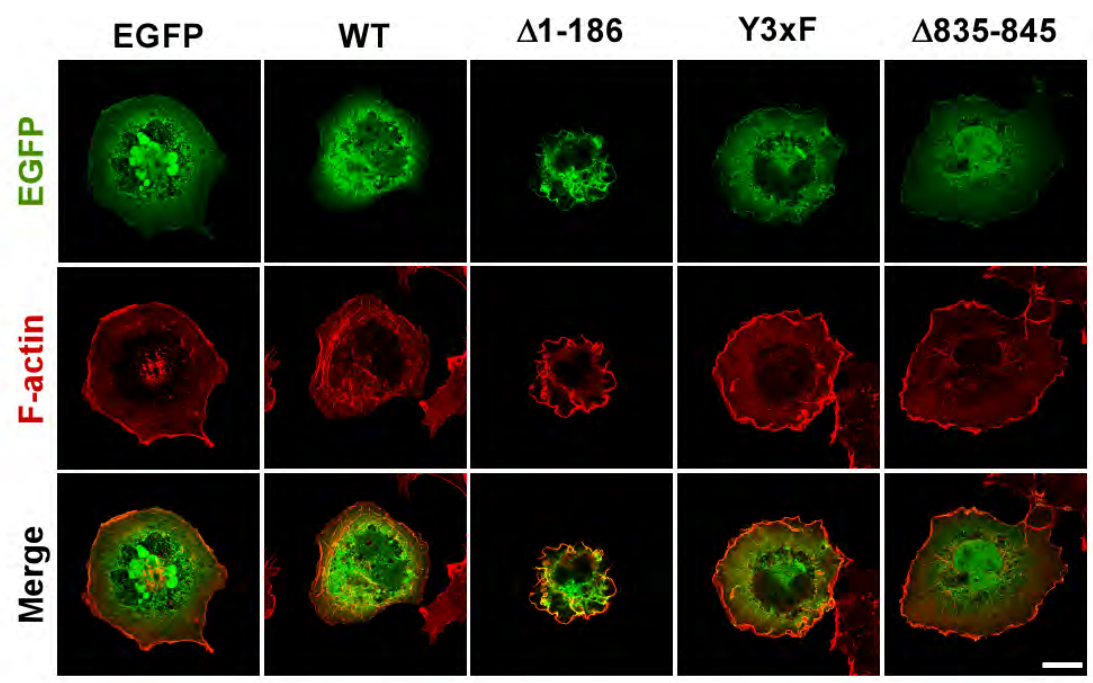

B
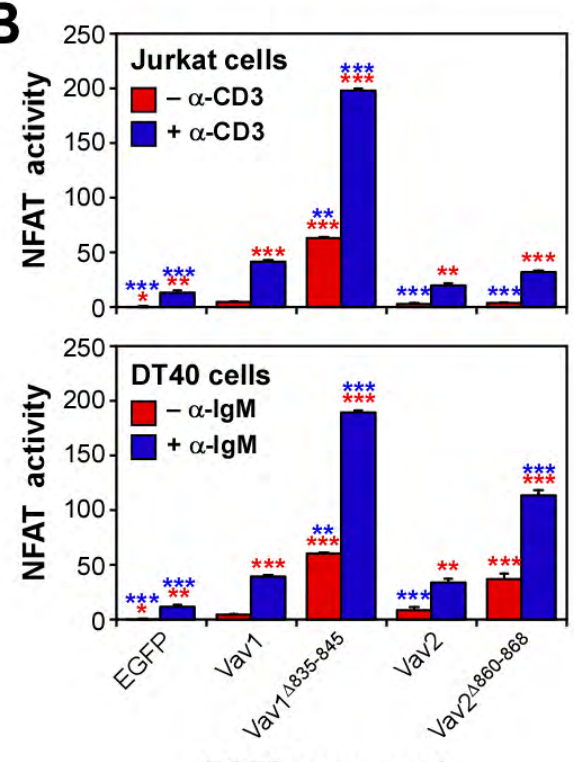

C

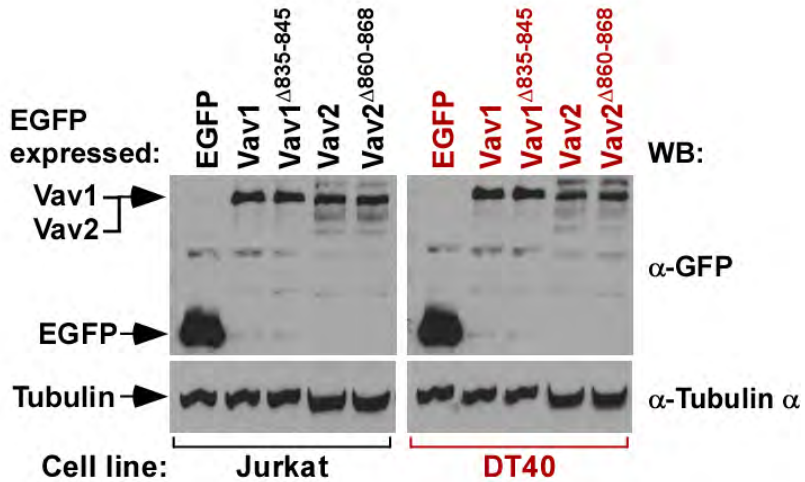

Fig. S2. Truncation of the CSH3 domain promotes the activation of Vav1 in cells. (A) COS 1 cells transfected with plasmids expressing EGFP or the indicated EGFP-tagged Vav1 proteins were fixed, treated with rhodamine-labeled phalloidin to stain the F-actin cytoskeleton, and then analyzed by confocal microscopy. Ectopic proteins were detected through the epifluorescence of the EGFP tag. Scale bar: $5 \mu \mathrm{m}$. Images are representative of four independent experiments. (B) Jurkat cells (top) and DT40 cells (bottom) were transfected with plasmids encoding the indicated proteins and then were left unstimulated or were stimulated through their respective antigen receptors before NFAT activity was determined. $P$ values are given relative to both nonstimulated (red asterisks) and stimulated (blue asterisks) cells expressing Vav1 ${ }^{\mathrm{WT}}$. Data are means \pm SEM from three independent experiments. (C) The abundance of indicated proteins from the cells used in (B) were determined by Western blotting analysis. Data from a representative experiment are shown. 


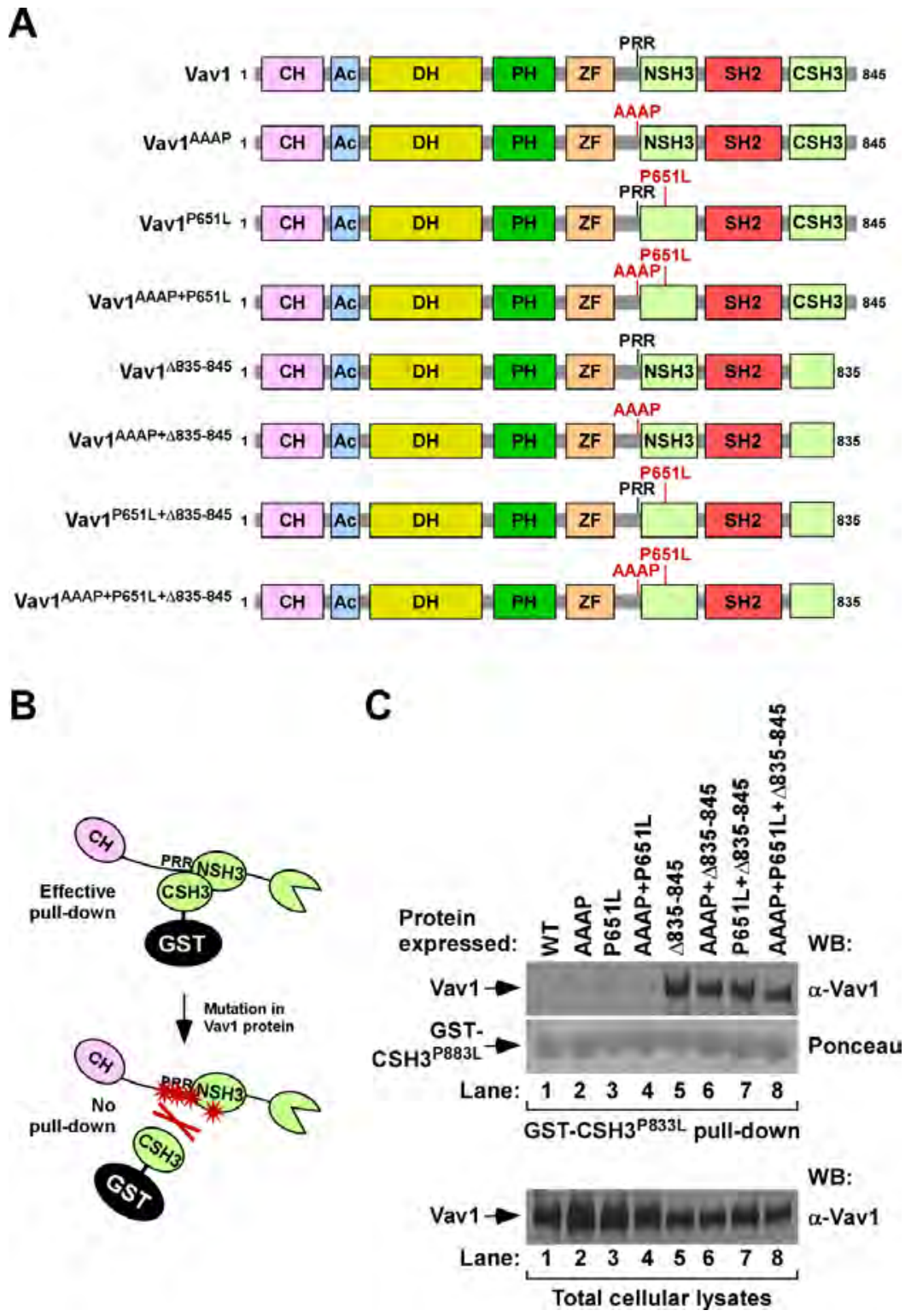

Fig. S3. The Vav1 CSH3 domain does not interact with the Vav1 PRR-NSH3 region. (A) Schematic representation of wild-type (WT) Vav1 and some of the Vav1 mutant proteins used in this experiment. (B) Scheme showing the rationale for the strategy used in these pull-down experiments. Mutations are depicted as red asterisks. (C) Top: Pull-down assays were performed to determine interactions between the GST-CSH3 ${ }^{\mathrm{P} 33 \mathrm{~L}}$ fusion protein and the indicated full-length (lanes 1 to 5) and $\operatorname{Vav} 1^{{ }^{835-845}}$ mutant proteins (lanes 5 to 8). Middle: The relative amounts of bait proteins were determined by Ponceau staining of the same blot. Bottom: The presence of the indicated Vav1 proteins was confirmed by Western blotting analysis of aliquots of the same total cellular lysates used in the pull-down assays with the indicated antibody. Data are representative of two independent experiments. 


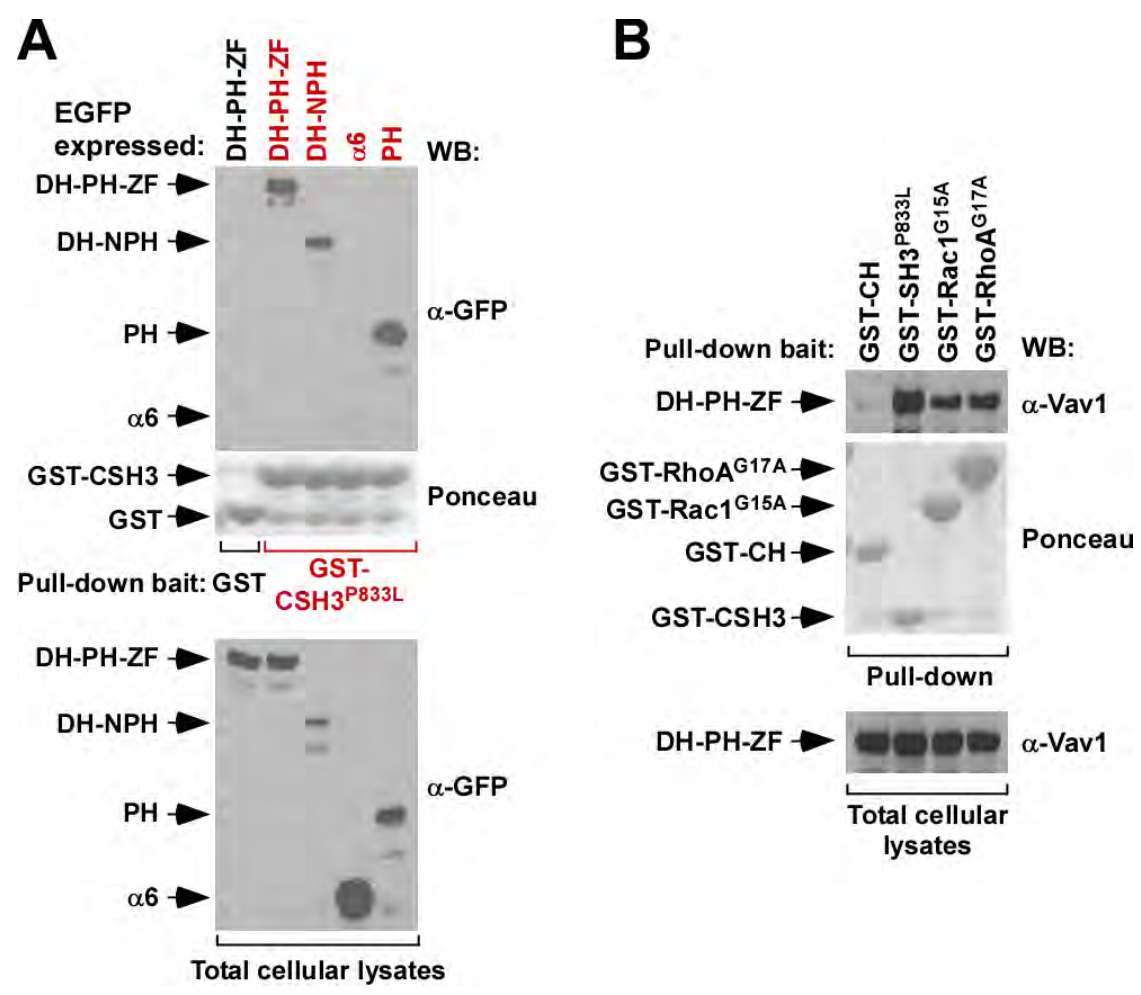

Fig. S4. The CSH3 domain inhibits Vav1 in cis. (A) Top: Pull-down assays were performed to investigate interactions between the indicated GST bait proteins and EGFPtagged Vav1 proteins. The relative amounts of bait proteins and ectopically expressed proteins used in each pull-down assay were determined by Ponceau staining (middle) and Western blotting analysis (bottom), respectively. Data are representative of four independent experiments. (B) Pull-down assays were performed to investigate interactions between the indicated GST fusion proteins and the EGFP-Vav1 DH-PH-ZF region. The relative amounts of bait and ectopically expressed proteins used in each pull-down assay were determined by Ponceau staining (middle) and Western blotting analysis (bottom), respectively. Data are representative of three independent experiments. 

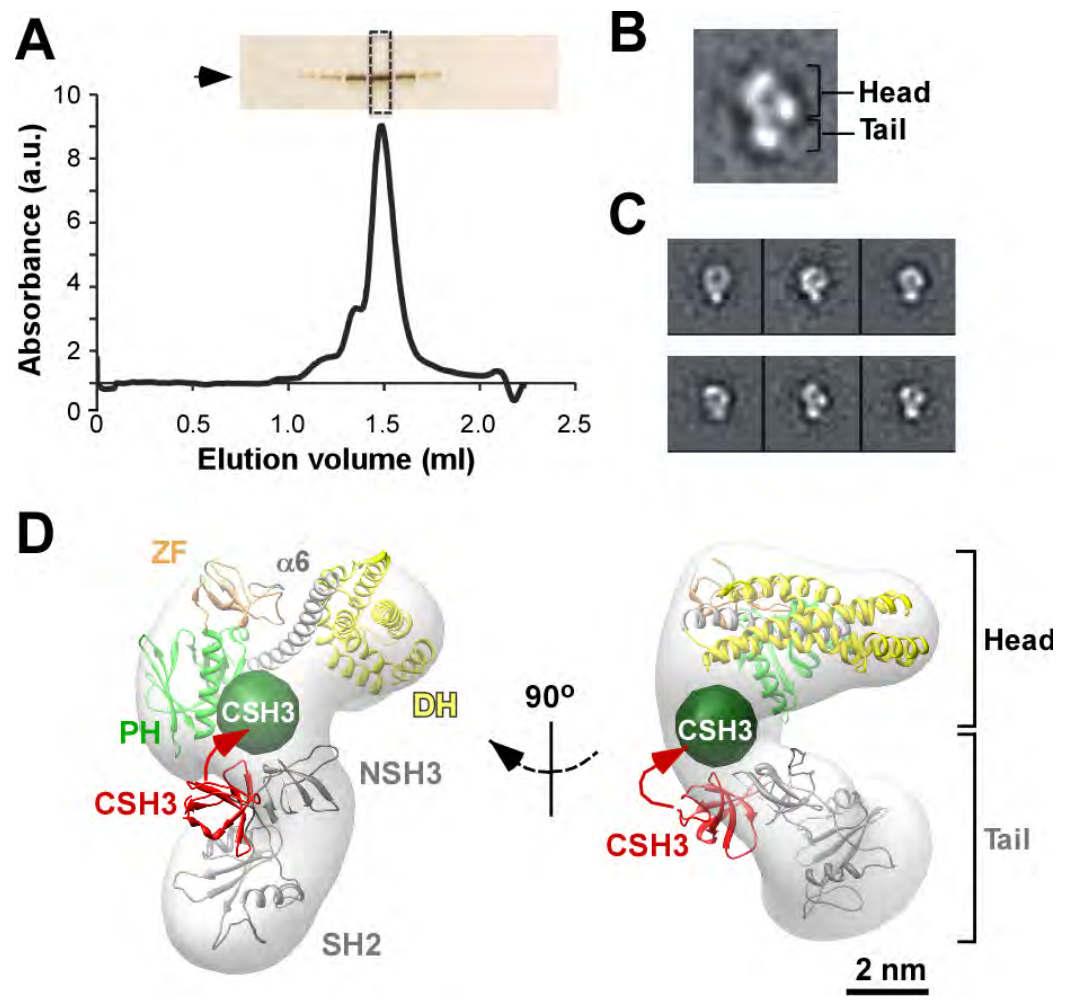

Fig. S5. EM structure of unphosphorylated 6xHis-Vav1 ${ }^{1-144}$. (A) Elution profile of $6 \times$ His-Vav1 $1^{1-144}$ purified by size exclusion chromatography. The indicated fractions were analyzed by SDS-PAGE (inset), and the peak (boxed) was selected for EM analysis. (B) Representative images from the 2D EM analysis of purified $6 \times \mathrm{His}-\mathrm{Vav} 1^{1-144}$ protein. The "head" and "tail" regions are indicated. (C) Several reference-free averages obtained for $6 \times \mathrm{His}^{-V a v} 1^{\mathrm{1}^{-1}-14}$ after classification of single molecule images. (D) Two orthogonal views of the 3D structure of $6 \times$ His-Vav1 $1^{1-144}$ (white translucent density) obtained by EM analysis and image-processing methodologies. The putative localization of the indicated domains of Vav1 and Grb2 is shown. The position of the SH3 domain of Grb2 that had to be displaced to fit within the density of the molecule is indicated as a green sphere that has the approximate size of the domain. The original position of the SH3 domain is shown in red. The rotation required for fitting that domain within the volume of $6 \times \mathrm{His}_{\mathrm{S}} \mathrm{Vav} 1^{\mathrm{s}^{1-144}}$ is indicated by an arrow. 

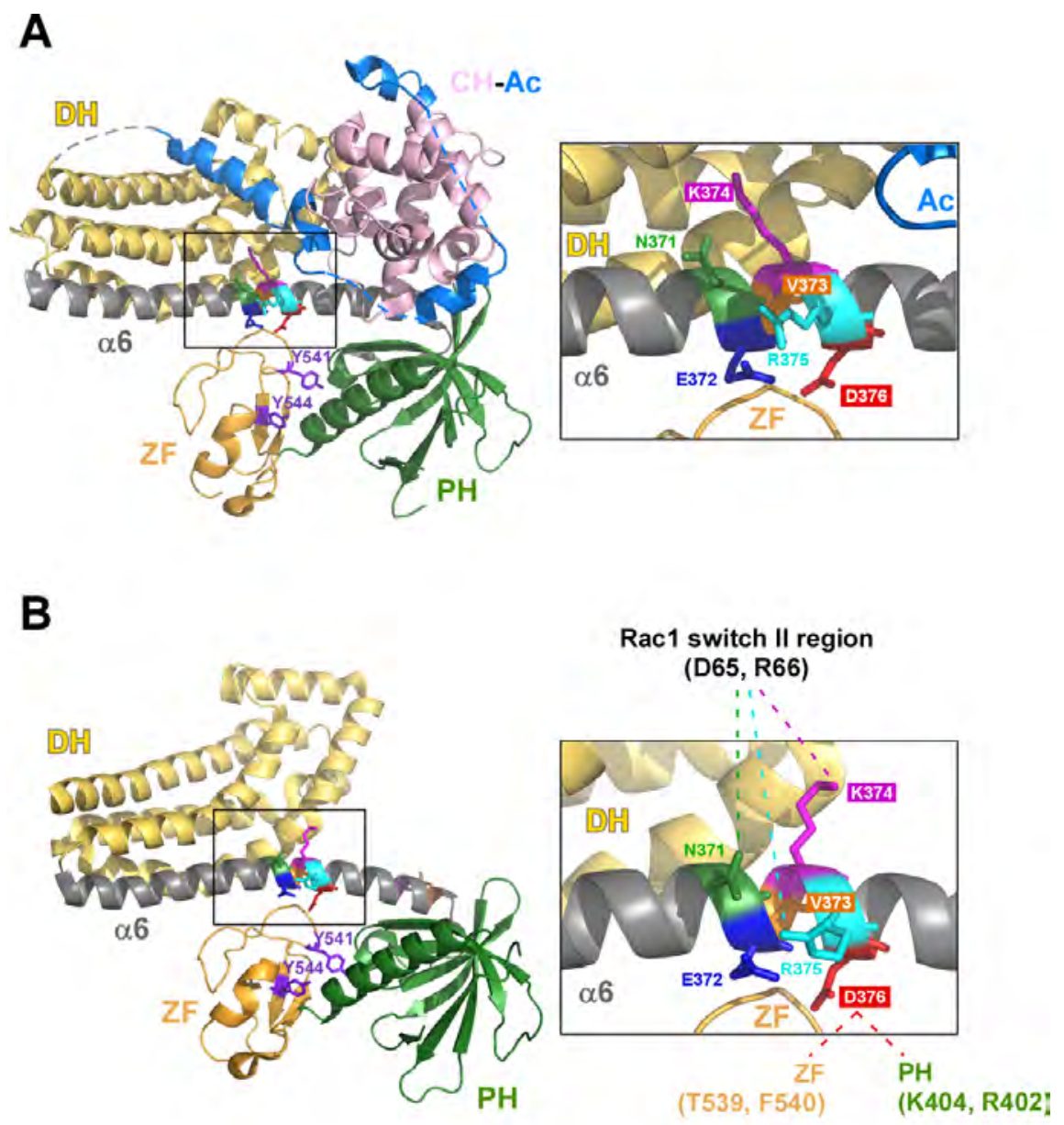

Fig. S6. Characterization of residues of the DH domain $\alpha 6$ helix that contribute to the stability of the inhibitory CSH3-Vav1 interaction. (A and B) Stereospatial views of the Vav1 DH domain $\alpha 6$ helix in the context of the crystal structures of (A) the $\mathrm{CH}-\mathrm{Ac}-\mathrm{DH}-$ $\mathrm{PH}-\mathrm{ZF}$ region and (B) the DH-PH-ZF region of Vav1. Mutated residues are depicted as sticks. Those amino acid residues with roles in the stability of the intramolecular CSH3Vav1 interaction are boxed. (B) The connectivity of these residues with amino acids present in other Vav1 domains or the Rac1 switch II region is indicated as broken lines. The specific amino acid residues that establish bonds with those mutated residues are also indicated. Structural data were based on previous publications (29-31). 


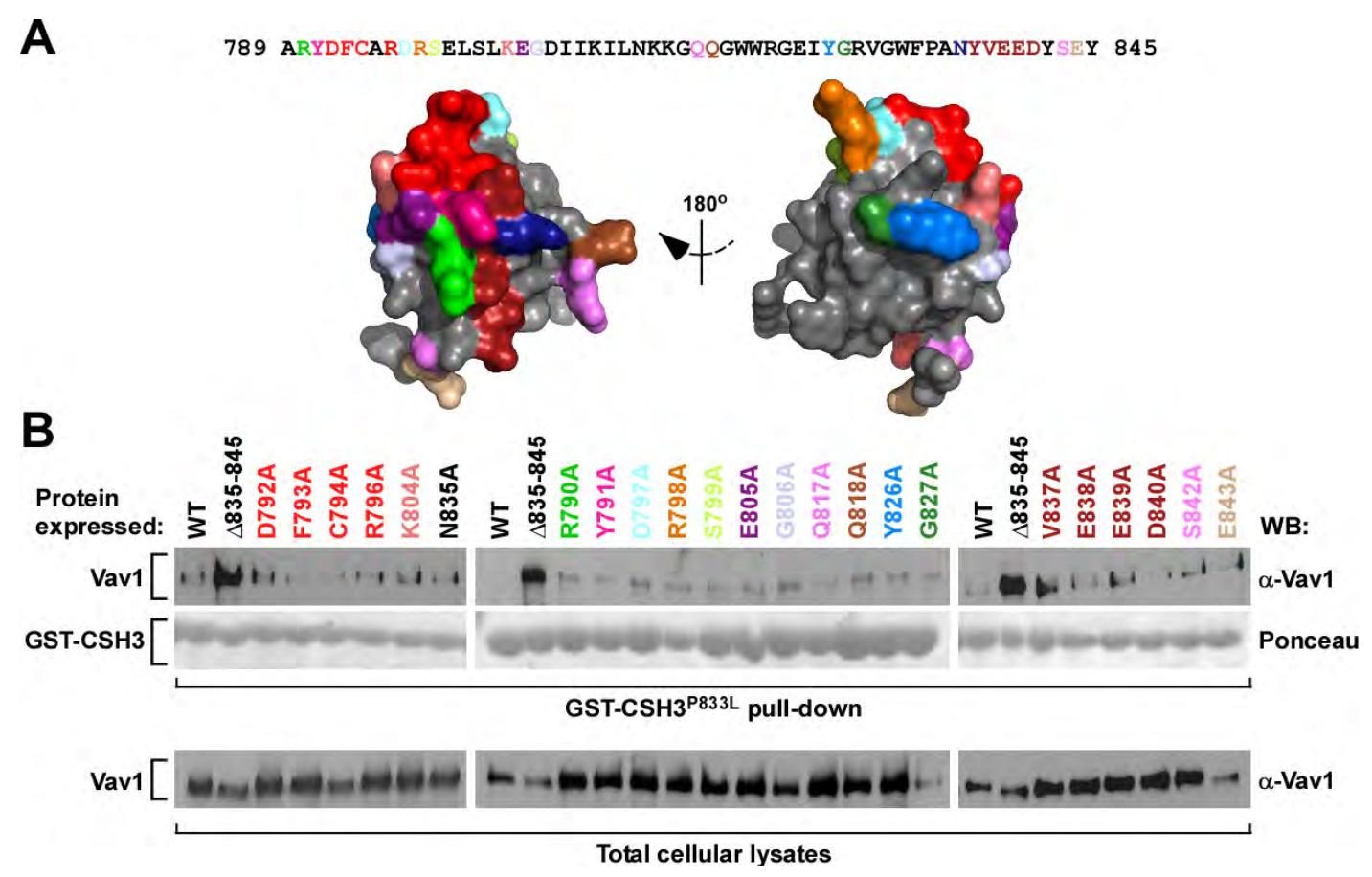

Fig. S7. The CSH3 domain of Vav1 uses two different topological regions to interact with the DH and PH domains. (A) Primary sequence (top) and two different views of the 3D structure of the Vav1 CSH3 domain (bottom) with the residues mutated in these experiments highlighted in color. (B) Pull-down assays were performed to investigate the interaction of the GST-CSH3 ${ }^{\mathrm{P} 833 \mathrm{~L}}$ fusion protein with the indicated Vav1 proteins. The color code for the indicated amino acid residues is the same as that for (A). The relative amounts of bait protein (middle) and ectopically expressed Vav1 proteins (bottom) were determined by Ponceau staining and Western blotting analysis, respectively. Data are representative of four independent experiments. 

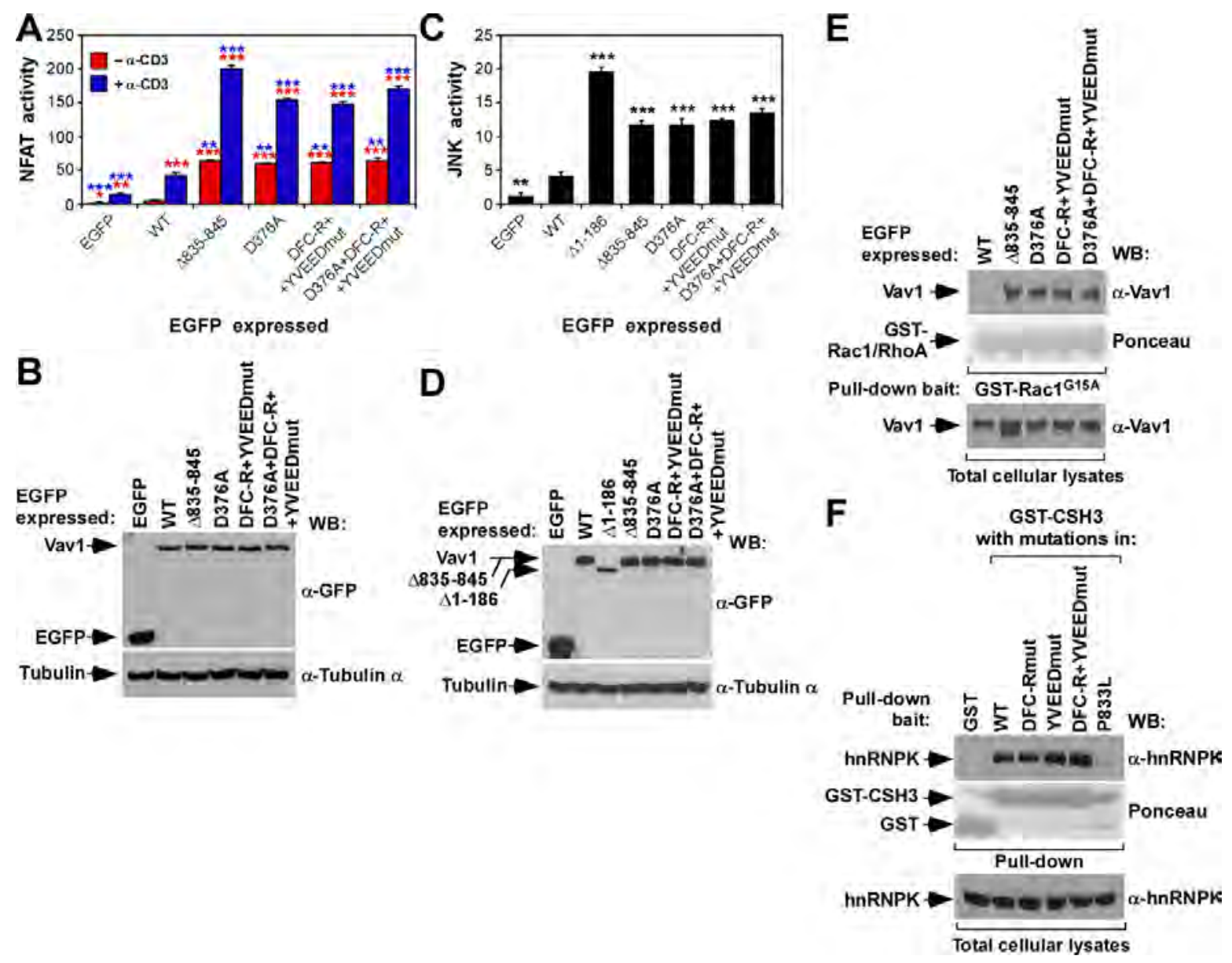

Fig. S8. Effect of the mutation of CSH3 DFC-R and YVEED sites in Vav1 biological activity. (A and B) Jurkat cells were transfected with plasmids expressing indicated proteins and, upon left untreated $(-)$ or being stimulated $(+)$ with an anti-CD3 antibody, assayed for NFAT activity (A). $P$ values are given as for Fig. 1C $(n=3)$. The amount of ectopic proteins obtained in each experiment was determined by Western blotting analysis with antibodies to the EGFP tag. As loading control, we measured the abundance of tubulin $\alpha$ in each sample. Western blot data from a single representative experiment are shown (B). (C and D) Analysis of JNK activity in COS1 cells transfected with plasmids expressing EGFP alone or indicated EGFP-Vav1 chimeras (C). $P$ values are given relative to activity shown by $\operatorname{Vav1}^{\mathrm{WT}}(n=3)$. Controls for protein expression (D) were done as for experiments shown in panels (A) and (B). (E) Top: Pull-down assays were performed to investigate interactions between indicated Vav1 and GST-GTPase proteins. The amounts of bait and ectopically expressed proteins used in each pull-down assay were determined by Ponceau staining (middle) and Western blotting analysis (bottom), respectively. (F) Top: Pull-down assays were performed to determine interactions between endogenous hnRNPK and GST-CSH3 proteins harboring the indicated mutations in the Vav1 CSH3 domain. The amounts of bait and endogenous hnRNPK used in each pull-down assay were determined as in $(E)$. Data in $(E)$ and $(F)$ are representative of two independent experiments. 
A

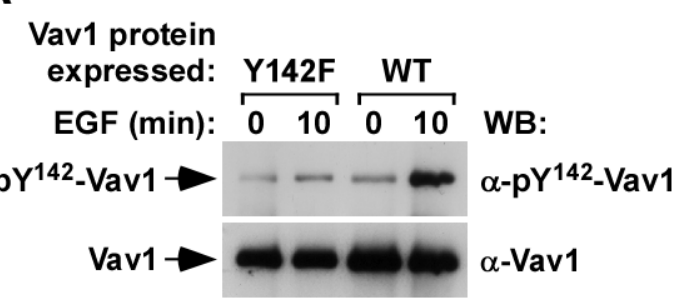

C

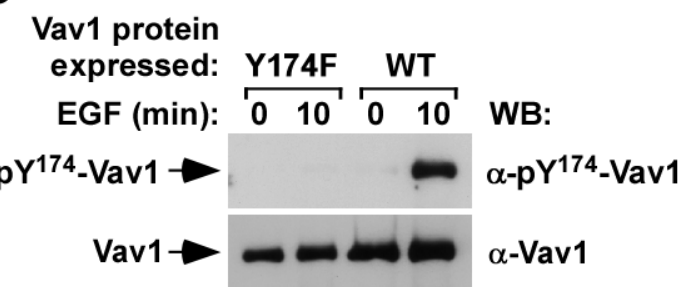

E

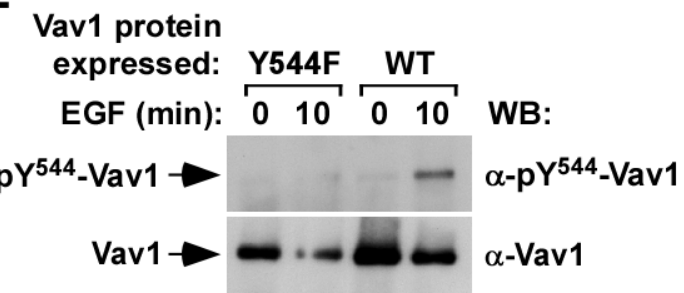

B

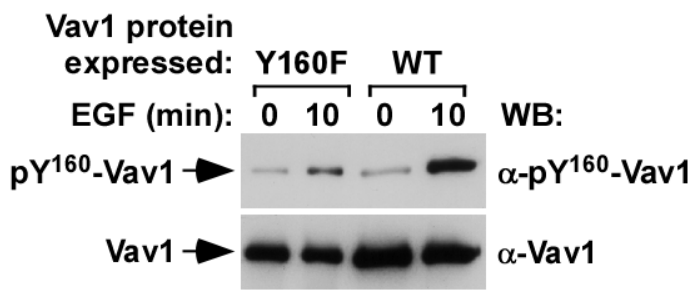

D

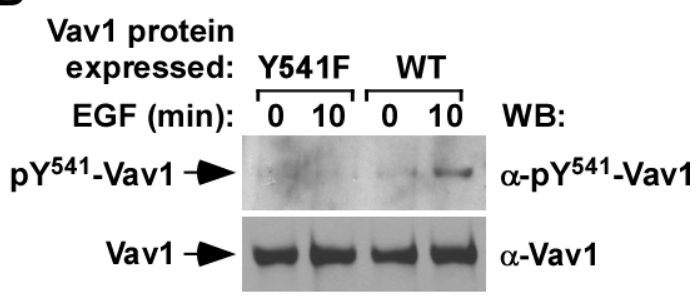

$\mathbf{F}$

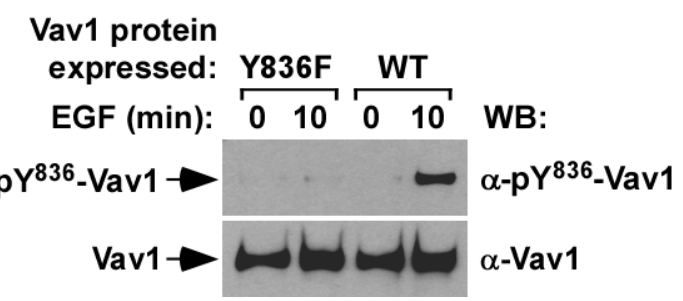

Fig. S9. Characterization of phospho-specific antibodies specific for Vav1. (A to F) COS1 cells were transiently transfected with plasmids encoding WT Vav1 or the indicated Vav1 mutant proteins and then serum-starved and stimulated with EGF for $10 \mathrm{~min}$ as indicated. Upon cell lysis and immunoprecipitation using the same anti-Vav1 antibody, the phosphorylation of the WT and indicated mutant versions of Vav1 was determined by Western blot using antibodies specific to the phosphorylated $\operatorname{Tyr}^{142}$ (A, top panel), $\mathrm{Tyr}^{160}$ (B, top panel), $\operatorname{Tyr}^{174}$ (C, top panel), $\operatorname{Tyr}^{541}$ (D, top panel), $\operatorname{Tyr}^{544}$ (E, top panel), and $\mathrm{Tyr}^{836}$ (F, top panel) residues. The blots were then stripped and re-analyzed with a rabbit polyclonal antibody specific for total Vav1 (A to F, bottom panels). Data are representative of three independent experiments. 


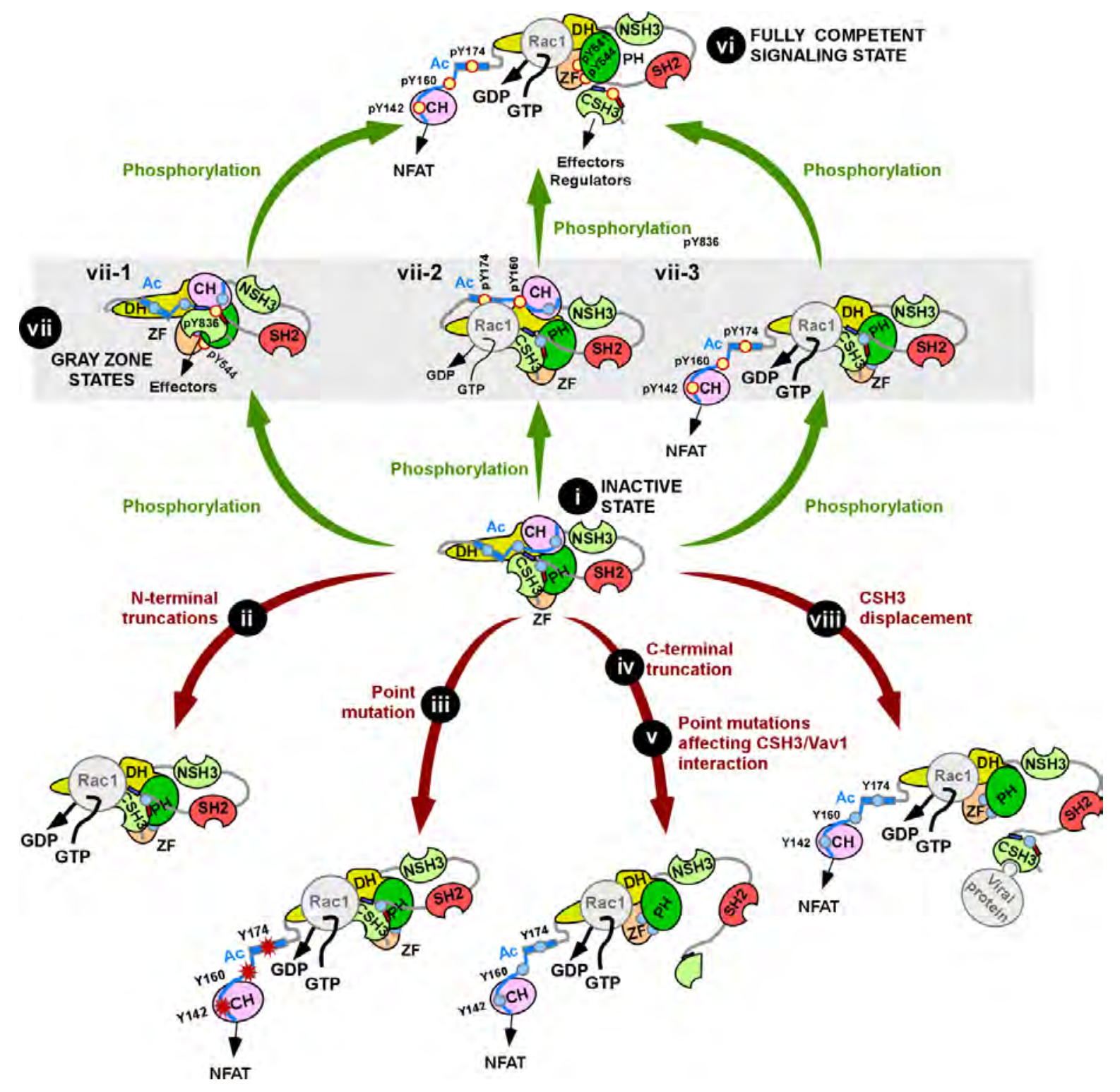

Fig. S10. Proposed model for the regulation of Vav family proteins. Physiological (green arrows) and spurious (red arrows) mechanisms of activation are shown. Icons used are the same as those used in fig. S1A. The depicted movements of the CH-Ac and NSH3$\mathrm{SH} 2-\mathrm{CSH} 3$ regions during the activation steps are hypothetical. There can be other "gray zone states" than those depicted (vii-1 to vii-3) if we take into account the possible permutations of phosphorylated residues, interacting proteins, or both. For the sake of simplicity, we have not included the interaction of Vav proteins with other signaling molecules. The old regulatory model can be found in fig. S1A. 
Table S1. Detection of indicated phosphosites in Vav1 using mass spectrometry.

\begin{tabular}{|l|c|c|}
\hline \multicolumn{1}{|c|}{ Tryptic peptide detected by mass spectometry } & $\begin{array}{c}\text { Phosphorylated } \\
\text { tyrosine } \\
\text { residue(s) }\end{array}$ & Condition $^{\mathbf{c}}$ \\
\hline VIYTLSALSWTPIAQNK & 110 & NS, SC, SJ \\
\hline CQMLLRGTFYQGYRCYR & 541,544 & SC, SJ \\
\hline AFRGLLELVEFYQQNSLKDCFK & 745 & SC \\
\hline IGWFPSNYVEEDYSEYC & 836 & SC, SJ \\
\hline & & \\
\hline LESVPTPPKMTEYDKR & $192^{\mathrm{d}}$ & $\mathrm{SC}, \mathrm{SJ}$ \\
\hline $\begin{array}{l}\text { DALAGPGATTLYQVFIK, } \\
\text { DALAGPGATTLYQVFIKYKR }\end{array}$ & $267^{\mathrm{d}}$ & $\mathrm{SC}, \mathrm{SJ}$ \\
\hline YAFLLDKALLICKR & $423^{\mathrm{d}}$ & $\mathrm{SC}$ \\
\hline CQMLLRGTFYQGYRCYR & $541,544,547^{\mathrm{d}}$ & $\mathrm{SC}$ \\
\hline
\end{tabular}

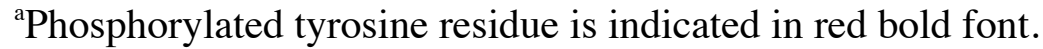

${ }^{b}$ Phosphorylated residues identified using a LCQ DECA XP apparatus (Thermo Finnigan). ${ }^{\mathrm{c}} \mathrm{NS}$, phosphosite detected in non-stimulated COS1 and Jurkat cells; SC, phosphosite detected in EGF-stimulated COS1 cells; SJ, phosphosite detected in TCR-stimulated Jurkat cells.

${ }^{\mathrm{d}}$ Phosphosite not consistently identified in all experiments. 
Table S2. List of additional plasmids.

\begin{tabular}{|c|c|c|}
\hline Name & Vector backbone & Encoded protein \\
\hline pKES27 & pMEX & $\operatorname{Vav} 1^{\mathrm{Y}^{3} \mathrm{~F}_{\Delta}{ }_{\Delta} 835-845}$ \\
\hline pMB35 & pGEX 6P-1 & GST-CSH3 $^{\mathrm{P} 833 \mathrm{~L}}$ \\
\hline pMB52 & pEGFP-C2 & EGFP-Vav1 $^{\text {AAAP }}$ \\
\hline pMB50 & pEGFP-C2 & EGFP-Vav1 $1^{\mathrm{P} 651 \mathrm{~L}}$ \\
\hline pMB53 & pEGFP-C2 & EGFP-Vav1 $1^{\mathrm{AAAP}+\mathrm{P} 651 \mathrm{~L}}$ \\
\hline pMB54 & pEGFP-C2 & EGFP-Vav $1^{\mathrm{AAAP}_{4}+835-845}$ \\
\hline pMB51 & pEGFP-C2 & EGFP-Vav1 $1^{\mathrm{P}^{2} 51 \mathrm{~L}{ }_{\Delta} 835-845}$ \\
\hline pMB55 & pEGFP-C2 & EGFP-Vav1 ${ }^{\mathrm{AAAP}+\mathrm{P} 651 \mathrm{~L}++_{\Delta} 835-84}$ \\
\hline pMB69 & pEGFP-C2 & EGFP-Vav1 $1^{\text {NEmut }_{\Delta} 835-845}$ \\
\hline pMB70 & pEGFP-C2 & EGFP-Vav $1^{\mathrm{VKmut}_{A} 835-845}$ \\
\hline pMB71 & pEGFP-C2 & EGFP-Vav $1^{\text {RDmut }_{\Delta}{ }_{\Delta} 835-845}$ \\
\hline pMB72 & pEGFP-C2 & ${\text { EGFP-Vav1 } 1^{\mathrm{NE}+\mathrm{RDmut}+}+835-845}$ \\
\hline pMB73 & pEGFP-C2 & 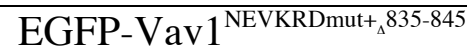 \\
\hline pMB74 & pEGFP-C2 & EGFP-Vav1 $1^{\mathrm{T}^{3} 84 \mathrm{~A}_{\Delta} 835-845}$ \\
\hline pMB75 & pEGFP-C2 & EGFP-Vav $1^{\mathrm{L388A+}{ }_{\alpha} 835-845}$ \\
\hline pMB90 & pEGFP-C2 & EGFP-Vav1 $1^{\mathrm{V} 373 \mathrm{~A}_{\mathrm{A}} 835-845}$ \\
\hline PMB91 & pEGFP-C2 & 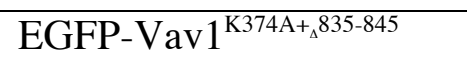 \\
\hline pMB92 & pEGFP-C2 & EGFP-Vav $1^{1375 A_{\Delta}+835-845}$ \\
\hline pMB93 & pEGFP-C2 & EGFP-Vav1 $1^{\mathrm{D} 376 \mathrm{~A}+{ }_{\mathrm{A}} 835-845}$ \\
\hline pMB98 & pEGFP-C2 & EGFP-Vav1 ${ }^{\text {R375A }}$ \\
\hline pMB99 & pEGFP-C2 & EGFP-Vav1 $1^{\text {D376A }}$ \\
\hline pMB77 & pEGFP-C2 & 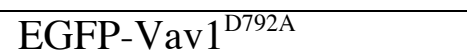 \\
\hline pMB86 & pEGFP-C2 & EGFP-Vav1 $1^{\mathrm{F} 793 \mathrm{~A}}$ \\
\hline pMB87 & pEGFP-C2 & EGFP-Vav1 $1^{\mathrm{C} 794 \mathrm{~A}}$ \\
\hline pMB78 & pEGFP-C2 & EGFP-Vav1 $1^{\text {R796A }}$ \\
\hline pMB88 & pEGFP-C2 & EGFP-Vav1 $1^{\mathrm{K} 804 \mathrm{~A}}$ \\
\hline pMB89 & pEGFP-C2 & 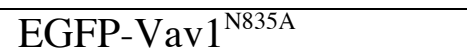 \\
\hline pMB58 & pEGFP-C2 & EGFP-Vav1 $1^{\text {R790A }}$ \\
\hline pMB59 & pEGFP-C2 & EGFP-Vav1 $1^{\mathrm{Y} 791 \mathrm{~A}}$ \\
\hline pMB60 & pEGFP-C2 & EGFP-Vav1 ${ }^{\text {D797A }}$ \\
\hline pMB61 & pEGFP-C2 & EGFP-Vav1 $1^{\text {R798A }}$ \\
\hline pMB62 & pEGFP-C2 & EGFP-Vav1 $1^{\mathrm{S} 799 \mathrm{~A}}$ \\
\hline pMB63 & pEGFP-C2 & EGFP-Vav1 ${ }^{\mathrm{E} 805 \mathrm{~A}}$ \\
\hline pMB64 & pEGFP-C2 & EGFP-Vav1 $1^{\mathrm{G} 806 \mathrm{~A}}$ \\
\hline pMB65 & pEGFP-C2 & EGFP-Vav1 $1^{\text {Q817A }}$ \\
\hline pMB66 & pEGFP-C2 & EGFP-Vav1 $1^{\mathrm{Q} 818 \mathrm{~A}}$ \\
\hline pMB67 & pEGFP-C2 & EGFP-Vav1 $1^{\mathrm{Y} 826 \mathrm{~A}}$ \\
\hline
\end{tabular}


Table S2 (continuation).

\begin{tabular}{|c|c|c|}
\hline Name & Vector backbone & Encoded protein \\
\hline pMB68 & pEGFP-C2 & EGFP-Vav1 $^{\text {G827A }}$ \\
\hline pMB79 & pEGFP-C2 & EGFP-Vav1 $^{\text {V837A }}$ \\
\hline pMB80 & pEGFP-C2 & EGFP-Vav1 $^{\text {E838A }}$ \\
\hline pMB81 & pEGFP-C2 & EGFP-Vav1 ${ }^{\text {E839A }}$ \\
\hline pMB82 & pEGFP-C2 & EGFP-Vav1 $^{\text {D840A }}$ \\
\hline pMB83 & pEGFP-C2 & EGFP-Vav1 $^{\mathrm{S} 842 \mathrm{~A}}$ \\
\hline pMB84 & pEGFP-C2 & EGFP-Vav1 $1^{\mathrm{E} 843 \mathrm{~A}}$ \\
\hline pMB94 & pEGFP-C2 & EGFP-Vav1 $^{\text {DFCmut }}$ \\
\hline pMB100 & pEGFP-C2 & EGFP-Vav1 ${ }^{\text {DFC-Rmut }}$ \\
\hline pMB101 & pEGFP-C2 & EGFP-Vav1 $1^{\text {YVEEDmut }}$ \\
\hline pMB104 & pEGFP-C2 & EGFP-Vav1 $1^{\text {DFC-R+YVEEDmut }}$ \\
\hline pMB111 & pEGFP-C2 & EGFP-Vav1 $1^{\text {D376A+DFC-Rmut }}$ \\
\hline pMB109 & pEGFP-C2 & EGFP-Vav1 ${ }^{\text {D376A+DFC-R+YVEEDmut }}$ \\
\hline pMB108 & pGEX 6P-1 & GST-CSH3 $^{\text {DFC-Rmut }}$ \\
\hline pMB130 & pGEX 6P-1 & GST-CSH3 ${ }^{\text {YVEEDmut }}$ \\
\hline pMB131 & pGEX 6P-1 & GST-CSH3 ${ }^{\text {DFC-R+YVEEDmut }}$ \\
\hline pMB115 & pGEX 6P-1 & GST-SH3 $3^{\text {DFC-R+P833Lmut }}$ \\
\hline pMB141 & pGEX 6P-1 & GST-SH3 $^{\text {P833L+YVEEDmut }}$ \\
\hline pMB142 & pGEX 6P-1 & GST-SH3 ${ }^{\text {DFC-Rmut+P833L+YVEEDmut }}$ \\
\hline pJRC64 & pEF1-Myc-His A & Vav1 ${ }^{\text {Y541F }}$ \\
\hline pMB13 & pEF1-Myc-His A & $\operatorname{Vav1}^{\mathrm{Y} 174 \mathrm{~F}+\mathrm{Y} 541 \mathrm{~F}}$ \\
\hline pMB23 & pEF1-Myc-His A & Vav1 $1^{\mathrm{Y} 541 \mathrm{E}}$ \\
\hline pMB124 & pEF1-Myc-His A & $\mathrm{Vav1}^{\mathrm{Y} 174 \mathrm{~F}+\mathrm{Y} 541 \mathrm{E}}$ \\
\hline pJRC65 & pEF1-Myc-His A & Vav1 $^{\text {Y544F }}$ \\
\hline pMB14 & pEF1-Myc-His A & Vav1 $^{\text {Y174F+Y544F }}$ \\
\hline pMB24 & pEF1-Myc-His A & Vav1 $^{\text {Y544E }}$ \\
\hline pMB31 & pEF1-Myc-His A & Vav1 $^{\text {Y174F+Y544E }}$ \\
\hline pMB41 & pGEX 6P-1 & GST-CSH3 ${ }^{\mathrm{Y} 836 \mathrm{~F}}$ \\
\hline pMB36 & pGEX 6P-1 & GST-CSH3 $^{\mathrm{Y} 836 \mathrm{E}}$ \\
\hline pMB144 & pEGFP-C2 & 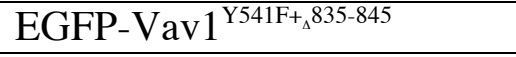 \\
\hline pMB147 & pEGFP-C2 & EGFP-Vav1 $1^{\mathrm{Y} 544 \mathrm{~F}_{\Delta} 835-845}$ \\
\hline
\end{tabular}


Table S3. List of primers. F, forward; R, reverse.

\begin{tabular}{|c|c|c|}
\hline Mutation & & Primer \\
\hline \multirow{2}{*}{ Y174F } & $\mathrm{F}$ & $\begin{array}{l}\text { 5'-GCA GAG GGG GAC GAG ATC TTC GAG GAC CTA ATG } \\
\text { CGC TTG-3' }\end{array}$ \\
\hline & $\mathrm{R}$ & $\begin{array}{l}\text { 5'-CAA GCG CAT TAG GTC CTC GAA GAT CTC GTC CCC CTC } \\
\text { TGC-3' }\end{array}$ \\
\hline \multirow{2}{*}{ P833L } & $\mathrm{F}$ & $\begin{array}{l}\text { 5'-CGG CCG GAT CGG CTG GTT CCC TTC TAA CTA TGT GGA } \\
\text { GGA AG-3' }\end{array}$ \\
\hline & $\mathrm{R}$ & $\begin{array}{l}\text { 5'-CTT CCT CCA CAT AGT TAG AAG GGA ACC AGC CGA } \\
\text { TCC GGC CG-3' }\end{array}$ \\
\hline \multirow{2}{*}{ AAAP } & $\mathrm{F}$ & 5'-GGA ATA CTA TGG GAT CGC TGC TGC ACC TGG AGC-3' \\
\hline & $\mathrm{R}$ & 5'-GCT CCA GGT GCA GCA GCG ATC CCA TAG TAT TCC-3' \\
\hline \multirow{2}{*}{ P651L } & $\mathrm{F}$ & 5'-GTC GGC TGG TTT CTC TGT AAC AGA GTG C-3' \\
\hline & $\mathrm{R}$ & 5'-GCA CTC TGT TAC AGA GAA ACC AGC CGA C-3' \\
\hline \multirow{2}{*}{ NEmut } & $\mathrm{F}$ & $\begin{array}{l}\text { 5'-GGG ACC TGG CAC AGT GCG TGG CCG CGG TCA AGA } \\
\text { GGG ACA ATG AAA CC-3' }\end{array}$ \\
\hline & $\mathrm{R}$ & $\begin{array}{l}\text { 5'-GGT TTC ATT GTC CCT CTT GAC CGC GGC CAC GCA CTG } \\
\text { TGC CAG GTC CC-3' }\end{array}$ \\
\hline \multirow{2}{*}{ VKmut } & $\mathrm{F}$ & $\begin{array}{l}\text { 5'-CTG GCA CAG TGC GTG AAC GAG GCC GCG AGG GAC } \\
\text { AAT GAA ACC CTA CGG-3' }\end{array}$ \\
\hline & $\mathrm{R}$ & $\begin{array}{l}\text { 5'-CCG TAG GGT TTC ATT GTC CCT CGC GGC CTC GTT CAC } \\
\text { GCA CTG TGC CAG-3' }\end{array}$ \\
\hline \multirow{2}{*}{ RDmut } & $\mathrm{F}$ & $\begin{array}{l}\text { 5'-GCA CAG TGC GTG AAC GAG GTC AAG GCG GCC AAT } \\
\text { GAA ACC CTA CGG CAG ATC AC-3' }\end{array}$ \\
\hline & $\mathrm{R}$ & $\begin{array}{l}\text { 5'-GTG ATC TGC CGT AGG GTT TCA TTG GCC GCC TTG ACC } \\
\text { TCG TTC ACG CAC TGT GC-3' }\end{array}$ \\
\hline \multirow{2}{*}{ NE+RDmut } & $\mathrm{F}$ & $\begin{array}{l}\text { 5'-GGG ACC TGG CAC AGT GCG TGG CCG CGG TCA AGG } \\
\text { CGG CCA ATG AAA CC-3' }\end{array}$ \\
\hline & $\mathrm{R}$ & $\begin{array}{l}\text { 5'-GGT TTC ATT GGC CGC CTT GAC CGC GGC CAC GCA } \\
\text { CTG TGC CAG GTC CC-3' }\end{array}$ \\
\hline \multirow{2}{*}{ NEVKRDmut } & $\mathrm{F}$ & $\begin{array}{l}\text { '-CTG GCA CAG TGC GTG GCC GCG GCC GCG GCG GCC } \\
\text { AAT GAA ACC CTA CGG-3' }\end{array}$ \\
\hline & $\mathrm{R}$ & $\begin{array}{l}\text { 5'-CCG TAG GGT TTC ATT GGC CGC CGC GGC CGC GGC } \\
\text { CAC GCA CTG TGC CAG-3' }\end{array}$ \\
\hline \multirow{2}{*}{ T384A } & $\mathrm{F}$ & $\begin{array}{l}\text { 5'-GGG ACA ATG AAA CCC TAC GGC AGA TCG CAA ACT } \\
\text { TTC AGC TGT CCA TTG AGA AC-3' }\end{array}$ \\
\hline & $\mathrm{R}$ & $\begin{array}{l}\text { 5'-GTT CTC AAT GGA CAG CTG AAA GTT TGC GAT CTG } \\
\text { CCG TAG GGT TTC ATT GTC CC-3' }\end{array}$ \\
\hline
\end{tabular}


Table S3 (continuation).

\begin{tabular}{|c|c|c|}
\hline Mutation & & Primer \\
\hline \multirow{2}{*}{ L388A } & $\mathrm{F}$ & $\begin{array}{l}\text { 5'-GGC AGA TCA CAA ACT TTC AGG CGT CCA TTG AGA } \\
\text { ACC TGG ACC-3' }\end{array}$ \\
\hline & $\mathrm{R}$ & $\begin{array}{l}\text { 5'-GGT CCA GGT TCT CAA TGG ACG CCT GAA AGT TTG } \\
\text { TGA TCT GCC-3' }\end{array}$ \\
\hline \multirow{2}{*}{ V373A } & $\mathrm{F}$ & $\begin{array}{l}\text { 5'-GGC ACA GTG CGT GAA CGA GGC CAA GAG GGA CAA } \\
\text { TGA AAC CCT AC-3' }\end{array}$ \\
\hline & $\mathrm{R}$ & $\begin{array}{l}\text { 5'-GTA GGG TTT CAT TGT CCC TCT TGG CCT CGT TCA CGC } \\
\text { ACT GTG CC-3' }\end{array}$ \\
\hline \multirow{2}{*}{ K374A } & $\mathrm{F}$ & $\begin{array}{l}\text { 5'-GGC ACA GTG CGT GAA CGA GGT CGC GAG GGA CAA } \\
\text { TGA AAC CC-3' }\end{array}$ \\
\hline & $\mathrm{R}$ & $\begin{array}{l}\text { 5'-GGG TTT CAT TGT CCC TCG CGA CCT CGT TCA CGC ACT } \\
\text { GTG CC-3' }\end{array}$ \\
\hline \multirow{2}{*}{ R375A } & $\mathrm{F}$ & $\begin{array}{l}\text { 5'-CAG TGC GTG AAC GAG GTC AAG GCG GAC AAT GAA } \\
\text { ACC CTA CGG-3' }\end{array}$ \\
\hline & $\mathrm{R}$ & $\begin{array}{l}\text { 5'-CCG TAG GGT TTC ATT GTC CGC CTT GAC CTC GTT CAC } \\
\text { GCA CTG-3' }\end{array}$ \\
\hline \multirow{2}{*}{ D376A } & $\mathrm{F}$ & $\begin{array}{l}\text { 5'-GTG AAC GAG GTC AAG AGG GCC AAT GAA ACC CTA } \\
\text { CGG CAG-3' }\end{array}$ \\
\hline & $\mathrm{R}$ & $\begin{array}{l}\text { 5'-CTG CCG TAG GGT TTC ATT GGC CCT CTT GAC CTC GTT } \\
\text { CAC-3' }\end{array}$ \\
\hline \multirow{2}{*}{ D792A } & $\mathrm{F}$ & $\begin{array}{l}\text { 5'-GCA CTG CCA AAG CCC GCT ACG CCT TCT GTG CCC } \\
\text { GGG ACA GGT C-3' }\end{array}$ \\
\hline & $\mathrm{R}$ & $\begin{array}{l}\text { 5’ - GAC CTG TCC CGG GCA CAG AAG GCG TAG CGG GCT } \\
\text { TTG GCA GTG C -3' }\end{array}$ \\
\hline \multirow{2}{*}{ F793A } & $\mathrm{F}$ & $\begin{array}{l}\text { 5' - CTG CCA AAG CCC GCT ACG ACG CCT GTG CCC GGG } \\
\text { ACA GGT CGG -3' }\end{array}$ \\
\hline & $\mathrm{R}$ & $\begin{array}{l}\text { 5'- CCG ACC TGT CCC GGG CAC AGG CGT CGT AGC GGG } \\
\text { CTT TGG CAG -3, }\end{array}$ \\
\hline \multirow{2}{*}{ C794A } & $\mathrm{F}$ & $\begin{array}{l}\text { 5'-CCA AAG CCC GCT ACG ACT TCG CTG CCC GGG ACA } \\
\text { GGT CGG AAC-3' }\end{array}$ \\
\hline & $\mathrm{R}$ & $\begin{array}{l}\text { 5'-GTT CCG ACC TGT CCC GGG CAG CGA AGT CGT AGC } \\
\text { GGG CTT TGG-3' }\end{array}$ \\
\hline \multirow{2}{*}{ R796A } & $\mathrm{F}$ & $\begin{array}{l}\text { 5'-CGC TAC GAC TTC TGT GCC GCG GAC AGG TCG GAA } \\
\text { CTG TCC C-3' }\end{array}$ \\
\hline & $\mathrm{R}$ & $\begin{array}{l}\text { 5'-GGG ACA GTT CCG ACC TGT CCG CGG CAC AGA AGT } \\
\text { CGT AGC G-3' }\end{array}$ \\
\hline \multirow{2}{*}{ K804A } & $\mathrm{F}$ & $\begin{array}{l}\text { 5'-GGA CAG GTC GGA ACT GTC CCT TGC GGA GGG TGA } \\
\text { TAT CAT CAA GAT C-3' }\end{array}$ \\
\hline & $\mathrm{R}$ & $\begin{array}{l}\text { 5'-GAT CTT GAT GAT ATC ACC CTC CGC AAG GGA CAG } \\
\text { TTC CGA CCT GTC C-3' }\end{array}$ \\
\hline
\end{tabular}


Table S3 (continuation).

\begin{tabular}{|c|c|c|}
\hline Mutation & & Primer \\
\hline \multirow{2}{*}{ N835A } & $\mathrm{F}$ & $\begin{array}{l}\text { 5'- CGG ATC GGC TGG TTC CCT TCT GCC TAT GTG GAG } \\
\text { GAA GAC TAT TC -3' }\end{array}$ \\
\hline & $\mathrm{R}$ & $\begin{array}{l}\text { 5'- GAA TAG TCT TCC TCC ACA TAG GCA GAA GGG AAC } \\
\text { CAG CCG ATC CG -3' }\end{array}$ \\
\hline \multirow{2}{*}{ R790A } & $\mathrm{F}$ & $\begin{array}{l}\text { 5'- GTA TTT TGG CAC TGC CAA AGC CGC CTA CGA CTT } \\
\text { CTG TGC CCG GGA C -3' }\end{array}$ \\
\hline & $\mathrm{R}$ & $\begin{array}{l}\text { 5'- GTC CCG GGC ACA GAA GTC GTA GGC GGC TTT GGC } \\
\text { AGT GCC AAA ATA C -3' }\end{array}$ \\
\hline \multirow{2}{*}{ Y791A } & $\mathrm{F}$ & $\begin{array}{l}\text { 5'- GCA CTG CCA AAG CCC GCG CCG ACT TCT GTG CCC } \\
\text { GGG -3' }\end{array}$ \\
\hline & $\mathrm{R}$ & $\begin{array}{l}\text { 5'- CCC GGG CAC AGA AGT CGG CGC GGG CTT TGG CAG } \\
\text { TGC }-3 \text { ' }\end{array}$ \\
\hline \multirow{2}{*}{ D797A } & $\mathrm{F}$ & $\begin{array}{l}\text { 5'- CGC TAC GAC TTC TGT GCC CGG GCC AGG TCG GAA } \\
\text { CTG TCC CTT AAG -3' }\end{array}$ \\
\hline & $\mathrm{R}$ & $\begin{array}{l}\text { 5'- CTT AAG GGA CAG TTC CGA CCT GGC CCG GGC ACA } \\
\text { GAA GTC GTA GCG -3' }\end{array}$ \\
\hline \multirow{2}{*}{ R798A } & $\mathrm{F}$ & $\begin{array}{l}\text { 5'- CTA CGA CTT CTG TGC CCG GGA CGC GTC GGA ACT } \\
\text { GTC CCT TAA GGA G -3' }\end{array}$ \\
\hline & $\mathrm{R}$ & $\begin{array}{l}\text { 5'- CTC CTT AAG GGA CAG TTC CGA CGC GTC CCG GGC } \\
\text { ACA GAA GTC GTA G -3' }\end{array}$ \\
\hline \multirow{2}{*}{ S799A } & $\mathrm{F}$ & $\begin{array}{l}\text { 5'- GAC TTC TGT GCC CGG GAC AGG GCG GAA CTG TCC } \\
\text { CTT AAG GAG G -3' }\end{array}$ \\
\hline & $\mathrm{R}$ & $\begin{array}{l}\text { 5'- CCT CCT TAA GGG ACA GTT CCG CCC TGT CCC GGG } \\
\text { CAC AGA AGT C -3' }\end{array}$ \\
\hline \multirow{2}{*}{ E805A } & $\mathrm{F}$ & $\begin{array}{l}\text { 5'- GTC GGA ACT GTC CCT TAA GGC GGG TGA TAT CAT } \\
\text { CAA GAT CC -3' }\end{array}$ \\
\hline & $\mathrm{R}$ & $\begin{array}{l}\text { 5'- GGA TCT TGA TGA TAT CAC CCG CCT TAA GGG ACA } \\
\text { GTT CCG AC -3' }\end{array}$ \\
\hline \multirow{2}{*}{ G806A } & $\mathrm{F}$ & $\begin{array}{l}\text { 5' - GAA CTG TCC CTT AAG GAG CGT GAT ATC ATC AAG } \\
\text { ATC C -3' }\end{array}$ \\
\hline & $\mathrm{R}$ & $\begin{array}{l}\text { 5'- GGA TCT TGA TGA TAT CAC GCT CCT TAA GGG ACA } \\
\text { GTT C -3' }\end{array}$ \\
\hline \multirow{2}{*}{ Q817A } & $\mathrm{F}$ & $\begin{array}{l}\text { 5'- GAT CCT CAA TAA GAA GGG ACG GCA AGG CTG GTG } \\
\text { GCG TGG GG -3' }\end{array}$ \\
\hline & $\mathrm{R}$ & $\begin{array}{l}\text { 5'- CCC CAC GCC ACC AGC CTT GCC GTC CCT TCT TAT TGA } \\
\text { GGA TC -3' }\end{array}$ \\
\hline \multirow{2}{*}{ Q818A } & $\mathrm{F}$ & $\begin{array}{l}\text { 5'- CTC AAT AAG AAG GGA CAG CGA GGC TGG TGG CGT } \\
\text { GGG GAG -3' }\end{array}$ \\
\hline & $\mathrm{R}$ & $\begin{array}{l}\text { 5'- CTC CCC ACG CCA CCA GCC TCG CTG TCC CTT CTT ATT } \\
\text { GAG -3' }\end{array}$ \\
\hline
\end{tabular}


Table S3 (continuation).

\begin{tabular}{|c|c|c|}
\hline Mutation & & Primer \\
\hline \multirow{2}{*}{ Y826A } & F & $\begin{array}{l}\text { 5'-CTG GTG GCG TGG GGA GAT CCG CGG CCG GAT CGG } \\
\text { CTG GTT C-3' }\end{array}$ \\
\hline & $\mathrm{R}$ & $\begin{array}{l}\text { 5'-GAA CCA GCC GAT CCG GCC GCG GAT CTC CCC ACG } \\
\text { CCA CCA G-3' }\end{array}$ \\
\hline \multirow{2}{*}{ G827A } & $\mathrm{F}$ & $\begin{array}{l}\text { 5'-CTG GTG GCG TGG GGA GAT CTA CCG CCG GAT CGG } \\
\text { CTG GTT CCC TTC-3' }\end{array}$ \\
\hline & $\mathrm{R}$ & $\begin{array}{l}\text { 5'-GAA GGG AAC CAG CCG ATC CGG CGG TAG ATC TCC } \\
\text { CCA CGC CAC CAG-3' }\end{array}$ \\
\hline \multirow{2}{*}{ V837A } & $\mathrm{F}$ & $\begin{array}{l}\text { 5'-CGG CTG GTT CCC TTC TAA CTA TGC GGA GGA AGA } \\
\text { CTA TTC CGA ATA TTG-3' }\end{array}$ \\
\hline & $\mathrm{R}$ & $\begin{array}{l}\text { 5'-CAA TAT TCG GAA TAG TCT TCC TCC GCA TAG TTA } \\
\text { GAA GGG AAC CAG CCG-3' }\end{array}$ \\
\hline \multirow{2}{*}{ E838A } & $\mathrm{F}$ & $\begin{array}{l}\text { 5'-CTG GTT CCC TTC TAA CTA TGT GGC GGA AGA CTA TTC } \\
\text { CGA ATA TTG-3' }\end{array}$ \\
\hline & $\mathrm{R}$ & $\begin{array}{l}\text { 5'-CAA TAT TCG GAA TAG TCT TCC GCC ACA TAG TTA } \\
\text { GAA GGG AAC CAG-3' }\end{array}$ \\
\hline \multirow{2}{*}{ E839A } & $\mathrm{F}$ & $\begin{array}{l}\text { 5'-CCT TCT AAC TAT GTG GAG GCA GAC TAT TCC GAA } \\
\text { TAT TGC-3' }\end{array}$ \\
\hline & $\mathrm{R}$ & $\begin{array}{l}\text { 5'-GCA ATA TTC GGA ATA GTC TGC CTC CAC ATA GTT } \\
\text { AGA AGG-3' }\end{array}$ \\
\hline \multirow{2}{*}{ D840A } & $\mathrm{F}$ & $\begin{array}{l}\text { 5'-CTT CTA ACT ATG TGG AGG AAG CCT ATT CCG AAT } \\
\text { ATT GCT GAG C-3' }\end{array}$ \\
\hline & $\mathrm{R}$ & $\begin{array}{l}\text { 5'-GCT CAG CAA TAT TCG GAA TAG GCT TCC TCC ACA } \\
\text { TAG TTA GAA G-3' }\end{array}$ \\
\hline \multirow{2}{*}{ S842A } & $\mathrm{F}$ & $\begin{array}{l}\text { 5'-CTA TGT GGA GGA AGA CTA TGC CGA ATA TTG CTG } \\
\text { AGC CTG-3' }\end{array}$ \\
\hline & $\mathrm{R}$ & $\begin{array}{l}\text { 5’-CAG GCT CAG CAA TAT TCG GCA TAG TCT TCC TCC } \\
\text { ACA TAG-3' }\end{array}$ \\
\hline \multirow{2}{*}{ E843A } & $\mathrm{F}$ & $\begin{array}{l}\text { 5'-GTG GAG GAA GAC TAT TCC GCA TAT TGC TGA GCC } \\
\text { TGG TGC-3' }\end{array}$ \\
\hline & $\mathrm{R}$ & $\begin{array}{l}\text { 5'-GCA CCA GGC TCA GCA ATA TGC GGA ATA GTC TTC } \\
\text { CTC CAC-3' }\end{array}$ \\
\hline \multirow[t]{2}{*}{ DFCmut } & $\mathrm{F}$ & $\begin{array}{l}\text { 5'-GCA CTG CCA AAG CCC GCT ACG CCG CCG CAG CCC } \\
\text { GGG ACA GGT CGG AAC TG-3' }\end{array}$ \\
\hline & $\mathrm{R}$ & $\begin{array}{l}\text { 5'-CAG TTC CGA CCT GTC CCG GGC TGC GGC GGC GTA } \\
\text { GCG GGC TTT GGC AGT GC-3' }\end{array}$ \\
\hline
\end{tabular}


Table S3 (continuation).

\begin{tabular}{|c|c|c|}
\hline Mutation & & Primer \\
\hline \multirow{2}{*}{ DFC-Rmut } & $\mathrm{F}$ & $\begin{array}{l}\text { 5'-CGC TAC GCC GCC GCA GCC GCG GAC AGG TCG GAA } \\
\text { CTG TCC C-3' }\end{array}$ \\
\hline & $\mathrm{R}$ & $\begin{array}{l}\text { 5'-GGG ACA GTT CCG ACC TGT CCG CGG CTG CGG CGG } \\
\text { CGT AGC G-3' }\end{array}$ \\
\hline \multirow{2}{*}{ YVEEDmut } & $\mathrm{F}$ & $\begin{array}{l}\text { 5'-CGG ATC GGC TGG TTC CCT TCT AAC GCA GCG GCG } \\
\text { GCA GCC TAT TCC GAA TAT TG-3' }\end{array}$ \\
\hline & $\mathrm{R}$ & $\begin{array}{l}\text { 5'-CAA TAT TCG GAA TAG GCT GCC GCC GCT GCG TTA } \\
\text { GAA GGG AAC CAG CCG ATC CG-3' }\end{array}$ \\
\hline \multirow{2}{*}{$\begin{array}{c}\text { P833L+YVE } \\
\text { EDmut }\end{array}$} & $\mathrm{F}$ & $\begin{array}{l}\text { 5'-CGG ATC GGC TGG TTC CCT TCT AAC GCA GCG GCG } \\
\text { GCA GCC TAT TCC GAA TAT TG-3' }\end{array}$ \\
\hline & $\mathrm{R}$ & $\begin{array}{l}\text { 5'-CAA TAT TCG GAA TAG GCT GCC GCC GCT GCG TTA } \\
\text { GAA GGG AAC CAG CCG ATC CG-3' }\end{array}$ \\
\hline \multirow{2}{*}{ Y541F } & $\mathrm{F}$ & $\begin{array}{l}\text { 5'-GGC ACA TTC TAC CAG GGA TTT CGC TGT TAC AGG } \\
\text { TGC CGG-3' }\end{array}$ \\
\hline & $\mathrm{R}$ & $\begin{array}{l}\text { 5'-CCG GCA CCT GTA ACA GCG AAA TCC CTG GTA GAA } \\
\text { TGT GCC-3' }\end{array}$ \\
\hline \multirow{2}{*}{ Y541E } & $\mathrm{F}$ & $\begin{array}{l}\text { 5’-GGC ACA TTC TAC CAG GGA GAG CGC TGT TAC AGG } \\
\text { TGC CGG-3' }\end{array}$ \\
\hline & $\mathrm{R}$ & $\begin{array}{l}\text { 5’-CCG GCA CCT GTA ACA GCG CTC TCC CTG GTA GAA } \\
\text { TGT GCC-3' }\end{array}$ \\
\hline \multirow{2}{*}{ Y544F } & $\mathrm{F}$ & 5'-GGC ACA TTC TAC CAG TTT GAA CGC TGT TAC AGG-3' \\
\hline & $\mathrm{R}$ & 5'-CCT GTA ACA GCG TTC AAA CTG GTA GAA TGT GCC-3' \\
\hline \multirow{2}{*}{ Y544E } & $\mathrm{F}$ & 5'-GGC ACA TTC TAC CAG GGA GAA CGC TGT TAC AGG-3' \\
\hline & $\mathrm{R}$ & 5'-CCT GTA ACA GCG TTC TCC CTG GTA GAA TGT GCC-3' \\
\hline \multirow{2}{*}{ Y836F } & $\mathrm{F}$ & $\begin{array}{l}\text { 5'-CGG CTG GTT CCC TTC TAA CTT TGT GGA GGA AGA CTA } \\
\text { TTC CG-3' }\end{array}$ \\
\hline & $\mathrm{R}$ & $\begin{array}{l}\text { 5'-CGG AAT AGT CTT CCT CCA CAA AGT TAG AAG GGA } \\
\text { ACC AGC CG-3' }\end{array}$ \\
\hline \multirow{2}{*}{ Y836E } & $\mathrm{F}$ & $\begin{array}{l}\text { 5'-GGC TGG TTC CCT TCT AAC GAG GTG GAG GAA GAC } \\
\text { TAT TCC-3' }\end{array}$ \\
\hline & $\mathrm{R}$ & $\begin{array}{l}\text { 5'-GGA ATA GTC TTC CTC CAC CTC GTT AGA AGG GAA } \\
\text { CCA GCC-3' }\end{array}$ \\
\hline
\end{tabular}

